\title{
Cellules avec vue sur la démocratie
}

cells with view on democracy

Fabienne Brion

\section{(2) OpenEdition}

1 Journals

\section{Édition électronique}

URL : http://journals.openedition.org/conflits/18906

DOI : $10.4000 /$ conflits. 18906

ISSN : $1777-5345$

Éditeur :

CCLS - Centre d'études sur les conflits lilberté et sécurité, L'Harmattan

\section{Édition imprimée}

Date de publication : 31 décembre 2014

Pagination : 135-201

ISBN : 978-2-343-05760-6

ISSN : 1157-996X

\section{Référence électronique}

Fabienne Brion, «Cellules avec vue sur la démocratie », Cultures \& Conflits [En ligne], 94-95-96 | étéautomne-hiver 2014, mis en ligne le 20 février 2016, consulté le 30 mars 2021. URL : http:// journals.openedition.org/conflits/18906; DOI : https://doi.org/10.4000/conflits.18906 


\section{Cellules avec vue sur la démocratie}

\section{Fabienne BRION}

Fabienne Brion est professeur à l'Université catholique de Louvain. Elle étudie les discours, processus et mécanismes qui contribuent, dans les sociétés démocratiques, à convertir des discriminations illégitimes en distinctions légitimes, avec une attention particulière pour les formes mouvantes de la racisation et de la criminalisation. Elle a coédité avec Bernard Harcourt Mal faire, dire vrai. Fonction de l'aveu en justice, cours prononcé par Michel Foucault en 1981 à Louvain (PUL/UCP, 2012).

«La découverte de la population est, en même temps que la découverte de l'individu et du corps dressable, l'autre grand noyau technologique autour duquel les procédés politiques de l'Occident se sont transformés. On a inventé à ce moment-là ce que j'appellerai, par opposition à l'anatomo-politique que j'ai mentionnée à l'instant, la bio-politique. [...] C'est à ce moment-là qu'est apparu le problème de savoir comment [...] nous pouvons régler le flux de la population, [...] régler également le taux de croissance d'une population, les migrations. Et, à partir de là, toute une série de techniques d'observation, parmi lesquelles la statistique, évidemment, mais aussi les grands organismes administratifs, économiques et politiques [...] chargés de cette régulation de la population. Il y a eu deux grandes révolutions dans la technologie du pouvoir : la découverte de la discipline et la découverte de la régulation, le perfectionnement d'une anatomo-politique et le perfectionnement d'une biopolitique $[\ldots]^{1}$.»

\footnotetext{
C'est un texte en fragments, alternant gros plans et plans larges, inspections empiriques et explorations théoriques ; un carnet d'esquisses, hésitant entre food for thought et work in progress. Il y est question de lutte contre la surpopulation carcérale, de grand renfermement des étrangers, de transfèrement des détenus et de déchéances de la nationalité ; il y est aussi question de Marx, Rusche, Althusser et Foucault. Chaque fragment peut se lire seul : le
}

1. Foucault M., «Les mailles du pouvoir », Dits et écrits, $I V, \mathrm{n}^{\circ}$ 297, Paris, Gallimard, 1994, pp. 193-194 [Barbarie, 4, 1981, pp. 23-27]. 
lecteur pressé peut - quitte à y revenir - faire l'impasse sur ce qui lui apparaît de prime abord comme une inutile digression philosophique. De l'inspection empirique, des questions émergent que l'exploration théorique tente d'affuter ; certaines intuitions sont élaborées, tandis que d'autres restent en chantier.

En 1972, Deleuze disait à Foucault qu'ils étaient peut-être « en train de vivre d'une nouvelle manière les rapports théorie-pratique ». Le modèle hypothético-déductif et le modèle inductif les conçoivent « sous forme d'un processus de totalisation » : le premier donne la pratique comme une " application » ou une " conséquence » de la théorie ; le second, comme son sol ou sa cause. Or, ajoutait-il, ces rapports sont « beaucoup plus partiels et fragmentaires » : impossible de théoriser sans rencontrer des murs, que seule la pratique peut percer ; impossible sans théorie de repérer une application dans les pratiques d'un autre domaine, plus ou moins éloigné. «La pratique, concluait le philosophe, est un ensemble de relais d'un point théorique à un autre, et la théorie un relais d'une pratique à une autre ${ }^{2}$. »

Le texte qui suit était initialement destiné à une revue juridique belge, la Revue de droit pénal et de criminologie. Mon objectif premier était de tenter d'y penser théoriquement, avec Foucault, l'échec de la lutte contre la surpopulation carcérale. L'exercice modifie notre façon de voir la criminalité, la nationalité, la citoyenneté et leurs relations, et met en évidence les limites et les dangers de la problématisation démographique de la surpopulation. Mais il donne aussi à voir le mouvement de l'œuvre du philosophe sous un jour différent, suggérant d'autres façons de penser la succession, dans ses écrits, d'un moment « disciplinaire », d'un moment « biopolitique » et d'un moment « démocratique », ainsi que les relations entre les catégories d'individu, de sujet, de population et de société. Les deux séries de bougés permettent d'éclairer certains enjeux, théoriques et pratiques, du dialogue - ou du combat ${ }^{3}$ - de Foucault avec Marx ; et d'entrevoir la signification, toujours actuelle, du diagnostic posé par le philosophe dans un texte sous-titré «vers une critique de la raison politique » : «En réussissant à combiner [...] le jeu de la cité et du citoyen et le jeu du berger et du troupeau [...] dans ce que nous appelons les États modernes, nos sociétés se sont révélées véritablement démoniaques ${ }^{4}$. »

2. Foucault M., «Les intellectuels et le pouvoir» (entretien avec G. Deleuze, 4 mars 1972), L’Arc, 49, 1972, rééd. in Foucault M., Dits et écrits, II, n 106, Paris, Gallimard, 1994, p. 307.

3. Balibar E., "Foucault et Marx. L'enjeu du nominalisme ", in La crainte des masses. Politique et philosophie avant et après Marx, Paris, Galilée, 1997, p. 282.

4. Foucault M., " "Omnes et singulatim" : vers une critique de la raison politique ", in Dits et écrits, IV, n² 291, Paris, Gallimard, 1994, p. 147 [“'Omnes et singulatim': Towards a Criticism of Political Reason", in McMurrin S. (ed.), The Tanner Lectures on Human Values, II, Salt Lake City, University of Utah Press, 1981, pp. 223-254]. 


\section{Fragment 1. Un nouveau " grand renfermement " ?}

Belgique, 1993. Le 12 janvier, la loi contenant un programme d'urgence pour une société plus solidaire ${ }^{5}$ abroge les dispositions légales organisant la répression du vagabondage et de la mendicité ${ }^{6}$. Cinq mois plus tard, le 6 mai, la loi modifiant la loi du 15 décembre 1980 sur l'accès au territoire, le séjour, l'établissement et l'éloignement des étrangers 7 institue des "centres fermés » administrés par le ministère de l'Intérieur. Au centre 127 situé dans la zone de transit de l'aéroport de Bruxelles National - le premier centre fermé de Belgique (soixante places), opérationnel depuis 1988, soit trois ans avant de recevoir une base légale ${ }^{8}$-, sont adjoints le centre 127bis, construit en 1993 et mis en service en 1994 (cent vingt places), et le centre INAD (pour « inadmissible passenger»), mis en service en 1995 (trente places) 9. S’y ajoutent le centre pour illégaux de Merxplas (CIM), colonie pour vagabonds convertie en centre fermé en 1994 (cent quarante-six places); le centre pour illégaux de Bruges (CIB), prison pour femmes convertie en centre fermé en 1995 (cent douze places); et le centre pour illégaux de Vottem (CIV), mis en service en 1999 (cent soixante places). Dans les établissements pénitentiaires, le nombre de places allouées aux étrangers détenus administrativement à la disposition de l'Office des étrangers est successivement limité à cent quatre-vingt (après la mise en service du CIM), cent cinquante (après celle du CIB) et cent (après celle du CIV). La part des étrangers sans moyens d'existence (SMEX) dans les flux des entrants étrangers en prison diminue, passant de $53 \%$ en 1992 à $11 \%$ cinq ans plus tard.

Ce réaménagement du dispositif d'enfermement a été justifié en 1992 par l'inflation carcérale 10 à laquelle est confrontée l'administration pénitentiaire - une inflation sans précédent au Xx ${ }^{\mathrm{e}}$ siècle, du moins si l'on excepte l'immédiat après-guerre. Dès 1990, la lutte contre la surpopulation carcérale générée par l'inflation se déploie sur deux fronts.

«Territoire » : après Bruges (632 places), inaugurée en 1991, Andenne (396 places), inaugurée en 1997, Ittre (405 places), inaugurée en 2003, Hasselt

5. Moniteur belge, 4 février 1993.

6. Les dispositions abrogées sont la loi du 27 novembre 1891 pour la répression du vagabondage et de la mendicité, loi modifiée en 1912, 1948, 1967, 1971 et 1980, ainsi que les articles 342 à 347 du Code pénal.

7. Moniteur belge, 21 mai 1993.

8. Cf. les développements précédant la Proposition de loi limitant strictement la détention de certaines catégories d'étrangers et demandeurs d'asile introduite par Mmes Marie-José Laloy et Marie Nagy, Sénat de Belgique, Document législatif $n^{\circ} 2-568 / 1$, Session de novembre 2000, 9 novembre 2000 (http://www.senate.be/www/?MIval=/publications/viewPub\&COLL $=\mathrm{S} \& \mathrm{LEG}=2 \& \mathrm{NR}=58 \& \mathrm{PUID}=33575838 \& \mathrm{LANG}=\mathrm{fr}$, consulté le 13 mars 2014).

9. Un nouveau centre fermé, le « Caricole », destiné à remplacer le centre 127 et le centre INAD, est entré en service en avril 2012.

10. Par « inflation carcérale », il faut entendre l'augmentation, non pas du nombre de détenus, mais du taux de détention, c'est-à-dire du nombre de détenus pour 100000 habitants. Cf. Tournier P., Dictionnaire de démographie pénale, Paris, L’Harmattan, 2010, p. 80. 
(450 places), inaugurée en 2005, le gouvernement programme dans son «masterplan pour une infrastructure pénitentiaire dans des conditions humaines 11 » la construction de sept nouvelles prisons ; sur les sites existants, il prévoit que la capacité soit étendue et que la capacité perdue soit restaurée. La prison de Marche-en-Famenne (312 places) est mise en service en 2013. En 2016, plus de 2500 places devraient être mises à disposition de la direction générale des établissements pénitentiaires; en attendant, 650 places ont été louées dans une prison néerlandaise, a priori jusqu'à la fin de l'année $2013{ }^{12}$.

«Population » : ce qu'il est désormais convenu d'appeler le «stock carcéral », s'analysant comme le produit du nombre d'entrées multiplié par la durée moyenne de détention, chacun de ces facteurs a fait l'objet d'une série d'interventions. Cela s'est traduit par la création d'" alternatives de première catégorie ${ }^{13}$ ", pour réduire le flux des entrées (outre l'abrogation des dispositions sur l'enfermement des vagabonds et la mise en service de centres fermés réservés aux étrangers ou aux mineurs ${ }^{14}$, diverses mesures ou sanctions ont été introduites dans le système pénal comme la médiation pénale, la liberté sous conditions, la peine de travail) et d' «alternatives de deuxième catégorie 15 », pour éroder la durée moyenne de détention (ainsi la libération provisoire permetelle dorénavant aux directions des prisons de libérer les détenus condamnés à des peines inférieures à trois ans dès la date d'admissibilité à la libération conditionnelle, pour autant qu'il ne s'agisse ni d'étrangers dépourvus de titre de séjour ni de personnes condamnées pour des infractions à caractère sexuel ${ }^{16)}$.

11. Masterplan 2008-2012-2016 pour une "infrastructure pénitentiaire dans des conditions humaines ", communiqué de presse du 23 mars 2011 (http://justice.belgium.be/fr/nouvelles/ communiques_de_presse/news_pers_2011-03-23_1.jsp, consulté le 18 mars 2013).

12. Rapport au Gouvernement de la Belgique relatif à la visite effectuée en Belgique par le Comité européen pour la prévention de la torture et des peines ou traitements inbumains ou dégradants (CPT) du 23 an 27 avril 2012, Conseil de l'Europe, CPT/Inf (2012) 36, p. 28 (http://www.cpt.coe.int/documents/bel/2012-36-inf-fra.pdf, consulté le 8 janvier 2014). La ministre de la Justice a récemment annoncé que le gouvernement évaluerait l'opportunité de poursuivre cette politique au-delà de 2013 ; en dépit des difficultés importantes auxquelles sont confrontés les détenus et leur famille en raison de l'éloignement, elle entend examiner «de manière approfondie en termes d'opportunités et de faisabilité (notamment sur le plan budgétaire) » les propositions visant à élargir l'expérience. Cf. la question écrite $\mathrm{n}^{\circ}$ 5-9010 posée par Bart Anciaux (sp.a) à la ministre de la Justice le 13 mai 2013 (http://www.senate.be/ www/?MIval=/index_senate\&LANG=fr, consulté le 4 décembe 2013).

13. Tournier P., "Démographie carcérale ", Dictionnaire de criminologie en ligne (http://www.criminologie.com/print/283, consulté le 9 mai 2013).

14. Aux établissements pénitentiaires se sont ajoutés non seulement les centres fermés destinés aux étrangers tenus à disposition par l'Office des étrangers, mais aussi trois centres fermés pour mineurs ayant commis un fait qualifié infraction inaugurés en 2001, 2010 et 2011.

15. Tournier P., « Démographie carcérale », art. cit.

16. Rapport au Gouvernement de la Belgique relatif à la visite effectuée en Belgique par le Comité européen pour la prévention de la torture et des peines ou traitements inbumains ou dégradants (CPT) du 23 au 27 avril 2012, Conseil de l'Europe, CPT/Inf (2012) 36, pp. 28-29. L'approche démographique du surpeuplement des prisons n'est pas propre à la Belgique; les mesures énumérées à l'annexe à la Recommandation $n^{\circ} R(99) 22 d u$ Conseil de l'Europe sur le surpeuplement des prisons et l'inflation carcérale adoptée par le Comité des ministres le 30 septembre 1999 sont appliquées dans de nombreux pays du Conseil de l'Europe. 
Vingt ans de lutte ont mis en évidence l'inefficacité des stratégies adoptées. La Cour des comptes a calculé que, «même en cas de stabilisation rapide de la population pénitentiaire ", il manquera neuf cent places une fois le "masterplan » mis en œuvre. Les mesures prises pour résoudre le problème du surpeuplement des prisons ayant un « impact budgétaire important », elle a cherché à « identifier pourquoi [elles] ont été avancées comme solution, comment elles sont mises en œuvre et si elles sont parvenues à réduire la population carcérale ». Elle note que l'extension de la capacité a été décidée sans tenir compte de l'effet d'aspiration qui pourrait en découler et observe que, " parmi toutes les mesures examinées, seule la libération anticipée a eu un impact substantiel sur la surpopulation 17 »; elle remarque qu'à peine introduites dans le système pénal, les alternatives cessent d'avoir pour " objectif premier 18 » la réduction de la surpopulation carcérale. Quant au Comité européen pour la prévention de la torture (CPT), il observe que « malgré les efforts entrepris par les autorités belges [...], la situation n’a pas cessé de s'aggraver, le nombre de personnes incarcérées croissant de 300 à 400 personnes par an 19 ». Le taux moyen de surpopulation atteint alors $24 \%$; dans certains établissements, le surpeuplement est tel qu'il assimile la détention à un traitement inhumain et dégradant ${ }^{20}$. Difficile dans ces conditions de ne pas se souvenir de Foucault qui, refusant de faire l'impasse sur quelque cent cinquante ans de critiques monotones et d'inutiles réformes, se demandait en 1975 à quoi sert l'échec de la prison ${ }^{21}$; difficile également de ne pas se demander aujourd'hui à quoi sert l'échec de la lutte contre la surpopulation. De quel problème lutte et échec construisent-ils la solution ? Quels en sont les effets et les fonctions ?

Les effets, pour commencer. Le premier est la transformation du système et du régime des peines. Nous l'avons vu : sur le front du «territoire », le souci de « ramener $[\ldots]$ les établissements pénitentiaires à un niveau qui, en termes de capacité, d'organisation et d'aménagement, satisfera aux exigences d'un pays démocratique 22 »'est traduit par la diversification des lieux d'enferme-

17. Cour des comptes, Mesures de lutte contre la surpopulation carcérale, p. 11 (https://www.ccrek.be/Docs/2012_05_Prisons_Conclusions.pdf, consulté le 20 mars 2013).

18. Ibid., p. 13. Certaines alternatives semblent contribuer à aggraver la surpopulation. Selon Philippe Mary, « [...] le nombre de condamnés libérés conditionnellement qui ne passent pas préalablement par la surveillance électronique est en érosion constante depuis 2007, passant de 75,6 \% à cette époque à 46,8 \% en 2010. Autrement dit, en 2010, les tribunaux de l'application des peines ont fait précéder la libération conditionnelle par un placement sous surveillance électronique dans plus de la moitié des cas. Or, de telles pratiques ont pour effet de retarder la libération contionnelle et, partant, de contribuer à l'allongement des peines et donc, à la surpopulation » (Mary P., «La surpopulation pénitentiaire », Cabier bebdomadaire $d u$ CRISP, 2012, 2137, p. 28).

19. Rapport au Gouvernement de la Belgique relatif à la visite effectuée en Belgique par le Comité européen pour la prévention de la torture et des peines ou traitements inhumains ou dégradants (CPT) du 23 an 27 avril 2012, p. 28 (http://www.cpt.coe.int/documents/ bel/2012-36-inf-fra.pdf, consulté le 8 janvier 2014).

20. Idem, pp. 12 et 19.

21. Foucault M., Surveiller et punir. Naissance de la prison, Paris, Gallimard, 1975, p. 276.

22. Communiqué de presse du ministre de la Justice et des réformes institutionnelles et vicePremier ministre, mars 2008 (http://www.detention-alternatives.be/spip.php?article138, consulté le 8 janvier 2014). 
ment et l'extension de la capacité carcérale ; sur le front de la « population », il a conduit à l'apparition de nouvelles méthodes pénales. Au point de jonction des deux fronts, la surveillance électronique redouble l'extension du territoire carcéral par la carcéralisation de l'espace domestique : alternative de troisième catégorie ${ }^{23}$, justifiée non sans ironie par l'impression de laxisme que donneraient les autres alternatives. Selon la ministre de la Justice, une « exécution effective et rapide des peines et principalement des courtes peines de prison constitue une nécessité afin de rendre sa crédibilité au système pénal »; vu «le contexte actuel de surpopulation carcérale », la surveillance électronique est « un outil qu'il convient de privilégier » - elle doit « sauf exception [...] devenir la norme en matière d'exécution des peines 24 ».

La transformation du système et du régime des peines est corrélée à la transformation des usages de la prison. Si la surpopulation s'explique par l'inflation carcérale, l'inflation s'explique par l'allongement des durées moyennes de détention. Effet d'une sévérité accrue ? Suivant une recherche portant sur les peines prononcées entre 1994 et 1998, non ${ }^{25}$; mathématiquement, effet (paradoxal) des alternatives à la prison. Vagabonds, étrangers détenus en vue de leur éloignement, mineurs, détenus condamnés à des peines d'emprisonnement subsidiaires ou à des peines inférieures à trois ans : les catégories les plus volatiles de la population détenue sont de moins en moins représentées dans des établissements pénitentiaires ; dans leur cas, les flux d'entrées ont été supprimés, détournés 26 ou limités. Sous l'effet de la pression médiatique et de la pression démographique, le flux des sorties a par ailleurs été réparti entre divers circuits d'accélération ou de décélération. Pour les condamnés à des peines inférieures à trois ans, susceptibles de bénéficier d'une libération provisoire, le laps de temps compris entre la date d'admissibilité à la libération anticipée et la date de sortie tend à diminuer; pour les condamnés à des peines plus lourdes, dont l'éventuelle libération anticipée doit prendre la forme d'une libération conditionnelle, il tend à s'allonger ${ }^{27}$. Résultat de ces interventions sur les flux : dans les maisons de peine, le pourcentage des condamnés à des

23. Pierre Tournier appelle « alternatives de troisième catégorie » les mesures qui réduisent le temps passé intra muros sans réduire le temps passé sous écrou (Tournier P., «Démographie carcérale ", art. cit.).

24. Circulaire ministérielle ET/SE-1 du 12 mars 2013 définissant la « réglementation de la surveillance électronique en tant que modalité d'exécution de la peine d'emprisonnement lorsque l'ensemble des peines en exécution n'excède pas trois ans d'emprisonnement ».

25. Deltenre S., «De l'impact du prononcé des peines privatives de liberté sur l'évolution de la population pénitentiaire belge enre 1994 et 1998 », Revue de droit pénal et de criminologie, 2, 2003, p. 193.

26. S'agissant des étrangers et des mineurs, il est remarquable qu'à peine ces flux détournés vers des centres fermés, les durées de détention aient été prolongées par la loi : la diversification des formes d'enfermement semble avoir été la condition de possibilité de l'allongement.

27. Il semble que la surveillance électronique retarde la libération conditionnelle : « [le] dépassement moyen de la date d'admissibilité à la LC [...] est considérablement plus long pour les détenus qui, au moment de leur libération, purgent leur peine sous le régime [...] de la surveillance électronique [...] que pour ceux qui purgent leur peine sous le régime “ordinaire” (classique) » -505 jours dans le premier cas, 371 dans le second. (Maes E., Tange C., « La libération conditionnelle sous le régime des tribunaux de l'application des peines. Bilan et enjeux 
peines correctionnelles excédant trois ans ne cesse d'augmenter. La circulaire du 12 mars 2013 parachève cette évolution : si l'ensemble des peines en exécution n'excède pas trois ans, la ministre de la Justice demande qu'elles soient purgées à domicile sous surveillance électronique.

La transformation des usages de la prison va de pair avec la transformation de sa population. Depuis 1974, première année où des chiffres ventilés en fonction de la nationalité sont disponibles, le nombre moyen de détenus étrangers n'a cessé d'augmenter : 1042 en 1974, 1212 en 1980 (+170), 1989 en 1990 (+777), 2951 en 2000 (+962), 4499 en 2010 (+1 548). Cette augmentation se double d'une augmentation de la proportion d'étrangers dans la population incarcérée : $18 \%$ en 1974, $22 \%$ en 1980, $35 \%$ en 1990, $39 \%$ en 2000, $44 \%$ en 2010. En 2012, il y avait en moyenne dans les prisons belges 11330 détenus, dont 5025 étrangers. Entre 1974 et 2012, le nombre de détenus a été multiplié par 1,8, le nombre de détenus nationaux par 1,2 et le nombre de détenus étrangers par 4,8. Tout se passe comme si l'inflation carcérale concernait avant tout les étrangers : toutes nationalités confondues, le taux de détention, calculé en rapportant le nombre de détenus au nombre d'habitants, est passé de 62 à 102 détenus pour 100000 habitants; pour les nationaux, il est passé de 58 à 64 détenus pour 100000 habitants; et pour les étrangers, de 134 à 440 détenus pour 100000 habitants. Les ressortissants des derniers États avec lesquels la Belgique a conclu des conventions bilatérales d'immigration à des fins économiques et démographiques - le Maroc et la Turquie en 1964, la Tunisie en 1969, l’Algérie et la Yougoslavie en 1970 - sont particulièrement concernés 28. Les Marocains représentent moins de $1 \%$ de la population du royaume; mais en 2012, le nombre moyen de détenus marocains s’élevait à 1 190, représentant $10 \%$ de la population des prisons. Le taux de détention, calculé en rapportant le nombre de détenus marocains au nombre d'habitants marocains enregistrés, était égal à 1416 détenus pour 100000 habitants, soit vingt-deux fois celui des nationaux.

émergeant d'une première année de fonctionnement (2007) », Revue de droit pénal et de criminologie, 11, 2011, p. 947).

28. Dans le même sens, voir De Ridder S., Beyens K., "Incarceraterd by numbers? Wat leren de cijfers ons over 'vreemdelingen' in de gevangenis?”, Panopticon, 33-4, 2012, p. 312. Selon ces auteurs, "la catégorie des Maghrébins et des Turcs est la plus surreprésentée parmi les détenus non belges : entre 1993 et 2009, leur nombre est passé de 1254 à 1957 (+56,1\%). Durant la période 2003-2009, ils représentent entre 39,9\% et 43,6\% de la population détenue non belge » (nous traduisons). Si, dans le débat public, il n'est qu'occasionnellement question des Algériens et des Tunisiens, peu nombreux en Belgique, ce sont bien les ressortissants de l'ensemble des États avec lesquels les dernières conventions d'immigration ont été signées (en ce compris les ressortissants des pays qui formaient l'ex-Yougoslavie) qui sont surreprésentés en prison. Certains d'entre eux sont des nouveaux migrants; d'autres sont des descendants d'immigrés, ayant à s'inscrire dans une société qui voit en eux une " postérité inopportune ", "qui ne sert plus ni à la reproduction de la force de travail, ni à la démographie du pays, ni comme "chair à canon" " (sur le concept de " postérité inopportune ", forgé par Abdelmalek Sayad en 1992, voir Palidda S., "La criminalisation des migrants », Actes de la recherche en sciences sociales, 129, septembre 1999, p. 46). 


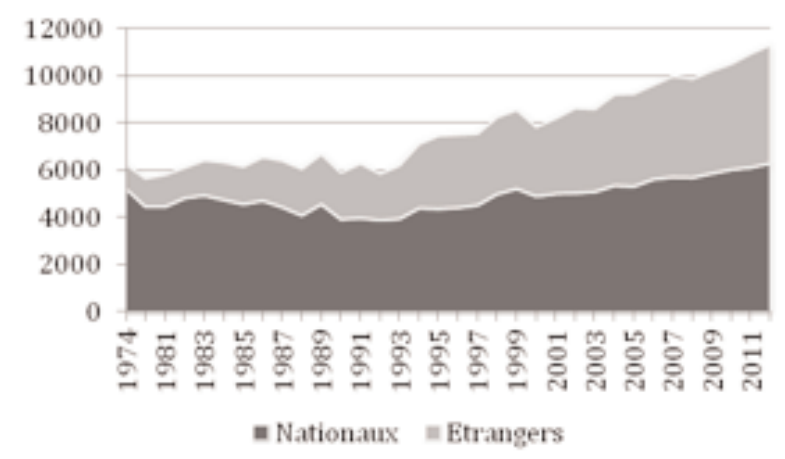

Figure 1 : Établissements pénitentiaires, 1974-2012 ("stock")

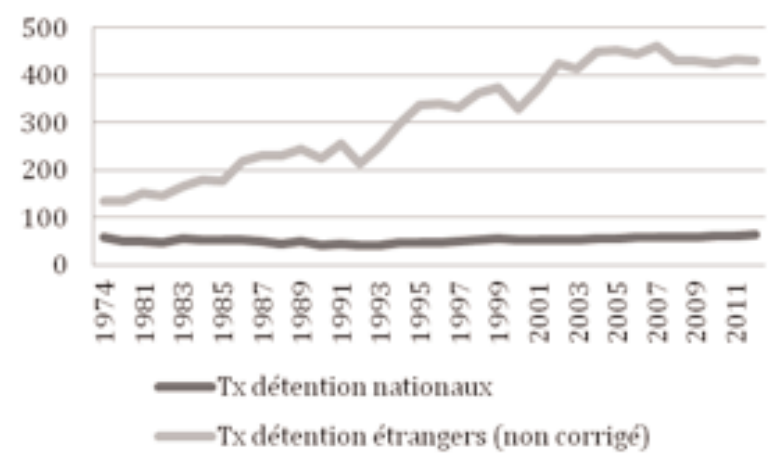

Figure 2 : Taux de détention (établissements pénitentiaires), 1974-2012

On objectera à raison que ces chiffres sont discutables. D'une part, il est possible que certaines modalités du comptage creusent l'écart entre le nombre et la proportion d'étrangers dans la population du pays et dans celle des prisons : les binationaux sont considérés comme des nationaux dans la première et suivant Steven De Ridder, ils seraient peut-être considérés comme des étrangers dans la seconde ${ }^{29}$. D'autre part, il ressort des réponses données par le gouvernement aux sénateurs Karl Vanlouwe (Nieurw-Vlaamse Alliantie, $\mathrm{N}-\mathrm{VA}$ ) et Bart Laeremans (Vlaams Belang, VB) que plus de $60 \%$ des étrangers détenus dans les établissements pénitentiaires sont en séjour illégal ${ }^{30}$. Ces

29. De Ridder S., "Criminological Research on Non-national Prisoners without a Legal Residence Permit. The Quest for the Holy Grail of Data”, in Beyens K., Christiaens J., Claes B., De Ridder S., Tournel H., Tubex H. (eds.), The Pains of Doing Criminological Research, Bruxelles, VUB Press, 2013, p. 78.

30. Le nombre de détenus étrangers sans titre de séjour s’élevait, le 12 janvier 2010, à 2097 individus, dont 757 prévenus et 1284 condamnés ; le 19 janvier 2011, à 2679 individus, dont 938 
détenus ne font pas - ou plus ${ }^{31}$ - partie des habitants recensés ; or le calcul des taux exige, par définition, de déduire du numérateur (les détenus) les individus non pris en compte au dénominateur (les habitants) ${ }^{32}$. Une fois cette correction effectuée, le taux de détention des étrangers est de 143 détenus pour 100000 habitants (soit 2,3 fois celui des nationaux) ; quant au nombre de Marocains détenus, il s'établit à 627 détenus pour 100000 habitants (soit dix fois celui des nationaux) ${ }^{33}$. Enfin, l'augmentation du taux de détention des étrangers résulte en l'occurrence de l'augmentation du nombre de détenus étrangers au numérateur, mais aussi de la diminution du nombre d'étrangers au dénominateur ${ }^{34}$ : les conditions d'attribution et d'acquisition de la nationalité belge ont été modifiées à six reprises entre 1984 et 2012 ; or, les cinq premières réformes, qui les ont élargies, ont affecté très différemment l'ensemble des détenus et celui des habitants, l'illégalité du séjour et les antécédents judiciaires faisant ou pouvant faire obstacle à l'acquisition. Remarque incidente : entre 1974 et 2012, la croissance du taux de détention des nationaux est quasiment nulle, malgré l'accroissement du nombre et du pourcentage de Belges d'origine étrangère dans la population nationale 35 : l'inflation carcérale pré-

prévenus et 1389 condamnés; le 20 juillet 2011, à 3215 individus, dont 1021 prévenus et 2053 condamnés ; le 2 mars 2012, à 3323 individus, dont 1034 prévenus et 2143 condamnés ; et le 29 mars 2013, à 3477 individus, dont 1436 prévenus et 2041 condamnés (source : SPF Intérieur, Office des étrangers et SPF Justice, calculs Office des étrangers). En première approximation, les détenus étrangers dépourvus de titre de séjour représentaient $47 \%$ des étrangers détenus en 2010, 62 \% en 2011, et 66 \% en 2012 (la réponse donnée par la secrétaire d'État à l'asile et à la migration, à l'intégration sociale et à la lutte contre la pauvreté livre des chiffres à des dates déterminées, et non des chiffres moyens par année. Question écrite $\mathrm{n}^{\circ} 5$ 5172 du sénateur Karl Vanlouwe (N-VA), 12 janvier 2012, http://www.senate.be/www/ ?MIval=/Vragen/SVPrint\&LEG=5\&NR=5172\&LANG=fr, consultée le 15 janvier 2014). Le 29 mars 2013, elle s'élevait à 67,4 \% (Source : SPF Intérieur, Officc des étrangers ; SPF Justice, DGEPI, SIDIS/Greffe ; nos calculs). Entre 2010 et 1013, il est donc exact, comme le note Bart Laeremans, que la part des détenus en séjour légal tend à baisser, et celle des détenus étrangers en séjour illégal à augmenter (Question écrite n 5-9894 du sénateur Laeremans (VB), 25 septembre 2013, http://www.senate.be/www/?MIval=/Vragen/SchriftelijkeVraag\&LEG= $5 \& \mathrm{NR}=9894 \& \mathrm{LANG}=\mathrm{fr}$, consulté le 14 janvier 2014).

31. Sur les 3125 étrangers dépourvus de titre de séjour détenus dans les établissements pénitentiaires le 20 juillet 2011, un tiers a fait partie de la population des habitants enregistrés. Onze pour cent ont été inscrits au registre d'attente, $8 \%$ au registre des étrangers et $14 \%$ - quelque 440 personnes - «dans un autre registre [le registre de la population dans la plupart des cas]» (Question écrite $n^{\circ}$ 5-5172 posée par le sénateur Karl Vanlouwe (N-VA), http://www.senate.be/www/ ?MIval=/Vragen/SVPrint\&LEG=5\&NR=5172\&LANG=fr, consultée le 15 janvier 2014).

32. Tournier P., Robert Ph., Étrangers et délinquances, Paris, L'Harmattan, 1991, p. 29.

33. Des 3125 étrangers dépourvus de titre de séjour détenus dans les établissements pénitentiaires le 20 juillet 2011, 644 (20\%) déclaraient être marocains, 582 (18\%) algériens, 78 $(2,4 \%)$ turcs, et 73 (2,3\%) tunisiens (Question écrite $n^{\circ}$ 5-5172 posée par le sénateur Karl Vanlouwe (N-VA), consultée le 15 janvier 2014, http://www.senate.be/ $\mathrm{www} /$ ?MIval=/Vragen/SVPrint\&LEG=5\&NR=5172\&LANG=fr).

34. Une illustration : le nombre de détenus marocains est passé de 740 en 1991 (population en fin d'année) à 1132 en 2010 (population journalière moyenne). Dans le même temps, le nombre d'habitants belges d'origine marocaine passait de 151265 à 279 694, et le nombre d'habitants marocains de 142098 à 81 943. L'augmentation du taux de détention des Marocains s'explique et par l'augmentation du nombre de détenus marocains, au numérateur, et par la diminution du nombre d'habitants d'origine marocaine recensés comme Marocains, au dénominateur. 
sente cette particularité - à expliquer - de ne pas être affaire d'origine nationale (ou de culture, ou de religion), mais affaire de nationalité, à strictement parler : dans la population des migrants et de leurs descendants, elle concerne principalement sinon exclusivement les individus qui ne sont ni des nationaux ni des binationaux.

Autre objection : si la surpopulation carcérale résulte de l'inflation carcérale et l'inflation carcérale de l'augmentation du nombre de détenus étrangers, alors cette augmentation est la cause, et non l'effet, de la lutte contre le surpeuplement des prisons. C'est à moitié vrai. Le nombre de détenus étrangers a commencé à augmenter avant l'introduction de la plupart des peines alternatives dans le système pénal ; mais cette introduction a accéléré le mouvement de substitution des «étrangers » aux nationaux en prison. Pensée d'un point de vue démographique, la lutte contre la surpopulation carcérale se réduit à une question de sélection et de classification - il faut déterminer qui entre, qui sort, qui reste. L'idée était d'imposer « des sanctions plus sévères pour certaines catégories de crimes considérés comme “graves” " et de proposer des «alternatives à la privation de liberté pour les infractions considérées comme moins graves » 36 : politique de bifurcation ${ }^{37}$. La réalité est différente : « dualisation » de la réaction pénale ${ }^{38}$. Si, comme Foucault l'a écrit, la prison « produit la délinquance 39 »- si elle « isole et souligne une forme d'illégalisme qui semble résumer symboliquement toutes les autres, mais qui permet de laisser dans l'ombre celles que l'on veut ou qu'on doit tolérer $40 »-$, les alternatives à la prison font système avec elle pour produire la «criminalité des immigrés »; elles fonctionnent comme autant de check points où étrangers et binationaux, nouveaux migrants et descendants d'immigrés sont arrêtés. Ce qui est en jeu n'est pas la gravité des faits qui leur sont reprochés : le pourcentage de condamnés à des peines criminelles est moins élevé parmi les détenus étrangers ${ }^{41}$. Le jeu normal des évaluations judiciaires convertit en différences pénales les inégalités sociales et les différences statutaires.

35. Entre 1991 et 2010, le nombre des personnes nées étrangères et devenues belges a presque triplé, passant de 285000 à 835426 ; suivant une estimation récente, elles étaient plus de 886700 au 1 er janvier 2012, représentant $9 \%$ de la population nationale et $8 \%$ de la population totale. La proportion de personnes devenues belges est comprise entre $10 \%$ et $40 \%$ s'agissant des personnes originaires d'un des pays de l'Union européenne ; elle dépasse $50 \%$ pour la plupart des pays tiers et atteint plus de $70 \%$ pour les personnes d'origine turque $(73 \%)$, marocaine $(71 \%$ ) et tunisienne (71 \%) (sur ce point, $c f$. Vause S., Eggerickx T., Dal L., Migrations et populations issues de l'immigration en Belgique, LLN/Bruxelles, UCL/Demo/Centre pour l'égalité des chances et la lutte contre le racisme, 2013, pp. 135-139 (http://www.diversite.be/ sites/default/files/documents/publication/rapport_statistique_et_demographique.pdf, consulté le 25 avril 2014).

36. Tubex H., Snacken S., «L'évolution des longues peines de prison : sélectivité et dualisation », in Faugeron C., Chauvenet A., Combessie P. (eds.), Approches de la prison, Bruxelles, De Boeck/Montréal, Presses de l'Université de Montréal/Ottawa, Presses de l'Université d'Ottawa, 1996, p. 223.

37. Bottoms, A., "Reflection on the Renaissance of Dangerousness", The Howard Journal of Penology and Crime Prevention, 16-2, 1977, pp. 70-95.

38. Tubex H., Snacken S., op. cit., p. 221. 
Les mécanismes de conversion, nombreux, sont cumulatifs. Les étrangers qui n'ont pas le droit de circuler librement sur le territoire des États de l'Union et qui ne sont pas ou plus autorisés à séjourner en Belgique - les «illégaux »-n'ont accès à aucune alternative, quelle que soit l'infraction pour laquelle ils sont poursuivis ou condamnés. L'accès à la médiation pénale - première alternative de première catégorie - est restreint par l'absence d' " occupation » (formation professionnelle, exercice régulier d'une activité professionnelle régulière) et barré par l'absence d'aveu ${ }^{42}$. L'accès à la liberté sous conditions - deuxième alternative de première catégorie - est compromis par l'absence ou l'insuffisance des « garanties de représentation » (avoir « quelque chose à perdre »-domicile, activité professionnelle régulière assurant régulièrement des « moyens d'existence »- est une circonstance de nature à rassurer le magistrat chargé d'évaluer le risque de soustraction à la justice et le risque de récidive, à tout le moins en matière d'infractions à la législation relative aux stupéfiants ou de délinquance acquisitive) ${ }^{43}$. L'accès à la suspension du prononcé, au sursis total à l'exécution des peines d'emprisonnement ${ }^{44}$ et aux peines alternatives - troisième, quatrième et cinquième alternatives de première catégorie - est barré par la détention préventive. L’accès à la libération conditionnelle - alternative de deuxième catégorie - est retardé par la procédure en vue d'un éventuel éloignement du territoire ${ }^{45}$, compliqué par la divi-

39. M. Foucault, Surveiller et punir, op. cit., p. 282.

40. Ibid., p. 281.

41. De Ridder S., Beyens K., "Incarceraterd by numbers? Wat leren de cijfers ons over 'vreemdelingen' in de gevangenis?", Panopticon, 33-4, 2012 ; Brion F., "La surreprésentation des étrangers en prison : quelques enseignements d'une brève étude de démographie carcérale ", in Brion F., Rea A., Schaut C. et Tixhon A. (eds.), Mon délit? Mon origine. Criminalité et criminalisation de l'immigration, Bruxelles, De Boeck Université, 2001, p. 255.

42. Adam C., Toro F., «La sous-utilisation de la médiation pénale : chiffres et processus », Revue de droit pénal et de criminologie, 79-9/10, 1999, p. 966-1004 ; Toro F., "Sanctions alternatives et délinquants étrangers : légalité et légitimation d'une incompatibilité discriminante ", in Brion F., Rea A., Schaut C. et Tixhon A. (eds.), op. cit., pp. 201-224. Quels que soient leur origine et les « codes culturels » qu'on leur suppose, il semble que les " gens sans aveu » avouent peu, peut-être parce que l'aveu a pour condition l'individualisation de la responsabilité, condition non réalisée quand des justiciables sont abordés comme membres de groupes réputés dangereux.

43. Brion F., Spiessens G., Verheyen L. (eds. Tulkens F., Hutsebaut F., van Outrive L.), L'inégalité pénale. Immigration, criminalité et système d'administration de la justice pénale, Bruxelles, SPPS, 1994 ; Snacken S., Raes A., Deltenre S., Vanneste C., Verhaeghe P., Kwalitatief onderzoek naar de toepassing van de voorlopige hechtenis en de vrijheid onder woorwaarden, Bruxelles, VUB/INCC, 1999.

44. Cf. Deltenre S., « De l'impact du prononcé des peines privatives de liberté sur l'évolution de la population pénitentiaire belge enre 1994 et 1998 ", Revue de droit pénal et de criminologie, 2, 2003, p. 188 : les proportions des peines prononcées avec sursis total, avec sursis partiel et sans sursis varient selon que les condamnés sont belges ou étrangers. En 1998, les proportions étaient les suivantes : sursis total $44,6 \%$ vs $26,2 \%$; sursis partiel $15,2 \%$ vs $21,5 \%$; sans sursis 40,2 \% vs 52,4 \%. Cf. aussi De Pauw W., Migranten in de balans, Bruxelles, VUBPress, 2000, et De Pauw W., Justitie onder invloed: Belgen en vreemdelingen voor de correctionele rechtbank in Brussel. 28 jaren straftoemeting in drugszaken, Bruxelles, VUBPress, 2009.

45. Brion F., Spiessens G., Verheyen L. (eds. Tulkens F., Hutsebaut F., van Outrive L.), op. cit. ; Reyaert P., Étrangers condamnés : un enfermement à double tour ?, communication à la journée d'études «Être étranger : un crime ? ", organisée à Louvain-la-Neuve le 21 mars 1997 ; Dupire V., Minet J.-F. (eds. Houchon G., Brion F.) « Les processus de réinsertion sociale des 
sion légale du travail procédural ${ }^{46}$, et barré par l'absence de «plan de reclassement convaincant ». L'accès aux alternatives de troisième catégorie est limité par le refus des détenus étrangers d'y consentir, tantôt par opposition à la carcéralisation de l'espace domestique que la surveillance électronique implique, tantôt par résistance au quadrillage des mouvements et du temps réglé par l'objectif d'une inscription sur le marché du travail formel, qui paraît utopique.

La lutte contre la surpopulation est en somme, en une spirale folle, tour à tour conséquence et instrument d'un nouveau " grand renfermement 47 », le grand renfermement des étrangers; machine à mailler menu la population et machine à superposer les personnages du délinquant et de l'immigré. Hors les

condamnés libérés conditionnellement », rapport de recherche établi à la demande du ministre de la Justice, 1998. De 1990 à 1997, la partie de la peine exécutée en détention par les détenus condamnés à des peines supérieures à trois ans a diminué s'agissant des nationaux, et augmenté s'agissant des étrangers; par contre, la partie de la peine exécutée en détention par les détenus condamnés à des peines intérieures à trois ans a diminué, quelle que soit la nationalité. En cause : la modalité de la libération anticipée, conditionnelle pour les premiers, provisoire pour les seconds ; et le poids du personnel de la prison d'attache - qui, d'une part, a du détenu une connaissance personnelle (et non une connaissance "sur dossier »), et d'autre part, doit gérer au quotidien les effets de la surpopulation -, limité dans le cadre des libérations conditionnelles et déterminant dans celui des libérations provisoires. Il semble par ailleurs que la durée de la procédure de décision d'éloignement des détenus étrangers autorisés à séjourner ou établis soit comprise entre dix-huit et vingt-quatre mois; or, d'une part, elle n'est pas entamée avant que la condamnation soit devenue définitive, et d'autre part, la procédure de libération conditionnelle ne l'est pas avant qu'elle ne soit arrivée à son terme. Il s'ensuit qu'un détenu étranger condamné à une peine correctionnelle comprise entre trois ans et cinq ans est rarement libéré conditionnellement : le plus souvent, la totalité de la peine a été purgée intra muros avant que les deux procédures soient arrivées à leur terme (Brion F., « La surreprésentation des étrangers en prison : quelques enseignements d'une brève étude de démographie carcérale ", art. cit., p. 238). Les transformations de la procédure de libération conditionnelle n'ont pas modifié la situation ( $c f$. infra) ; l'introduction de la surveillance électronique a sans doute accentué la différenciation.

46. Sur ce point, voir Mulier C., Giacometti M., «Le durcissement du régime de la libération conditonnelle : une réforme opportune ? ", Annales de droit de Lowvain, 2013, en particulier pp. 209-211. La loi du 17 mars 2013 a supprimé l'automaticité de l'examen des demandes de libération conditionnelle. Auparavant, c'était au directeur de la prison d'attache qu'il incombait d'introduire la procédure de libération conditionnelle, par le biais d'un avis rendu au plus tôt quatre mois et au plus tard deux mois avant que le condamné atteigne la date d'admissibilité à la libération conditionnelle. Désormais, le directeur doit informer le condamné de la possibilité d'introduire lui-même une demande six mois avant la date d'admissibilité ; et c'est le condamné qui doit initier la procédure en déposant une demande écrite au greffe de la prison. La réforme est justifiée par une volonté de "responsabilisation » et d'" activation » des détenus, analogue à la volonté de « responsabilisation » et d' «activation » des demandeurs d'emploi, et conforme aux impératifs de subjectivation propres à la formule néolibérale de gouvernement ( $c f$. Brion F., "Éthique et politique dans les sociétés libérales avancée ", $L a$ Pensée et les Hommes, 48-57, 2005, pp. 115-134). Ainsi que le notent Caroline Mulier et Mona Giacometti : «Certains détenus plus isolés ou fragiles (illettrés, ne parlant pas la langue, n'ayant plus de famille, d'amis, de liens professionnels, de lieu de résidence, d'avocat...) ne disposeront pas des ressources suffisantes ou ne trouveront pas l'énergie nécessaire pour introduire la procédure, et deviendront ainsi les « oubliés du système» (op. cit., p. 211). Apparemment "neutre ", la volonté de "responsabilisation » et d' "activation » risque de fonctionner comme un mécanisme de sélection sociale et nationale des détenus libérés, ou comme un mécanisme d'hétéro-exclusion déguisé en mécanisme d'auto-exclusion, déguisement - ou forme - typique de la rationalité néolibérale.

47. Foucault M., Histoire de la folie à l'âge classique, Paris, Gallimard, pp. 56-91. 
murs, les prisons sont devenues le point de comparaison à partir duquel il est possible de regarder comme des faveurs désirables des mesures de surveillance qui seraient insupportables si elles n'étaient pas des alternatives à la détention - voire même de demander et de se réjouir, au nom de l'humanisme, de leur extension. Dans les murs, la proportion des détenus étrangers semble valoir invitation à considérer qu'il suffirait de procéder à leur éloignement pour résoudre le problème du surpeuplement. En septembre 2013, le leader de la NV-A déclarait qu'à la place de la ministre de la Justice, il aurait déjà « essayé depuis longtemps de construire une prison belge au Maroc », ajoutant : «Il y a près de 1200 Marocains derrière les barreaux dans notre pays. De quoi remplir une prison complète... 48 » Provocation ? Peut-être. Mais selon la presse, la ministre de la Justice elle-même avait « fait examiner la faisabilité » du projet, avant de conclure qu'il était «irréaliste et inapplicable » ${ }^{49}$. Du reste, l'idée de lutter contre la surpopulation en délocalisant l'exécution des peines de prison n'a peut-être pas été abandonnée : pour la réaliser, d'autres voies semblent se dessiner.

La Convention du Conseil de l'Europe sur le transfèrement des personnes condamnées signée le 21 mars 1983 encourage les États signataires à autoriser les personnes condamnées dans tel État, appelé «État de condamnation », à purger leur peine dans les prisons de l'État dont elles ont la nationalité, appelé "État d'exécution ». Le protocole additionnel signé le 18 décembre 1997 dispose en outre en son article 3 que «Sur demande de l'État de condamnation, l'État d'exécution peut, sous réserve de l'application des dispositions de cet article, donner son accord au transfèrement d'une personne condamnée sans le consentement de cette dernière lorsque la condamnation prononcée à l'encontre de celle-ci, ou une décision administrative prise à la suite de cette condamnation, comportent une mesure d'expulsion ou de reconduite à la frontière ou toute autre mesure en vertu de laquelle cette personne, une fois mise en liberté, ne sera plus admise à séjourner sur le territoire de l'État de condamnation. » De même, la Belgique et le Maroc ont signé, le 7 juillet 1997, une convention bilatérale sur l'assistance aux personnes détenues et le transfèrement des personnes condamnées, convention aux termes de laquelle un Marocain condamné en Belgique peut purger sa peine au Maroc, et un Belge condamné au Maroc purger sa peine en Belgique ${ }^{50}$. La Convention ne permettant que le transfèrement volontaire, un protocole additionnel a été signé

48. Enregistrement audiovisuel de l'entretien (http://www.hln.be/hln/nl/4833/Gevangenissen/ article/detail/1710469/2013/09/24/De-Wever-Bouw-Belgische-gevangenis-inMarokko.dhtml, consulté le 8 janvier 2014). Selon Bart De Wever, il s'agirait d'une opération gagnant-gagnant, la construction d'une prison au Maroc pouvant y contribuer à la création d'emplois.

49. "Prison au Maroc : "Irréaliste et inapplicable", selon Turtelboom », La libre, 26 septembre 2013 (http://www.lalibre.be/actu/belgique/prison-au-maroc-irrealiste-et-inapplicable-selonturtelboom-5243ed4535703eef3a076712, consulté le 25 novembre 2013).

50. Loi du 17 mars 1999 portant assentiment à la Convention entre le Royaume de Belgique et le Royaume du Maroc sur l'assistance aux personnes détenues et le transfèrement des personnes condamnées, signée à Bruxelles le 7 juillet 1997, Moniteur belge, 6 juillet 1999. 
en 2007 ; il insère un article 5 bis $\$ 1$ aux termes duquel la personne condamnée «sera, dans les meilleurs délais, transférée sans son consentement vers l'État d'exécution » si elle fait également l'objet d'une mesure en vertu de laquelle, « une fois mise en liberté, [elle] ne sera plus admise à séjourner sur le territoire de l'État de condamnation ${ }^{51}$ ».

Le transfèrement volontaire des personnes condamnées était conçu comme un moyen de favoriser leur réinsertion - ou, à tout le moins, de limiter leur désinsertion familiale et sociale ${ }^{52}$; le transfèrement forcé est désormais pensé comme un moyen de lutter contre la surpopulation carcérale ${ }^{53}$. Au

51. Loi portant assentiment au Protocole additionnel, signé à Rabat le 19 mars 2007, à la Convention entre le Royaume de Belgique et le Royaume du Maroc sur l'assistance aux personnes détenues et le transfèrement des personnes condamnées, signée à Bruxelles le 7 juillet 1997, Moniteur belge, 21 avril 2011 (http://www.ejustice.just.fgov.be/cgi/ article_body.pl?language $=$ fr\&caller $=$ summary\&pub_date $=11-04-21 \&$ numac $=2009015034$ ).

52. Entre 2005 et 2010, 212 détenus ont introduit une demande en vue de subir leur peine dans leur pays d'origine ou de résidence sur la base de la Convention européenne sur le transfèrement des personnes condamnées du 21 mars 1983 (Chambre des Représentants de Belgique, Questions et réponses écrites (Gouvernement chargé des affaires courantes), QRVA 53-008, $2^{\text {e }}$ session de la 53e législature, 2010-2011, p. 56, (http://www.lachambre.be/QRVA/ pdf/53/53K0008, consulté le 5 février 2014).

53. Voir la question écrite n ${ }^{\circ}$ 4-7177 posée par le sénateur Alain Destexhe (MR) le 12 mars 2010, (http://www.senate.be/www/?MIval=/Vragen/SchriftelijkeVraag\&LEG=4\&NR=7177\&LA NG=fr, consulté le 25 novembre 2013) : " Le 7 juillet 1997 le Royaume du Maroc et le Royaume de Belgique ont conclu une Convention sur l'assistance aux personnes détenues et le transfèrement des personnes condamnées [...]. Ce Traité permettait le transfèrement volontaire de ressortissants des deux États parties condamnés dans l'un des deux États parties à purger sa peine dans son pays d'origine [...]. Cette Convention ne permettant que le transfèrement volontaire, nos deux pays ont conclu, le 19 mars 2007, un Protocole additionnel permettant, moyennant toute une série de conditions [...], un transfèrement sans consentement. Ce protocole a été ratifié par notre pays [...]. À l'heure où notre pays souffre d'une surpopulation carcérale, la question de l'efficacité de tels instruments conventionnels ne peut manquer de se poser. Je vous serais dès lors reconnaissant de bien vouloir répondre aux questions suivantes : [...]» (nous soulignons). Dans le même sens, voir la question $n^{\circ} 4$ du député Renaat Landuyt (sp-a) au ministre de la Justice le 29 juillet 2010 : « La surpopulation dans nos prisons reste dramatiquement élevée, tout comme la proportion de détenus étrangers au sein de la population carcérale belge. Il a été préconisé et promis à plusieurs reprises d'intensifier les efforts pour que les prisonniers étrangers purgent leur peine dans leur pays d'origine. Il est déjà possible de transférer les prisonniers étrangers vers leur pays d'origine. [...]. Il est également possible de transférer des détenus contre leur gré mais un protocole spécial est nécessaire a cet effet. La Belgique a signé un tel protocole mais il n’a toujours pas été ratifié par le Maroc. [...] » (Chambre des Représentants de Belgique, Questions et réponses écrites (Gouvernement chargé des affaires courantes), QRVA 53-008, 2e session de la 53e législature, 2010-2011, p. 55 (http://www.lachambre.be/QRVA/pdf/53/53K0008, consulté le 5 février 2014). Dans le même sens encore, la question $n^{\circ} 209$ du député Laurent Louis (PP) au ministre de la Justice le 25 novembre 2010 : « [...] Le 7 juillet 1997 le Royaume du Maroc et le Royaume de Belgique ont conclu une convention sur l'assistance aux personnes détenues et le transfèrement des personnes condamnées. [...] Cependant, comme cette convention ne vise que le transfèrement volontaire, nos deux pays ont conclu, le 19 mars 2007, un protocole additionnel permettant, moyennant toute une série de conditions [...], un transfèrement sans consentement. [...] À l'beure ou notre pays souffre d'une surpopulation carcérale qui nous pousse même à devoir louer à prix d'or une prison aux Pays-Bas faute de solutions réelles et actuelles sur notre territoire, la question de l'efficacité de tels instruments conventionnels revêt une importance significative. 1. a) Le protocole additionnel du 19 mars 2007 est-il déjà entré en vigueur ? [...] 2. a) De tels accords existent-ils également avec d'autres pays ou d'autres sontils en voie d'être conclus ? [...] " (nous soulignons) (Chambre des Représentants de Belgique, 
niveau international, le «but » du gouvernement est « de continuer à [le] promouvoir autant que possible », soit en " persuad[ant] un maximum de pays de ratifier le Protocole additionnel », soit en proposant « un instrument bilatéral [...] aux pays qui ne veulent pas adhérer à l'instrument précité 54 ». Au niveau national, c'est la mise en ouvre des dispositions relatives au transfèrement contre leur gré des détenus étrangers qui est visée. Le Protocole additionnel à la Convention européenne est entré en vigueur en 2005 : entre 2005 et 2010, trente détenus étrangers condamnés en Belgique ont été transférés sans y avoir consenti ; la mesure a été envisagée pour trois cent vingt détenus ${ }^{55}$. Le protocole additionnel à la Convention belgo-marocaine a été ratifié par la Belgique en 2009 et par le Maroc en 2011 : en septembre 2011, la Belgique a transmis au Maroc les dossiers de cent quatre-vingt-dix détenus remplissant les conditions d'un transfèrement forcé ; de mai 2012 à décembre 2013, quinze d'entre eux ont été transférés ${ }^{56}$. Lutte contre la surpopulation oblige, la ministre de la Justice et son administration communiquent sur ces mesures en termes criminologiques ( criminalité 57 », « réinsertion sociale 58 »), mais aussi en termes démographiques et économiques (durée cumulée des peines, coût journalier, avantage financier pour la Belgique) : vocabulaire de gestionnaire ${ }^{59}$.

Questions et réponses écrites (Gouvernement chargé des affaires courantes), QRVA 53-032, 2e session de la 53e législature, 2010-2011, p. 28 (http://www.lachambre.be/ QRVA/pdf/53/53K0032.pdf, consulté le 5 février 2014).

54. Réponse donnée par le ministre de la Justice le 25 novembre 2010 à la question posée par le député Renaat Landuyt le 29 juillet 2010, Chambre des Représentants de Belgique, Questions et réponses écrites (Gouvernement chargé des affaires courantes), QRVA 53-008, 2e session de la 53e législature, 2010-2011, p. 58 (http://www.lachambre.be/QRVA/pdf/53/53K0008, consulté le 5 février 2014). Outre la convention belgo-marocaine, des conventions bilatérales sur le transfèrement sans le consentement de la personne condamnée ont été conclues avec la République du Congo, l'Albanie, et le Kosovo (idem). Voir aussi la question écrite n ${ }^{\circ}$ 5-133 posée par la sénatrice Martine Taelman (Open Vld) au ministre de la Justice le 10 septembre 2010 à propos de la ratification des conventions sur le transfèrement sans consentement conclues avec le Maroc, la République du Congo et l'Albanie, sur leurs conditions et sur leur mise en œuvre (Sénat de Belgique, Session extraordinaire de 2010, http://www.senate.be/www/?MIval=/Vragen/SVPrintNLFR\&LEG=5\&NR=133\&LANG= fr, consulté le 25 novembre 2013).

55. Ibid., p. 56-57.

56. SPF Justice, Nouvelles, 16 décembre 2013 (http://justice.belgium.be/fr/nouvelles/communiques_de_presse/news_pers_2013-12-16_2.jsp).

57. Cf. SPF Justice, Nonvelles, 16 décembre 2013 (http://justice.belgium.be/fr/nouvelles/communiques_de_presse/news_pers_2013-12-16_2.jsp, consulté le 8 janvier 2014) : « [...] Ce matin, un avion est parti pour Rabat avec à son bord six prisonniers marocains. Il s'agit de détenus qui ont été emprisonnés pour des infractions de drogues, faux et usages de faux, escroqueries, viols et tentatives d'assassinat. Pour la ministre de la Justice, Annemie Turtelboom, "ces six détenus sont des criminels graves [...] qui n'ont aucun lien avec notre pays. Il est donc normal qu'ils puissent purger leurs peines dans leur pays d'origine" [...] » (nous soulignons).

58. Cf. Réponse d'Annmie Turtelboom, ministre de la Justice, à Peter Logghe (VB) in Chambre des Représentants de Belgique, Compte Rendu Intégral, CRIV 53 COM 506, p. 3 (http://www.lachambre.be/doc/CCRI/pdf/53/iC506.pdf\#search="12073", consulté le 8 janvier 2014) : "Un détenu est transféré vers son pays d'origine pour favoriser sa réinsertion sociale [...]. »

59. Ibid. : "Seuls cinq détenus ont effectivement pris l'avion [...]. La durée cumulée des peines encourues dans notre pays était de 36 ans » (nous soulignons) ; SPF Justice, Nouvelles, 16 décembre 2013 (http://justice.belgium.be/fr/nouvelles/communiques_de_presse/ 
On objectera qu'aux termes du protocole additionnel à la Convention belgo-marocaine, seule une minorité de détenus marocains peuvent faire l'objet d'un transfèrement forcé ${ }^{60}$. C'est vrai. Mais s'il a suffi d'une décennie pour passer du transfèrement volontaire au transfèrement involontaire, il faut craindre qu'à l'avenir, un autre protocole additionnel étende les conditions sous lesquelles ce dernier peut être pratiqué ; à la Chambre, certaines voix s'élèvent déjà pour exiger le "rapatriement » des détenus binationaux ${ }^{61}$. Le risque existe par ailleurs que le dispositif ne soit effectif que dans un sens : plusieurs Belgo-Marocains nés en Belgique ou y vivant depuis l'enfance sont aujourd'hui détenus au Maroc, où ils ont été condamnés dans le cadre d'affaires de terrorisme; malgré les rapports établis par des organisations internationales de défense des droits de l'homme 62 - et, dans certains cas, malgré des allégations de torture corroborées par des cicatrices ${ }^{63}$-, ils n'ont pas obtenu

news_pers_2013-12-16_2.jsp, consulté le 8 janvier 2014) : « [...] Ensemble, ces six criminels ont été condamnés à 51 ans et 3 mois de prison. [...] C'est la troisième fois que des détenus marocains sont transférés. Jusqu'à présent, au total quinze détenus ayant été condamnés ensemble à une peine de 125 ans ont été transférés. Ces transfèrements représentent un avantage financier pour notre pays de près de six millions d'euros » (nous soulignons).

60. Aux termes de l'article 5 bis $\$ 2$ ajouté à la Convention par le protocole additionnel, ne peut faire l'objet d'un transfèrement forcé le condamné né dans l'État de condamnation ou qui y soit installé à un âge ne dépassant pas 12 ans et qui y ait résidé depuis; ou bénéficiant du statut de réfugié ; ou ayant séjourné de manière ininterrompue sur le territoire de l'État de condamnation pendant cinq années; ou exerçant avant la décision d'expulsion dans l'État de condamnation une autorité parentale en sa qualité de père, mère, de tuteur légal vis-à-vis d'au moins un enfant séjournant de manière habituelle dans l'État de condamnation ; ou répondant à toutes les conditions à même de lui octroyer la nationalité de l'État de condamnation ; ou lié à un citoyen ou citoyenne de l'État de condamnation par un acte de mariage conclu avant la décision d'expulsion; ou dont le père ou la mère réside de manière habituelle et régulière dans l'État de condamnation; ou qui, lors d'un séjour habituel dans l'État de condamnation, a été victime d'un accident de travail ou d'une maladie professionnelle et qui bénéficie d'une rente viagère de l'État de condamnation; ou qui, lors d'un séjour habituel dans l'État de condamnation est atteint d'une maladie grave ou dont la prise en charge ne peut s'effectuer dans l'État d'exécution.

61. Cf. les questions posées par Peter Logghe (VB) à la ministre de la Justice, in Chambre des représentants de Belgique, Compte rendu intégral, CRIV 53 COM 506, pp. 1-2, http://www.lachambre.be/doc/CCRI/pdf/53/iC506.pdf\#search="12073" (consulté le 8 janvier 2014) : «Le ministre De Clerck avait établi sous la législature précédente une liste de 190 détenus marocains qui, sur la base d'une série de conditions, entraient en ligne de compte pour un rapatriement. Cette liste ne comportait ni Marocains nés en Belgique, ni personnes détenant une double nationalité, ni détenus mariés à un conjoint belge [...]. Je ne comprends pas pourquoi les détenus ayant une double nationalité ne seraient pas renvoyés chez eux ? Des objections d'ordre juridique s'opposent-elles à ce retour ? Ne pourrait-on d'ailleurs les priver de la nationalité belge sur la base de la législation en matière de nationalité ? "

62. Cf. sur ce point Human Rights Watch, “The 'Belliraj' Mass Terrorism Trial, 'Just Sign Here': Unfair Trials Based on Confessions to the Police in Morocco", juin 2013, pp. 36-59 (http://www.hrw.org/reports/2013/06/21/just-sign-here-0, consulté le 4 février 2014).

63. Ibid., pp. 46-59, ainsi que le courrier adressé par Juan A. Mendez, rapporteur spécial des Nations unies sur la torture et autres traitements cruels, inhumains ou dégradants, reproduit sur le site internet de soutien à Ali Aarrass : http://www.freeali.eu/?p=4219. Il est intéressant de lire ces documents à l'aune de la réponse donnée par la ministre de la Justice aux questions posées le 28 décembre 2011 par Bert Anciaux (sp.a). Au sénateur qui lui demande « [...] Comment le ministre pourra-t-il demander des garanties quant au fait que ces détenus seront traités au Maroc de manière conforme à la dignité humaine ? Le respect de la Convention européenne de sauvegarde des droits de l'homme et des libertés fondamentales y est-il parfaitement garanti ? ", la ministre répond : « [...] La collaboration internationale en matière 
de pouvoir exécuter leur peine en Belgique, quand bien même leur famille (parents, fratrie, voire épouse et enfants) y est établie. Bien plus : un de ces binationaux - Mohamed R'ha, né et élevé en Belgique, devenu belge à l'âge de 12 ans par déclaration de ses parents - a été déchu de la nationalité belge le 18 novembre 2010, au motif qu'il avait manqué gravement à ses devoirs de citoyen belge.

Faut-il craindre alors que le «terroriste islamiste » soit à la déchéance ce que, selon Foucault, le « criminel » est à la prison : une justification, et la partie émergée d'un iceberg dont la partie immergée est la répression 64 ? Redouter - puisque la binationalité est un obstacle au transfèrement forcé que de plus en plus de détenus binationaux soient déchus de leur nationalité belge avant d'être renvoyés vers leur " pays d'origine ", comme le demande un député nationaliste flamand 65 ? À ce jour, la déchéance est encore rare ${ }^{66}$. Il n'empêche : ignorée des cours et des tribunaux pendant six décennies ${ }^{67}$, elle

pénale avec le Maroc repose sur la confiance mutuelle. [...]. Avant de procéder au transfèrement, la Belgique prend en considération les informations de condamnations de la Cour européenne des droits de l'homme (ou d'autres instances en matière de droits de l'homme) et/ou les évaluations menées par les organes d'inspection. Par conséquent, aucun transfèrement n'aura lieu vers un pays où les droits de l'homme sont violés. [...] " (Sénat de Belgique, Question écrite $\mathrm{n}^{\circ}$ 5-4704 posée par Bert Anciaux (sp.a) le 28 décembre 2011, (http://www.senate.be/www/?MIval=/Vragen/SchriftelijkeVraag\&LEG=5\&NR=4704\&LA $\mathrm{NG}=$ fr, consultée le 8 janvier 2014).

64. Foucault M., «Enquête sur les prisons : brisons les barreaux du silence » (Entretien de C. Angeli avec M. Foucault et P. Vidal-Naquet, 1971), in Foucault M., Dits et écrits, II, n 88, Paris, Gallimard, 1994, p. 179 : «[...] L'institution prison, c'est pour beaucoup un iceberg. La partie apparente, c'est la justification : "Il faut des prisons parce qu'il y a des criminels." La partie cachée, c'est le plus important, le plus redoutable : la prison est un instrument de répression sociale. »

65. Cf. supra, la question posée par Peter Logghe (VB) à la ministre de la Justice, in Chambre des représentants de Belgique, Compte rendu intégral, CRIV 53 COM 506, pp. 1-2 (http://www.lachambre.be/doc/CCRI/pdf/53/iC506.pdf\#search="12073", consulté le 8 janvier 2014).

66. Outre l'arrêt rendu par la Cour d'appel d'Anvers le 18 novembre 2010, trois arrêts ont été rendus par la Cour d'appel de Bruxelles «sur la base de condamnations pour cause d'activités terroristes inspirées par un extrémisme religieux »-deux le 26 janvier 2009, à l'encontre de deux Belgo-Tunisiens ; le troisième le 6 janvier 2010, à l'encontre d'un Belgo-Marocain. S'y ajoutent trois arrêts rendus par la Cour d'appel de Gand pour des « faits frauduleux qui ont été déterminants dans l'octroi de la nationalité belge ", à l'encontre d'un Belgo-Bouthanais, le 11 décembre 2008, d'un Belgo-Albanais, le 5 février 2009, et d'une Belgo-Thaïlandaise, le 4 juin 2009, et un arrêt rendu par la Cour d'appel de Liège le 16 janvier 2012 à l'encontre d'un homme d'origine serbo-monténégrine, pour « usage de faux documents ou de documents falsifiés [...] qui ont conduit à l'obtention de la nationalité belge » (cf. la réponse du ministre de la Justice du 23 septembre 2011 à la question n 543 posée par le député Theo Francken le 7 juillet 2011, in Chambre des représentants de Belgique, Questions et réponses écrites (Gouvernement chargé des affaires courantes), QRVA 53-041, 2e session de la 53e législature, 2010-2011, p. 95 ; et la réponse du ministre de la Justice du 24 juillet 2012 à la question n ${ }^{\circ} 525$ posée par le député Theo Francken le 10 mai 2012, in Chambre des représentants de Belgique, Questions et réponses écrites, QRVA 53-076, 3e session de la 53e législature, 2011-2012, p. 232).

67. Cf. la réponse de la ministre de la Justice à la question $n^{\circ} 491$ posée par le député Jan Van Esbroek (N-VA) le 25 avril 2012, in Chambre des représentants de Belgique, Questions et réponses écrites, QRVA 53-067, 3e session de la 53e législature, 2011-2012, p. 177, ainsi que Foblets M.-C., "La lutte contre l'immigration dans l'économie de l'article $\mathrm{K}$ du Traité de Maastricht. Enjeux de la citoyenneté », in Tulkens F., Bosly H.-D. (eds.), La Justice pénale et 
jouit d'un regain d'intérêt ${ }^{68}$; et les récentes évolutions législatives ne laissent pas d'inquiéter. D’une part, les motifs de déchéance se sont multipliés : suivant l'article 23 du Code de la nationalité, «manquements graves [aux] devoirs de citoyen belge », mais aussi, depuis juin 2006, acquisition frauduleuse de la nationalité ; suivant l'article 23/1 y inséré en décembre 2012, acquisition de la nationalité à la suite d'un mariage " annulé pour cause de mariage de complaisance ", condamnation comme auteur, coauteur ou complice à une peine d'emprisonnement d'au moins cinq ans sans sursis du chef d'une infraction «dont la commission a été manifestement facilitée par la possession de la nationalité belge » ou du chef d'une des infractions mentionnées dans l'article - des infractions qui, pour la plupart, n'existaient pas il y a vingt ans et ont été insérées dans le code pénal ou dans la loi du 15 décembre 1980 « sur les étrangers 69 » (sic) récemment. D’autre part, la procédure a été dédoublée : l'article 23 prévoit que les actions en déchéance sont poursuivies devant les cours d'appel ; l'article 23/1, que la déchéance peut être prononcée par le juge de première instance à titre de peine accessoire.

Comme Marie-Claire Foblets le remarquait il y a près de vingt ans déjà, «[1]e souci de protéger leurs nationaux contre la concurrence des ressortissants d'États tiers aboutit à accentuer la menace que fait peser sur l'Union - et à travers elle sur les États - une présence étrangère indésirable 70 ». Certes, la ministre de la Justice, interpellée à l'occasion de l'affaire Sharia4Belgium, a rappelé en mai 2012 que la déchéance de la nationalité est une « mesure exceptionnelle qui n'a pas été appliquée pendant des décennies dans notre pays » : ce n'est, a-t-elle ajouté, « qu'au cours de ces dernières années qu'un certain nombre d'arrêts on été prononcés dans le cadre d'infractions terroristes et de fraude 71 ». Mais qu'il faille le rappeler suffit à montrer que la multiplication des motifs de déchéance et la simplification de la procédure inscrite à l'article 23/1 ont amorcé un processus de normalisation de la mesure, processus qui n'est sans doute pas terminé. Un indice ? La proposition de loi déposée en juin 2013 par la sénatrice Christine Defraigne (Mouvement réformateur, MR) vise

l'Europe, Bruxelles, Bruylant, 1996, p. 328, n. 4. Il semble que seules quatre déchéances de nationalité aient été prononcées entre 1934 et 1940, et trente-quatre dans l'immédiat aprèsguerre. Par la suite, aucun individu n'aurait été déchu de sa nationalité avant 2008. La possibilité de déchoir Tarek Maaroufi - un des deux Belgo-Tunisiens déchus en janvier 2009 - de la nationalité qu'il avait acquise par mariage en 1993 fut envisagée en 1996 ; il était soupçonné d'avoir participé à un trafic d'armes au profit du Groupe islamiste armé. (Sénat de Belgique, Commission de la Justice, Annales des réunions publiques de commission. Séance du mardi 26 novembre 1996, 1-63 COM, p. $514 \mathrm{sq})$.

68. Renauld B., «S'il faut déchoir Fouad Belkacem de la nationalité belge, un jugement est nécessaire : Pourquoi ? ", Justice en ligne, 27 juin 2012 (http://www.justice-enligne.be/article455.html, consulté le 5 février 2014).

69. C'est ainsi que l'article 23/1 abrège l'intitulé de la loi sur l'accès au territoire, le séjour, l'établissement et l'éloignement des étrangers.

70. Foblets M.-C., op. cit., p. 334.

71. $C f$. la réponse de la ministre de la Justice à la question $n^{\circ} 491$ posée par le député Jan Van Esbroek (N-VA) le 25 avril 2012, in Chambre des représentants de Belgique, Questions et réponses écrites, QRVA 53-067, 3e session de la 53e législature, 2011-2012, p. 177. 
à « renforcer les possibilités de déchéance » de diverses façons : en érigeant en présomption de «manquement grave aux devoirs du citoyen belge »la condamnation du chef de toute infraction commise en qualité de récidiviste ou la condamnation à une peine inférieure à cinq ans basée sur la loi du 30 juillet 1981 tendant à réprimer certains actes inspirés par le racisme ou la xénophobie; en ajoutant d'autres infractions à celles que liste l'article 23/1; en automatisant la déchéance des binationaux condamnés du chef d'une des infractions mentionnées ${ }^{72}$.

Pour certaines catégories de citoyens belges, le danger charrié par ce processus de normalisation est considérable. Les conséquences résultant des faits motivant la déchéance diffèrent en effet selon que la nationalité a été transmise ou acquise et selon que les individus concernés sont originaires d'un État membre de l'Union ou non. Ni les individus tenant leur nationalité belge d'un père ou d'une mère belge au jour de leur naissance, ni ceux dont l'un des parents est né en Belgique et y a résidé cinq ans durant les dix années précédant leur naissance ne peuvent être déchus : dans leur cas, la nationalité est un attribut. Peuvent l'être par contre les individus nés en Belgique et devenus belges par déclaration de leurs parents, ou ceux qui sont devenus belges par déclaration, mariage ou naturalisation. Par ailleurs, pour les binationaux ayant la nationalité d'un autre État membre de l'Union, la perte de la nationalité belge n'entraîne pas celle de la citoyenneté européenne. Pour ceux qui ont la nationalité d'un État tiers, elle se double de la perte de la citoyenneté européenne et des libertés qui lui sont associées. Résultante de ce jeu de dispositions ? Contrairement aux adultes dont les parents étaient des immigrés italiens, espagnols ou grecs, la plupart des adultes venus avec leurs parents du Maroc et de Turquie sont aujourd'hui encore en citoyenneté conditionnelle, c'est-à-dire en liberté(s) conditionnelle(s).

72. Cf. «Proposition de loi modifiant le Code de la nationalité belge en vue de renforcer les possibilités de déchéance de la nationalité déposée par Mme Christine Defraigne le 4 juin 2013 ", Sénat de Belgique, Session de 2012-2013, 5-2141/1,(http://www.senate.be/www/?MIval=/ publications/viewPub.html\&COLL $=S \& L E G=5 \& N R=2140 \&$ VOLGNR $=1 \& L A N G=f r$, consultée le 5 février 2014). Dans le même sens, le sénateur FN Michel Delacroix proposait en 2009 que la condamnation définitive à une peine privative de liberté d'un an minimum, assortie ou non d'un sursis, entraîne de plein droit la déchéance de la nationalité belge pour les Belges qui ne tiennent pas leur nationalité d'un auteur belge au jour de leur naissance et les Belges qui ne se sont pas vus attribuer leur nationalité en vertu de l'article 11 («Proposition de loi modifiant le Code de la nationalité belge en vue d'automatiser la déchéance de la nationalité en cas de condamnation pénale à une peine privative de liberté d'un an minimum déposée par M. Michel Delacroix [FN] le 17 août 2009 ", Sénat de Belgique, Session 2008-2009, 41439/1 (http://www.senate.be/www/?MIval=/publications/viewPub.html\&COLL=S\&LEG $=4 \& \mathrm{NR}=1439 \& \mathrm{VOLGNR}=1 \& \mathrm{LANG}=\mathrm{fr})$. La clé prévue par la sénatrice du MR - à l'article 23 , référence à la récidive - participe du travail de légitimation de la proposition, en limitant à peine son extension. L'offensive se poursuit par ailleurs du côté des nationalistes flamands, la sénatrice Inge Faes (N-VA) ayant récemment demandé à la ministre de la Justice des chiffres relatifs aux déchéances prononcées depuis 2007, ventilés selon les motifs prévus par la loi ( $c f$. Sénat de Belgique, Question écrite n ${ }^{\circ}$ 5-9893 posée le 24 septembre 2013 par Inge Faes (NVA) à la ministre de la Justice (http://www.senate.be/www/?MIval=/Vragen/ SVPrint $\&$ LEG $=5 \& N R=9893 \& L A N G=$ fr). 


\section{Fragment 2. Foucault avec Marx : généalogie de la force de travail}

Après les effets, les fonctions. Un bref détour théorique s'avère nécessaire avant d'aborder la question. Pour expliquer l'évolution pénale, Durkheim a énoncé deux lois : la loi des variations quantitatives de la peine et la loi des variations qualitatives de la peine ${ }^{73}$. Rusche et Kirchheimer ont étudié la transformation des régimes punitifs en prenant appui sur Marx ${ }^{74}$. Foucault s'est demandé, d'une part, comment, " du temps et du corps des hommes, de la vie des hommes », " quelque chose » est fait, qui est « de la force productive » ${ }^{75}$, et d'autre part, comment un « système de pouvoir commandant l'accumulation des hommes » a été couplé à un «système économique favorisant l'accumulation du capital ». Le philosophe sera, dans ce qui suit, la référence principale - la référence ou le sujet car ce fragment prend la forme d'un tableau, où deux épisodes de son combat avec Marx sont brossés à grands traits.

Au bas du tableau : Punishment and Social Structure, de Rusche et Kirchheimer. Loin de définir comme Durkheim le crime comme ce qui heurte les états forts et définis de la conscience collective et la peine comme une réaction au crime, les chercheurs de l'École de Francfort tiennent que lier la criminalité à la pénalité - supposer que celle-ci explique celle-là ou que celle-là a pour fonction de réprimer ou prévenir celle-ci ; voir dans le crime et la peine les deux faces d'une même pièce de monnaie - entrave l'étude des «époques de l'histoire des systèmes punitifs dans leurs rapports aux époques de l'histoire économique et à celles de la lutte économique des classes 76 », et " fait obstacle à toute compréhension de [son] sens propre ». Du reste, « [1]a peine en soi n'existe pas : il n'existe que des systèmes de peines concrets et des pratiques pénales particulières 77 ».

La thèse des auteurs est que « [t] out système de production tend à inventer des méthodes punitives qui correspondent à ses rapports de production ». C'est, écrivent-ils, " un lieu commun de constater [...] qu'à une phase donnée du développement économique correspond un mode spécifique de punition. Il est évident que l'esclavage comme mode de punition ne peut exister hors

73. Durkheim E., «Deux lois de l'évolution pénale », Année sociologique, vol. IV, 1899-1900, pp. 65-95.

74. Rusche G., Kirchheimer O., Punishment and Social Structure, New York, Columbia University Press, 1968 [1939]; Rusche G., Kirchheimer O., Peine et structure sociale. Histoire et " théorie critique " du régime pénal, texte présenté et établi par Lévy R., Zander H., trad. Laroche F., Paris, éditions du Cerf, 1994.

75. Foucault M., «La vérité et les formes juridiques », Dits et écrits, II, n 139, Paris, Gallimard, 1994, p. 620 (Foucault dit : « [...] comment faire du temps et du corps des hommes, de la vie des hommes quelque chose qui soit de la force productive?»).

76. Rusche G., « Marché du travail et régime des peines. Contribution à la sociologie de la justice pénale (1934) ", réédité in Rusche G., Kirchheimer O., Peine et structure sociale. Histoire et "théorie critique " du régime pénal, op. cit., p. 106.

77. Ibid., p. 123. 
d'une économie esclavagiste, que le travail carcéral est impensable sans la manufacture ou l'industrie, et que les peines d'amende pour toutes les classes sociales ne sont possibles que dans une économie monétaire 78 ». Esclaves, serfs, ouvriers : pour la classe dominée, quel que soit le mode de production, ces méthodes sont aussi déterminées par la valeur de la vie humaine réduite à la valeur de la force de travail. À surabondance de bras, châtiments meurtriers ; à pénurie, travail forcé. Liquider, capter : telles sont, quand les personnes concernées appartiennent à la classe dominée, les fonctions de la pénalité.

Dans les sociétés capitalistes, les maisons d'arrêt et de peine ont été alternativement des lieux de mise au travail et des lieux de mise à mort sociale. Selon Rusche, le nombre de détenus et les conditions de détention y dépendent des conditions matérielles d'existence du prolétariat, lesquelles dépendent de l'offre et de la demande sur le marché du travail. Contrairement aux idées sur le «sens de la peine », ces conditions d'existence sont déterminantes (marxiste, Rusche est matérialiste ; il laisse ouverte la question de savoir si la peine « est destinée à venger l'acte, dissuader ou amender son auteur, protéger la société ou remplir quelque autre fonction ", à ses yeux non pertinente) ${ }^{79}$. En période de crise économique, l'augmentation du nombre de détenus et la dégradation des conditions de vie intra muros suivent automatiquement la dégradation des conditions de vie extra muros ${ }^{80}$. Le seul moyen d'y remédier - le seul moyen de « lutter contre l'inflation et la surpopulation carcérales »est de corriger les effets du jeu de l'offre et de la demande sur le marché du travail par des politiques sociales.

Longtemps méconnu, réédité en 1968, Punishment and Social Structure est aujourd'hui un classique. Avec humour - car il y a entre Durkheim et les deux chercheurs de l'École de Francfort moins de points d'accord que de désaccords -, Dario Melossi regroupe les travaux qui s'en inspirent selon qu'ils

78. Ibid., pp. 123-124.

79. Cette proposition matérialiste de Rusche a parfois été confondue avec une reformulation du principe de dissuasion, renommé « principe de moindre éligibilité ». Ainsi que l'indiquent René Lévy et Hartwig Zander dans leur introduction à la traduction française du livre de Rusche et Kirchheimer (p. 63), la notion trouve son origine dans une phrase de Shaw citée par Rusche - «Quand nous considérons la partie la plus pauvre, la plus opprimée de notre population, nous trouvons que ses conditions d'existence sont si misérables qu'il serait impossible d'administrer une prison avec humanité sans rendre le sort du criminel plus acceptable [eligible] que celui de maints citoyens libres. Si la misère humaine n'est pas plus profonde dans la prison que dans le taudis, le taudis se videra et la prison se remplira ». À noter que Rusche luimême précise, après avoir cité Shaw, qu'il « ne faut pas, bien entendu, croire que c'est dans les termes mêmes où on l'a ici exprimé que ce raisonnement acquiert son efficacité sociale » (Rusche G., « Marché du travail et régime des peines. Contribution à la sociologie de la justice pénale (1934)», art. cit., p. 103).

80. Sur ce point, voir Rusche G., "Révoltes pénitentiaires ou politique sociale. À propos des événements d'Amérique (1930) », réédité in Rusche G., Kirchheimer O., op. cit., pp. 85-98 : selon Rusche, le système pénitentiaire américain serait « pendant plus d'un siècle, apparu comme un modèle inégalé d'humanité »; en l'absence de politiques sociales, il a cessé de l'être quand, suite à la crise de 1929, le nombre des chômeurs « ramena à rien leur valeur ». 
étudient les variations qualitatives ou quantitatives de la peine ${ }^{81}$. Les premiers étudient comment tel régime punitif (galères, déportation, prisons...) apparaît, devient hégémonique et disparaît : Sellin, qui avait lu le manuscrit de Rusche en 1934 82, décrit ainsi dans Slavery and the Penal System comment, après 1865 , l'esclavage pénal a pris le relais de l'esclavage dans le Sud des ÉtatsUnis ${ }^{83}$. Les seconds tentent d'expliquer les variations du nombre de personnes condamnées ou enfermées : durant le dernier quart du $\mathrm{XX}^{\mathrm{e}}$ siècle, des dizaines de recherches ont montré que l'évolution des chiffres des prisons ne suit pas l'évolution des chiffres de la criminalité mais celle des chiffres du chômage ${ }^{84}$; qu'elles rapportent ces corrélations à la valeur du travail (explication «économique »), aux représentations des agents du système pénal (explication «idéologique ») ou aux nécessités structurelles du capitalisme (explication "politique») ${ }^{85}$, toutes se basent sur les thèses posées par Rusche en 1930 et 193486.

Surveiller et punir fait-il partie du premier groupe défini par Dario Melossi ? Oui : le livre, sous-titré Naissance de la prison, décrit le passage à une pénalité de détention ; l'objectif est d'en faire vaciller l'évidence, qui de l'hégémonie est une dimension ou un autre nom. Non : Punishment and Social Structure semble avoir plutôt relancé le «combat avec Marx » qui, selon Etienne Balibar, est coextensif « de toute l'œuvre de Foucault » - un combat qui, précise-t-il, n'est pas un «simple duel » et n'a jamais « sa fin en luimême ». Foucault, écrit-il, «ne cesse de poser à Marx des questions qui lui viennent d'autres lieux philosophiques et historiques, comme il ne cesse de poser à d'autres interlocuteurs, ou adversaires, des questions dont la formulation dépend de Marx 87 ». En l'occurrence, tout se passe comme s’il posait, sur

81. Melossi D., "An Introduction: fifty years later, Punishment and Social Structure in comparative analysis", Contemporary Crises, 13-4, 1989, p. 313.

82. Melossi D., "Georg Rusche: a biographical essay", Crime \& Social Justice, 14, 1980, pp. 5163 ; sur l'histoire des textes de Rusche et du manuscrit de Punishment and Social Structure, voir aussi Zander H., "Georg Rusche, marché du travail et régime des peines : introduction à la genèse de l'œuvre de Georg Rusche ", Déviance et société, 1980, 4-3, pp. 99-213 ; ainsi que Lévy R., Zander H., «Introduction », in Rusche G., Kirchheimer O., op. cit., pp. 9-42.

83. Sellin Th., Slavery and the Penal System, New York, Elsevier, 1976. Sur ce point, cf. Brion F., Sociologie de la pénalité, Louvain-la-Neuve, École de criminologie, 2001 ; pour un autre exemple, voir Melossi D., Pavarini M., Carcere e fabbrica : alle origine del sisteme penitenziaro (XVI-XIX secolo), Bologne, Il Mulino, 1978.

84. Sur ce point, voir notamment Lévy R., Zander H., art. cit., p. 57 ; Melossi D., "An Introduction: fifty years later, Punishment and Social Structure in comparative analysis", art. cit., p. 311-326 ; Laffargue B., Godefroy T., « La prison républicaine et son environnement économique ", Déviance et Société, 14-1, 1990, pp. 39-58 ; Laffargue B., Changements économiques et répression pénale. Plus de chômage, plus d'emprisonnement ?, Paris, CESDIP, 1991 ; Vanneste C., "L'évolution de la population pénitentiaire belge de 1830 à nos jours : comment et pourquoi ? Des logiques socio-économiques à leur traduction pénale », Revne de droit pénal et de criminologie, 2000, p. 689; Vanneste C., Les chiffres des prisons. Des logiques économiques à leur traduction pénale, Paris, L'Harmattan, 2003.

85. Chiricos T.G., Delone M., "Labor Surplus and Punishment: A Review and Assessment of Theory and Evidence", Social Problems, 39-4, 1992, pp. 421-446.

86. Rusche G., "Révoltes pénitentiaires ou politique sociale. À propos des événements d'Amérique (1930) », art. cit., pp. 85-98; Rusche G., « Marché du travail et régime des peines. Contribution à la sociologie de la justice pénale (1934) », art. cit., pp. 99-113. 
les prisons, des questions dont la formulation dépend de Rusche et de Marx, et que parallèlement, remettant sur le métier notions et propositions, il posait à ces auteurs des questions lui venant d'Althusser ou de son expérience au sein du Groupe d'information sur les prisons.

$\mathrm{Du}$ «grand livre de Rusche et Kirchheimer », le philosophe dit retenir plusieurs repères « essentiels 88 ». Primo, renoncer à croire que la pénalité est " avant tout $[\ldots]$ une manière de réprimer les délits » et varie en quantité ou qualité selon «les formes sociales, les systèmes politiques ou les croyances ». Secundo, analyser non pas la pénalité, mais des systèmes punitifs concrets ; les analyser « comme des phénomènes sociaux dont ne peuvent rendre compte ni l'armature juridique de la société, ni ses choix éthiques fondamentaux ». Tertio, situer ces systèmes punitifs «dans leur champ de fonctionnement », où prévention et punition ne sont pas les seuls éléments. Quarto, montrer que l'efficacité des pratiques punitives n'est pas seulement «négative » (elles interdisent, elles détruisent), mais « positive » (elles produisent) ${ }^{89}$; en repérer les effets et leur utilité. Quinto, se rappeler que si les peines «sont fait[e]s pour sanctionner les infractions »-ce qui ne signifie pas que c'est tout ce qu'elles font -, « la définition des infractions et leur poursuite sont faites en retour pour entretenir les mécanismes et leurs fonctions 90 ".

Sur la corrélation entre régimes punitifs et systèmes productifs, Foucault tient qu'il y aurait sans doute « bien des remarques à faire »; il garde toutefois « ce thème général que, dans nos sociétés, les systèmes punitifs sont à replacer dans une certaine "économie politique" du corps 91 ». De La société punitive 92 à Mal faire, dire vrai ${ }^{93}$ en passant par «La vérité et les formes juridiques ${ }^{94}$ »,

87. Balibar E., «Foucault et Marx. L'enjeu du nominalisme », art. cit., pp. 282-283.

88. Foucault M., Surveiller et punir, op. cit., p. 29.

89. Ibid., p. 196. "Il faut cesser de toujours décrire les effets du pouvoir en termes négatifs : il "exclut", il "réprime", il "refoule", il "censure", il "asbtrait", il "masque", il "cache". En fait le pouvoir produit ; il produit du réel ; il produit des domaines d'objets et des rituels de vérité. L'individu et la connaissance qu'on peut en prendre relèvent de cette production "). L'insistance de Foucault sur la positivité des effets produits par les méthodes pénales ne vaut pas approbation de ces méthodes, ni plus généralement approbation de l'utilititarisme, comme semble le supposer David Garland (cf. Garland D., "Frameworks of Inquiry in the Sociology of Punishment", The British Journal of Sociology, 41-1, 1990, pp. 5-6). Elle renvoie à la productivité du pouvoir, d'une part ; elle a aussi partie liée avec ce que Paul Veyne appelle le « positivisme » de Foucault ( $c f$. Veyne P., "Foucault révolutionne l'histoire », Comment on écrit l'histoire, Paris, Seuil, 1996, p. 419) - ou avec ce « contre-positivisme » dont Foucault disait à Louvain qu'il n'est pas le « contraire du positivisme, mais son contrepoint » (Foucault M., Mal faire, dire vrai. Fonction de l'aven en justice. Cours de Louvain (1981), éd. établie par F. Brion et B. E. Harcourt, Louvain-la-Neuve, Presses universitaires de Louvain/Chicago, University of Chicago Press, 2012, p. 10).

90. Ibid., p. 29.

91. Ibid., p. 30.

92. Foucault M., La société punitive. Cours an Collège de France (1972-1973), éd. établie par B. E. Harcourt, Paris, Gallimard/Seuil, 2013.

93. Foucault M., Mal faire, dire vrai. Fonction de l'aven en justice. Cours de Louvain (1981), op. cit.

94. Foucault M., «La vérité et les formes juridiques », art. cit., pp. 538-623. 
il diversifie les séries d'études qui forment la matière des cours sur les régimes punitifs en fonction des modes de production antique, féodal et capitaliste 95 . Sur deux points, il se démarque de l'analyse marxiste. Point méthodologique : aux explications qui "visent une dernière instance [...], économie pour les uns, démographie pour les autres ", il substitue l'analyse généalogique, qui "suppose le déploiement d'un réseau causal à la fois complexe et serré [...] d'un autre type ", réseau " qui n'obéirait pas justement à l'exigence de saturation par un principe profond unitaire pyramidalisant et nécessitant » 96 . Point de philosophie ontologique : à ses yeux, « le travail n'est absolument pas l'essence concrète de l'homme ${ }^{97}$.

Le combat s'engage à partir de là. Il prend, logiquement, la forme d'une " ontologie historique de nous-mêmes ", dans nos rapports "à la vérité », «à un champ de pouvoir » et «à la morale » (soit les «trois domaines de généalogies possibles $98 »)$. L'enjeu est tout à la fois pratique et théorique. Pratique : pour que «l'essence de l'homme puisse apparaître comme étant le travail », il faut « la synthèse effectuée par un pouvoir politique » ${ }^{99}$; la défaire suppose de décrire la «série d'opérations complexes par lesquelles les hommes se trouvent effectivement liés - d'une manière non pas analytique, mais synthétique - à l'appareil de production pour lequel ils travaillent 100 » : comment le temps et le corps des hommes deviennent-ils temps et force de travail ? Théorique : Marx décrit la société comme un édifice à deux niveaux, l'infrastructure, qui est la base matérielle, et la superstructure, qui comporte ellemême deux niveaux, l'un juridico-politique et l'autre idéologique ; Foucault pose que pouvoir et savoir 101 «ne se superposent pas aux relations de production, mais se trouvent très profondément enracinés dans ce qui constitue celles-ci », de sorte que « la définition de ce qu'on appelle l'idéologie doit être revue $» 102$.

95. Implicite dans la constitution des séries qui forment les cours sur les régimes punitifs, la référence au mode de production peut aussi être explicite dans certains textes. Ainsi, dans la conclusion de "La vérité et les formes juridiques ", cycle de cinq conférences prononcées en 1973 : «L'enquête et l'examen sont précisément des formes de savoir-pouvoir qui viennent fonctionner au niveau de l'appropriation des biens dans la société féodale, et au niveau de la production et de la construction du sur-profit capitaliste. C'est à ce niveau fondamental que se situent les formes de savoir-pouvoir de l'enquête et de l'examen. » (Foucault M., «La vérité et les formes juridiques ", art. cit., p. 623.

96. Foucault M., "Qu'est-ce que la critique ? [Critique et Aufklärung] ", Bulletin de la Société française de philosophie, 84-2, 1990, Paris, Armand Colin, p. 50.

97. Foucault M., "La vérité et les formes juridiques », art. cit., p. 621.

98. Foucault M., "À propos de la généalogie de l'éthique : un aperçu du travail en cours », Dits et écrits, $I V, \mathrm{n}^{\circ}$ 344, Paris, Gallimard, 1994, p. 618.

99. Foucault M., «La vérité et les formes juridiques », op. cit., p. 622.

100. Ibid., pp. 621-622.

101. Sur la substitution du concept du savoir-pouvoir à la notion d'idéologie, voir Foucault M., Du gouvernement des vivants. Cours au Collège de France, 1980-1981, Paris, Gallimard/Seuil, 2012, pp. 12-13.

102. Ibid., p. 623. 
$\mathrm{Au}$ centre $\mathrm{du}$ premier champ de bataille : la série « discipline/individu/sujet ». Contre Marx, Foucault joue Althusser. En toile de fond : les thèses posées par l'auteur de Pour Marx dans Idéologie et appareils idéologiques d'État ${ }^{103}$. Le point de départ de la réflexion est la question de savoir comment la reproduction de la force de travail est assurée : c'est, écrit Althusser, en analysant de ce point de vue droit, État et idéologie - i.e., la superstructure, en ses niveaux juridico-politique et idéologique - qu'il lui semble possible de dépasser la métaphore de l'édifice pour penser ce qu'elle décrit. Posant d'une part que "l'idéologie a une existence matérielle » (elle existe "dans un appareil idéologique matériel, prescrivant des pratiques matérielles réglées par un rituel matériel, lesquelles pratiques existent dans les actes matériels d'un sujet agissant en toute conscience selon sa croyance 104 »), et d'autre part, qu'il «n'est d'idéologie que par le sujet et pour des sujets 105 », il oppose à l'idéalisme des philosophies de la conscience la thèse matérialiste de la constitution des individus en sujets. Auparavant, il a proposé de distinguer non plus seulement «pouvoir d'État » et «appareil d'État», comme « la théorie marxiste de l'État », mais « appareil répressif d'État » et « appareils idéologiques d'État »- précisant que des institutions privées peuvent « parfaitement “fonctionner" comme des appareils idéologiques d'État».

Les dernières conférences données par Foucault à Rio de Janeiro en 1973 peuvent se lire comme une première élaboration de ces propositions. Il y étudie l'apparition, au XIX e siècle, d'une série d' "institutions d'assujettissement » où « l'État et ce qui n'est pas étatique viennent se confondre, s'entrecroiser 106 », de sorte qu'il est « difficile de dire si elles sont franchement étatiques ou extra-étatiques, si elles font partie ou non de l'appareil d'État 107 ». Que les procédures d'assujettissement y prennent une forme «compacte » (dans les écoles, les maisons de correction, les prisons) ou « douce » (le philosophe cite les caisses d'épargne et d'assistance), elles forment, dit-il, « un réseau institutionnel de séquestration, qui est intra-étatique 108 ». Quelles sont les fonctions de ces « institutions d'assujettissement » ? Extraire le temps des hommes pour le transformer en temps de travail ; contrôler leur corps pour le transformer en force de travail ; extraire enfin - car ces institutions sont des mines de

103. Althusser L., «Idéologie et appareils idéologiques d’État (Notes pour une recherche) », La pensée, 151, juin 1970, reéd. in Althusser L., Positions (1964-1975), Paris, Les éditions sociales, 1976, p. 105. La même hypothèse de lecture soutient l'analyse de Warren Montag (cf. Montag W., “'The Soul is the Prison of the Body': Althusser and Foucault, 1970-1975”, Yale French Studies, 88, 1995, p. 71).

104. Ibid., p. 109.

105. Althusser L., "Idéologie et appareils idéologiques d'État (Notes pour une recherche)", art. cit., pp. 109-110.

106. Foucault M., «La vérité et les formes juridiques », art. cit., p. 615. Foucault reviendra à plusieurs reprises sur la question de ce qui relève ou ne relève pas de l'État, du public et du privé, et de ce qui entre ou sort de la sphère du gouvernement et de la gouvernementalité. Voir entre autres Foucault M., «La "gouvernementalité" ", Dits et écrits, $I I I, n^{\circ} 239$, Paris, Gallimard, 1994, p. 656.

107. Foucault M., «La vérité et les formes juridiques », art. cit., p. 615.

108. Idem, pp. 612 et 615 . 
savoir - un savoir technologique et un savoir sur les individus né « de [leur] observation [...], de leur classement, de l'enregistrement et de l'analyse de leurs comportements, de leur comparaison ", l'un et l'autre utiles pour transformer la force de travail en force productive. Le pouvoir exercé sur les individus, polymorphe, est tout à la fois économique, politique, disciplinaire et épistémologique ; "profondément enraciné dans la vie des hommes 109 », il ne se réduit en aucune façon à un système de représentations.

Surveiller et punir prolonge la discussion. Althusser s'interroge sur les conditions de la reproduction des rapports de production et de la force productive. Foucault étudie, en amont, les conditions de production de la force productive ; plus exactement, il entreprend d'en faire la généalogie, pour défaire la synthèse - propre à « la société moderne, industrielle, capitaliste »qui donne à voir dans le travail l'essence concrète de l'homme. Althusser tient que l'idéologie est immanente aux appareils, pratiques, rituels et actes qui la réalisent. Foucault, conséquent, ne parle plus d'idéologie mais de dispositif de savoir-pouvoir ; il décrit minutieusement comment, avant de coloniser l'institution judiciaire au XIX ${ }^{\mathrm{e}}$ siècle, les procédés disciplinaires se sont développés au XVIII siècle, en réponse à la croissance de la population, à la croissance de l'appareil de production, et à la « nécessité d'ajuster leur corrélation 110 ». Althusser écrit que «toute idéologie a pour fonction (qui la définit) de “constituer" des individus concrets en sujets "; il précise que l'âme est l'une des dénominations sous laquelle la catégorie de sujet opère ${ }^{111}$. Foucault examine comment, dans la société disciplinaire, «l'individu [...] est soigneusement fabriqué selon toute une tactique des forces et des corps 112 »; brouillant comme Althusser la limite entre idéologie et violence, il définit l'âme comme un double « réel et incorporel » reproduit en permanence au moyen de procédures de punition et de surveillance ${ }^{113}$.

Nouveaux développements dans Mal faire, dire vrai. Selon Althusser, ce qui constitue un individu en sujet est une interpellation dans laquelle il se reconnaît. Foucault examine les formes matérielles de l'interpellation et de la reconnaissance, et décrit comment les individus se transforment en tel ou tel « doppeltes Ich 114 » - juge et accusé, administrateur et administré, surveillant et surveillé. Matérialisme oblige, la question de l'articulation du gouvernement et de l'assujettissement devient celle des « points d'intersection entre techniques de domination et techniques de soi 115 ». En 1975, le philosophe a écrit que l'âme est « le corrélatif actuel d'une certaine technologie du pou-

109. Idem, pp. 618-620 et p. 623 .

110. Foucault M., Surveiller et punir, op. cit., p. 220.

111. Althusser L., "Idéologie et appareils idéologiques d'État », art. cit., p. 110.

112. Foucault M., Surveiller et punir, op. cit., p. 219.

113. Ibid., p. 34.

114. Foucault M., Introduction à l'Anthropologie, Paris, Vrin, 2008, p. 23.

115. Foucault M., "Subjectivity and truth", The Politics of Truth, édition établie par Sylvain Lotringer, Los Angeles, Semiotext(e), 1997, p. 154. 
voir 116 ». En 1981, à Louvain, il explore les procédés de fabrication du sujet déterminant et de l'objet déterminé, de l' «âme » et du corps, de « l'âme, prison du corps 117 ». Deux ans plus tôt, à Chicago, il a visité l'atelier où sont conçus les sujets supposés par le néolibéralisme ${ }^{118}$. Pour Marx, dit-il dans Naissance de la biopolitique, temps et force de travail sont les composantes $\mathrm{du}$ travail «abstrait », " amputé de toute sa réalité humaine », que le capitalisme met sur le marché ${ }^{119}$; pour Gary Becker, cette abstraction n’est pas « le fait du capitalisme réel, [mais celui] de la théorie économique que l'on a faite de la production capitaliste 120 ». Le néolibéralisme interpelle tout un chacun en entrepreneur de soi et des siens ; il invite à se représenter en portefeuille de capitaux et à se gérer en capitaliste - version inédite du «doppeltes Ich». Plutôt que force et temps de travail, il parle « investissement dans le capital humain 121 »; ce faisant, il gomme l'opposition entre travail et capital essentielle à la théorie de la lutte des classes, et individualise les causes de la pauvreté ou de l'absence de réussite, qu'il code comme résultats prouvant les défauts ou les défaillances de sujets toujours coupables de leur faillite.

Les disciplines, écrit Foucault en 1975, sont « à prendre comme des techniques qui permettent d'ajuster [...] la multiplicité des hommes à la multiplication des appareils de production ». Mais suffisent-elles à corréler « accumulation des hommes et accumulation du capital 122 » ? La « noso-politique réfléchie 123 » qui naît au XVIII siècle le montre : la conjoncture historique décrite dans Surveiller et punir - essor démographique, développement de l'appareil de production - a appelé deux réponses ${ }^{124}$, « technologie fine et calculée de l'assujettissement 125 » et « projet d'une technologie de la population ». Ici comme là, « on peut dire en gros qu'il s'agit de la préservation, de l'entretien

116. Foucault M., Surveiller et punir, op. cit., p. 34.

117. Idem.

118. Foucault consacre les leçons du 14 mars, 21 mars et 28 mars 1979 de Naissance de la biopolitique, cours prononcé au Collège de France en 1978-1979, à l'étude du néolibéralisme américain tel qu'il est conçu par les économistes de l'Université de Chicago, au premier rang desquels Gary Becker, professeur d'économie et prix Nobel d'économie, célèbre notamment pour sa théorie du capital humain (Becker G., Human Capital: A Theoretical and Empirical Analysis, Chicago, University of Chicago Press, 1993 [1964]) et pour son approche microéconomique du crime et de la peine (Becker G., "Crime and Punishment: An Economic Approach”, The Journal of Political Economy, 76-2, 1968, pp. 169-217). Gary Becker est une figure majeure du courant dit de Law E Economics, comme Richard Posner et Richard Epstein, également professeurs à l'Université de Chicago.

119. Foucault M., "Leçon du 14 mars 1979 ", Naissance de la biopolitique. Cours au Collège de France. 1978-1979, édition établie par M. Senellart, Paris, Gallimard \& Seuil, 2004, p. 227.

120. Idem.

121. Ibid., p. 226.

122. Ibid., p. 222.

123. Foucault M., "La politique de la santé au XVIII siècle », Les machines à guérir. Aux origines de l'hôpital moderne, Paris, Institut de l'environnement, 1976, pp. 11-21, rééd. in Foucault M., Dits et écrits, III, n 168, Paris, Gallimard, 1994, p. 14.

124. Cf. Ibid., p. 18 et Foucault M., «Intervista a Michel Foucault », in Fontana A. et Pasquino P. (eds.), Microfisica del potere: interventi politici, Turin, Einaudi, 1977, pp. 3-28, rééd. in Foucault M., Dits et écrits, III, n 192, Paris, Gallimard, 1994, p. 153.

125. Foucault M., Surveiller et punir, op. cit., p. 222. 
et de la conservation de la "force de travail” "; ici et là, la technologie investit "le "corps" - corps des individus et corps des populations »; ici et là, il s'agit d'assurer la « majoration constante de leur utilité 126 ». Mais le dispositif est différent. Côté savoir, la «biopolitique » nécessite « estimations démographiques », " calcul de la pyramide des âges, des différentes espérances de vie, des taux de morbidité ", " étude du rôle que jouent l'une par rapport à l'autre la croissance des richesses et celle de la population 127 »; elle analyse les régularités propres aux populations (le nombre et la distribution des morts, des maladies, des accidents...) et les effets liés à leur agrégation, à leurs activités et à leurs déplacements (« les grandes épidémies, les expansions endémiques, la spirale du travail et de la richesse 128 »...). Côté pouvoir, il faut, pour majorer l'utilité, non plus « assujettir », mais « traiter, contrôler, diriger l'accumulation des hommes 129 » : encourager ou décourager la natalité ; développer des politiques de santé ; diriger «dans telle ou telle région, vers telle activité, les flux de population $130 » ;$ " régler également [...] les migrations 131 »...

D’où, autour de la série biopolitique/population/société, un second champ de bataille. La toile de fond est un patchwork où, peut-être, se retrouvent des éléments de The General Theory of Law and Marxism, de Pashukanis, ou $D u$ "Capital » à la philosophie de Marx, d'Althusser. En Europe occidentale, note Foucault, « un système économique qui favorisait l'accumulation du capital et un système de pouvoir qui commandait l'accumulation des hommes sont devenus, à partir du XVII e siècle, deux phénomènes corrélatifs et indissociables l'un de l'autre 132 ». Le problème est que suivant les analyses marxistes, ce couplage ne va pas sans contradiction. Selon Pashukanis, l'histoire de la transition du féodalisme au capitalisme est aussi celle de la juridification des relations humaines et de la généralisation de la forme légale ${ }^{133}$. Or, la spécificité de la loi n'est pas la contrainte, mais les sujets de droits, égaux et libres, qui sont ses corrélats. Simple voile masquant rapports de force et intérêts de classe ? Non pas. Condition formelle de possibi-

126. Foucault M., «La politique de la santé au XVIII' siècle », art. cit., p. 18.

127. Ibid., p. 18. Par « biopolitique », Foucault entend «la manière dont on a essayé, depuis le XVIIII siècle, de rationaliser les problèmes posés à la pratique gouvernementale par les phénomènes propres à un ensemble de vivants constitués en population : santé, hygiène, natalité, longévité, races... » Il ajoute : «On sait quelle place croissante ces problèmes ont occupée depuis le XIXe siècle, et quels enjeux économiques et politiques ils ont constitué jusqu'aujourd'hui (Foucault M., "Naissance de la biopolitique ", Annuaire du Collège de France, 79e année, Histoire des systèmes de pensée, année 1978-1979, 1979, p. 367, rééd. in Foucault M., Dits et écrits, III, n 274 , Paris, Gallimard, 1994, p. 818).

128. Foucault M., "La "gouvernementalité” ", art. cit., p. 651.

129. Entretien avec Michel Foucault, Dits et écrits, III, n 192, Paris, Gallimard, 1994, p. 153.

130. Foucault M., «La "gouvernementalité" », art. cit., p. 652.

131. Foucault M., "Les mailles du pouvoir », art. cit., p. 194.

132. Entretien avec Michel Foucault, Dits et écrits, III, $\mathrm{n}^{\circ}$ 192, Paris, Gallimard, 1994, p. 153.

133. Cf. Kamenka E., "Marxism, Economics and Law", disponible en ligne (s.r.), pp. 58-59 (http://biblio.juridicas.unam.mx/libros/3/1014/7.pdf, consulté le 5 février 2014). Sur l'histoire de la jurification des relations humaines - où, peut-être, il faut voir l'un des mécanismes de la transformation du mode de production féodal en un autre -, $c f$. Foucault M., Mal faire, dire vrai. Fonction de l'aven en justice, op. cit., pp. 201-202 et pp. 174-189. 
lité du type d'échanges sur lesquels l'économie de marché est fondée - suivant le théoricien marxiste du droit, le libéralisme est immanent au capitalisme. Question alors : "Dans un système soucieux du respect des sujets de droit et de la liberté d'initiative des individus, comment le phénomène "population" avec ses effets et ses problèmes spécifiques peut-il être pris en compte ? Au nom de quoi et selon quelles règles peut-on le gérer ${ }^{134}$ ? »

En 1975, Foucault annonce qu'il va analyser le système de politique criminelle conçu au tournant des XIXe et XXe siècles par Prins, pénaliste et « criminaliste » belge convaincu qu'il faut, pour défendre la société contre le danger que représentent les vagabonds et la sédition, ajouter au droit pénal des lois entant la répression non plus sur la responsabilité, mais sur la dangerosité ${ }^{135}$. Guerre des races versus lutte des classes, discours de dominants qui se sentent menacés versus discours de dominés qui se font menaçants 136 : cinq ans avant d'animer à Louvain un séminaire sur la généalogie de la défense sociale en Belgique ${ }^{137}$, le philosophe livre dans « Il faut défendre la société » une première généalogie du « dispositif de guerre 138 » dont elle procède ; il montre que les coordonnées du système de politique criminelle promu par l'inspecteur général des prisons belges sont guerrières avant d'être judiciaires. Si référence à Althusser il y a, elle vient à ce point-là. Marx, écrit ce dernier, « considère la société actuelle [...] à la fois comme un résultat et comme une société ». Ce qu'il étudie dans Le Capital n'est pas le "mécanisme de la transformation d'un mode de production en un autre ", qui permet de résoudre le problème du résultat, mais "le mécanisme qui fait exister comme société le résultat de la production d'une histoire 139 ». Et d'insister : «Lorsque Marx nous dit donc qu'en expliquant la société par sa genèse on rate son "corps", qu'il s'agit justement d'expliquer, il fixe à son attention théorique la charge de rendre compte du mécanisme par lequel tel résultat fonctionne précisément

134. M. Foucault, «La "gouvernementalité" ", art. cit., p. 656.

135. Defert D., "Le "dispositif de guerre" dans l'analyse des rapports de pouvoir », in Bertani M., Defert D., Fontana A., Holt T.C., Lectures de Michel Foucault. À propos de "il faut défendre la société ", textes réunis par J.-Cl. Zancarini, Paris, ENS Editions, 2001, p. 61.

136. Foucault M., "Il faut défendre la société ". Cours an Collège de France, 1976, Paris, Seuil/Gallimard, 1997, pp. 18-19.

137. En 1981, Foucault a dirigé à l'École de criminlogie de l'Université catholique de Louvain un séminaire de recherche sur la généalogie de la défense sociale en Belgique ( $c f$. Tukens F. (ed.), Généalogie de la défense sociale en Belgique (1880-1914). Travaux du séminaire tenu à l'Université catholique de Louvain sous la direction de Michel Foucault, Bruxelles, StoryScientia, 1988.

138. Defert D., "Le "dispositif de guerre" dans l'analyse des rapports de pouvoir », art. cit., p. 61 ; Foucault M., "Il faut défendre la société ", Annuaire du Collège de France, 76 e année, Histoire des systèmes de pensée, année 1975-1976, réédité in Foucault M., Dits et écrits, III, n 187, Paris, Gallimard, p. 125.

139. Althusser précise : "c'est donc le mécanisme qui donne à ce produit de l'histoire, qu'est justement le produit-société qu'il étudie, la propriété de produire l'“effet de société", qui fait exister ce résultat comme société, et non comme tas de sable, fourmilière, magasin d'outils ou simple rassemblement humain » (Althusser L., "Du "Capital” à la philosophie de Marx », in Althusser L., Balibar E., Establet R., Macherey P., Rancière J., Lire le Capital, Paris, Presses universitaires de France, 1996, p. 74 ; italiques dans le texte original). 
comme société, donc du mécanisme qui produit l'“effet de société” propre au mode de production capitaliste ${ }^{140}$. »

Tout se passe comme si la population était à la société ce que l'individu est au sujet ; ou encore, tout se passe comme si population et société étaient au dispositif de guerre ce qu'individu et sujet sont au dispositif disciplinaire. Au nom de quoi et selon quelles règles peut-on gérer la population ? Au nom de la société. Et quel est le mécanisme qui produit l'“effet de société" propre au mode de production capitaliste ? La guerre. La lutte des classes ? Non. Supposé que la population vivant sur le territoire d'un État soit représentée par deux cercles concentriques, classe dominante à l'intérieur et classe dominée ${ }^{141}$ à l'extérieur (en 1972 et 1973, Foucault dit aussi « plèbe », prolétarisée ou pas; ou encore « peuple», par quoi il faut entendre les classes populaires, «laborieuses » et «dangereuses » 142 ) ; supposé que le « peuple » lui-même soit divisé par une seconde ligne de partage, de sorte qu'au lieu de deux cercles concentriques, il y en a trois : cette seconde ligne délimite, d'une part, la société que ses membres sont appelées à défendre (au XIXe siècle, la «bourgeoisie » et les «classes laborieuses »; dans la terminologie marxiste, les «bourgeois » et le « prolétariat»), et d'autre part, la partie du peuple que la société refoule comme son rebut (au XIXe siècle, les «classes dangereuses », le Lumpenproletariat), en un geste qui tout à la fois la définit et la constitue.

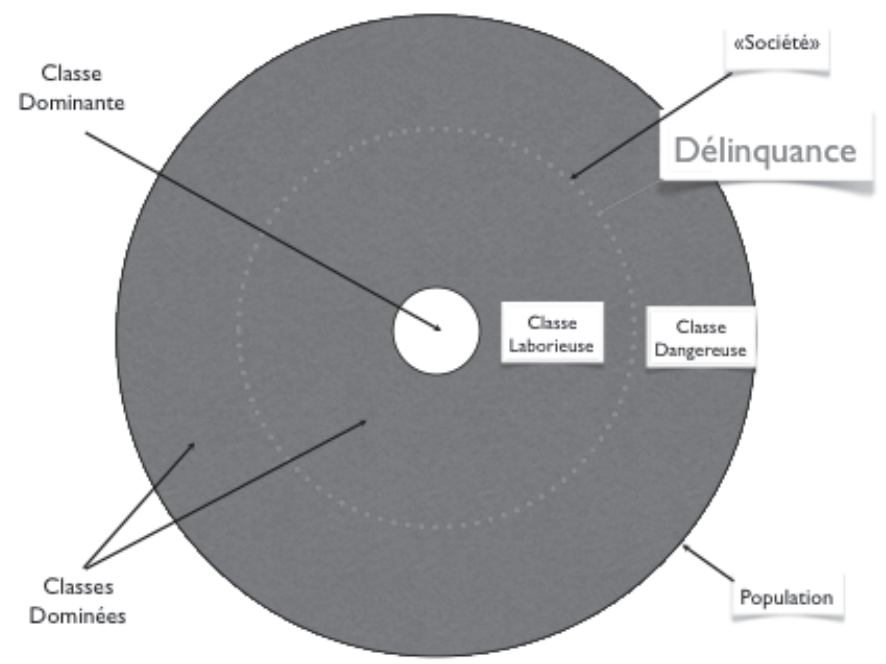

Figure 3 : Population et société (I)

140. Idem.

141. Foucault M., «Sur la justice populaire. Débat avec les maos », Dits et écrits, $I I, \mathrm{n}^{\circ} 198$, Paris, Gallimard, 1994, p. 358.

142. Sur ce point, $c f$. Senellart M., « Michel Foucault : plèbe, peuple, population », in Chêne J., Ihl O., Vial E., Waterlot G. (eds.), La Tentation populiste an coeur de l'Europe, Paris, La Découverte, 2003, pp. 301-313. 
Or, ce geste, quel est-il ? Selon Michel Senellart, pour Foucault, « la coupure entre plèbe prolétarisée et non prolétarisée, si elle découle des conditions socio-économiques, se trouve entretenue et approfondie par le système pénal, au profit des intérêts capitalistes »; elle est « le résultat d'un système de pouvoir s'exerçant à travers les institutions punitives 143 ».

\section{Fragment 3. La société qu'il faut défendre}

Retour à la lutte contre la surpopulation carcérale et au grand renfermement des étrangers. Selon les auteurs qui, à la suite de Rusche et Kirchheimer, expliquent la corrélation entre les chiffres des prisons et les chiffres du chômage par la nécessité de rencontrer les besoins structurels du capitalisme, les prisons drainent ("siphon off », disent Samuel Myers et William Sabol 144) la « classe de travailleurs la plus superflue 145 » ou la plus «menaçante» ( the social dynamite ", écrit Steven Spitzer ${ }^{146}$ ). Dans quels buts ? À l'échelle des individus, surveiller : peines et mesures pénales seraient les équivalents fonctionnels, en période de basse conjoncture, des mécanismes de contrôle social entés sur le travail, en période de haute conjoncture ${ }^{147}$. À l'échelle de la population, réguler : les prisons permettraient de contrôler la taille de l'armée de réserve de travailleurs ${ }^{148}$. À l'échelle du système, légitimer : en contrôlant les effectifs de l'armée de réserve, elles préviendraient les questions relatives à la légitimité d'un mode de production qui réduit les hommes à leur force de travail et cette force de travail à une marchandise, avant d'abaisser certains d'entre eux au rang d'individus « redondants 149 »; elles protégeraient ainsi « l'idéologie égalitaire si essentielle à la légitimation des relations [capitalistes] de production 150 ».

Que les prisons «drainent », c'est aussi, en 1972, ce que pense Foucault : la «surcharge » du système pénitentiaire, dit-il, s'explique par le fait qu'il «doit à lui tout seul remplir [les] fonctions » que l'armée et la colonisation remplissaient avec lui auparavant, " en déplaçant les individus et en les expatriant 151 ». À l'échelle des individus, il participe au procès de réduction des hommes à une force de travail : il brise et assujettit, forçant la docilité le temps

143. Ibid., p. 306.

144. Myers S. Jr., Sabol W., "Business Cycles and Racial Disparities”, Contemporary Policy Issues, 5-4, 1987, p. 48.

145. Idem.

146. Spitzer S., “Toward a Marxian theory of deviance”, Social Problems, 22-5, 1975, p. 646.

147. Adamson C., "Toward a Marxian penology. Captive criminal populations as economic threats and resources”, Social Problems, 31-4, 1984, pp. 435-458 ; M. J. Lynch, “The extraction of surplus value, crime and punishment. A preliminary examination”, Contemporary Crises, 12-4, 1988, pp. 329-344.

148. Jankovic I., "Labor market and imprisonment”, Crime and Social Justice, 8, 1977, pp. 17-31 ; Quinney R., Class State and Crime, New York, David McKay and co, 1977.

149. Chiricos T. G., Delone M. A. , "Labor Surplus and Punishment: A Review and Assessment of Theory and Evidence”, art. cit., p. 424.

150. Spitzer S., "Toward a Marxian theory of deviance”, art. cit., p. 643.

151. Foucault M., «Sur la justice populaire. Débat avec les maos », art. cit., p. 353. 
de forger à grands renforts de surveillance « l'âme, prison du corps 152 ». À l'échelle de la population, c'est un des appareils d'État qui contribue à ajuster la corrélation entre accumulation des hommes et accumulation du capital ${ }^{153}$. D'une part, il discipline et disqualifie - fabrique d'une main-d'œuvre d'appoint. D'autre part, il retient et relâche, avale et recrache - gestion de ses flux et reflux en fonction des besoins. À l'échelle du système, il légitime : autour des détenus, il construit une « barrière idéologique (concernant le crime, le criminel, le vol, la pègre, les dégénérés, la sous-humanité) qui a partie liée avec le racisme 154 ", divisant la classe populaire : la justice pénale fonctionne « de façon à introduire des contradictions au sein du peuple »; elle a « un rôle constitutif dans les divisions de la société actuelle 155 ».

Après avoir étudié ces deux « révolutions dans la technologie du pouvoir » que sont « la découverte de la discipline et la découverte de la régulation, le perfectionnement d'une anatomo-politique et le perfectionnement d'une biopolitique 156 », le philosophe s'est interrogé, dans $D u$ gouvernement de soi et des autres ${ }^{157}$, sur les rapports du dire-vrai et de la démocratie. Le mouvement même de son œuvre invite à mener l'analyse plus avant. Notre actualité n'est plus celle que Foucault a connue. En 1971, le philosophe citait dans un entretien ce chiffre, dont il précisait qu'il donnait «beaucoup à réfléchir » : cette année-là, en France, 16 \% des détenus étaient « des immigrés » 158. En 2012, en Belgique, 44 \% des détenus sont des ressortissants d'autres États. Que nous apprennent l'inflation carcérale et le « grand renfermement » des étrangers sur les fonctions des prisons et ce que nous sommes aujourd'hui ? Que nous apprennent-ils sur la démocratie ? Grâce aux séries reconstituées par Charlotte Vanneste pour les années allant de 1831 à 1996 159, il est possible de situer les évolutions décrites ci-avant dans l'histoire longue des pratiques d'enfermement.

Trois faits sont remarquables. Primo, la concomitance de la disparition des « colonies de vagabonds » et de l'apparition - ou de l'institution - des « centres fermés pour illégaux » (à Merksplas, les bâtiments affectés aux premiers ont été réaffectés aux seconds). Secundo, les « pics » de détention : avant 1919, ils correspondent, ainsi que l'observe Charlotte Vanneste, aux « creux » des

152. Foucault M., Surveiller et punir, op. cit., p. 34.

153. Idem, p. 220 sq.

154. Foucault M., «Sur la justice populaire. Débat avec les maos », art. cit., p. 353.

155. Ibid., p. 356.

156. Foucault M., «Les mailles du pouvoir », art. cit., pp. 193-194.

157. Foucault M., Le gouvernement de soi et des autres. Cours au Collège de France, 1982-1983, Paris, Gallimard/Seuil, 2008.

158. Foucault M., «Enquête sur les prisons : brisons les barreaux du silence » (Entretien de C. Angeli avec M. Foucault et P. Vidal-Naquet, 1971), Dits et écrits, II, n 88, Paris, Gallimard, 1994, p. 179.

159. Vanneste C., «L'évolution de la population pénitentiaire belge de 1830 à nos jours : comment et pourquoi ? Des logiques socio-économiques à leur traduction pénale ", Revue de droit pénal et de criminologie, 6, 2000, p. 689 ; Les chiffres des prisons. Des logiques économiques à leur traduction pénale, Paris, L'Harmattan, 2003. 
deux premiers cycles de Kondratieff (1848/1850, 1892/1896) 160, à tout le moins si les vagabonds sont pris en considération; ce n'est plus le cas ensuite 161 . Tertio, l'amplitude variable des vagues d'enfermement : impressionnante de 1831 à 1919, réduite de 1919 à 1992, spectaculaire après 1992, elle

160. Pour étudier les relations entre économie et pénalité, Charlotte Vanneste s’appuie sur la théorie des cycles économiques longs formulée par Kondratieff, économiste russe qui, du juriste Pashukanis, fut le contemporain et partagea le destin. Selon Kondratieff, les contradictions du capitalisme résultent en un développement économique cyclique ; un «cycle économique long » dure de cinquante à soixante ans et comprend une phase d'expansion et une phase de récession durant chacune de vingt-cinq à trente ans. Suivant Charlotte Vanneste, les chronologies proposées pour la Belgique correspondent à peu près à celles qui ont été établies pour d'autres pays ; cela, que leurs auteurs privilégient des indicateurs de prix, comme Dupriez, ou des quantités, comme van Duijn. Un premier " pic », situé en 1809 ou 1815, est antérieur à la formation de l'État belge ; il est suivi d'un « creux » en 1845-1850, d'un « pic » en 1872, d'un « creux » en 1892-1896, d'un « pic » en 1920, d'un « creux » en 1939-1948 et d'un « pic » en 1973. Sur la théorie des cycles économiques longs, appelés aussi «cycles de Kondratieff », voir Kondratieff N. D., "The Long Waves in Economic Life", The Review of Economic Statistics, 17-6, 1935, pp. 105-115 ; Kondratieff N., The Long Wave Cycle, ed. G. Daniels et J. Snyders, New York, Snyders \& Richardson, 1984 ; Dupriez L.-H., Des mouvements économiques généraux, Louvain, UCL/IRES, 1951 ; van Duijn J.J., The Long Wave in Economic Life, Londres, Allen \& Unwin, 1983 ; van Duijn J.J., “The Long Wave in Economic Life”, De Economist, 125-4, 1977, pp. 554-576 (http://link.springer.com/article/10.1007/ BF01221051\#page-1, consulté le 30 novembre 2013) ; de manière synthétique : Goldstein J., Long Cycles: Prosperity and War in the Modern Age, New Haven, Yale University Press, 1988, en particulier pp. 40-63 ; de manière critique, Maddison A., Dynamic Forces in Capitalist Development. A Long-Run Comparative View, Oxford/New York, Oxford University Press, 1991, en particulier pp. 89-111.

161. Pendant la phase de récession du troisième cycle de Kondratieff (1920-1939), on n'observe pas d'augmentation du nombre de détenus. En ce qui concerne le quatrième cycle - et le « creux » marquant le passage du quatrième cycle au cinquième -, une question préliminaire doit être prise en considération. Â l'exception de Rostow, qui tient que les phases d'expansion et de récession du quatrième cycle s'étendent respectivement de 1935 à 1951 et de 1951 à 1972, et dont les projections donnent les années 1980 comme la phase d'expansion du cinquième cycle de Kondratieff (Rostow W.W., The World Economy. History and Prospect, Austin, Texas University Press, 1978), les théoriciens des cycles longs ou des ondes longues du capitalisme considèrent généralement que les années 1968-1974 ont marqué le point de départ de la phase de récession du quatrième cycle de Kondratieff, phase qui se prolongerait durant les années 1980. Ils divergent par contre sur la suite. La question posée est, dans sa formulation la plus radicale, celle de savoir s'il y a ou y aura un cinquième cycle de Kondratieff (cf. Bruckmann G., "Will There Be a Fifth Kondratieff?", in Vasko T. (ed.), The Long-Wave Debate. Selected Papers, Weimar, GDR, 1985, Berlin, Heidelberg, New York, Londres, Paris, Tokyo, Springer Verlag/ International Institute for Applied Systems Analysis, 1987, p. 3). À cette question, certains économistes répondent par la négative - c'est le cas de Mandel (Mandel E., Long Waves of Capitalist Development: the Marxist Interpretation, Cambridge, Cambridge University Press, 1980) -, et d'autres par l'affirmative. Aux yeux des premiers, la crise qui clôt le quatrième cycle de Kondratieff se prolonge parce qu'il s'agit d'une crise structurelle dont la résolution suppose, non pas de passer à une autre phase du processus de développement du capitalisme, mais à un autre mode de production ; les seconds tentent de dégager («dig out », écrit Bruckmann) le cinquième cycle, ce qui rétrospectivement devrait permettre de délimiter le «creux » marquant le passage du quatrième cycle au cinquième. Les auteurs s'opposent par ailleurs sur le problème des conditions du retournement d'une onde longue à la hausse et du passage d'un cycle de Kondratieff à l'autre. Les écoles de l'investissement du capital (Capital Investment School) et de l'innovation (Innovation School) tiennent qu'ils s'expliquent par des variables endogènes (infrastructurelles); l'école de la crise du capitalisme (Capitalist Crisis School), que les variables endogènes sont des conditions nécessaires mais non suffisantes du changement, et que des variables exogènes semi-autonomes (superstructurelles) doivent s'y ajouter ( $c f$. sur ce point Louça F., “Ernest Mandel and the Pulsation of History”, in Achcar G. (ed.), The Legacy of Ernest Mandel, Londres, Verso, 1999, p. 112). 
varie en fonction des définitions de la citoyenneté, des modes d'attribution ou d'acquisition de la nationalité belge et des objectivations des travailleurs étrangers 162 . Effet, sur le système punitif, de trois dispositifs 163 successifs : autres problématisations, autres énoncés, autres législations, autres réglementations, autres chirurgies du corps social (autres découpes opérées dans la population), autres méthodes et «pactes de sécurité 164 ». C’est, dans ce qui suit, ce qui retiendra l'attention : selon Foucault, l'art de gouverner est un art « d'utiliser des tactiques plutôt que des lois, ou à la limite d'utiliser au maximum les lois comme des tactiques 165 » pour « disposer » choses et gens et les conduire ainsi à une fin leur convenant ; l'amplitude variable de la courbe de détention montre comment les « dispositions » propres à trois «formules de gouvernement 166 » affectent les pratiques d'enfermement.

Le capitalisme peut bien avoir besoin de supposer des sujets libres et égaux : au XIXe siècle, l'idée de liberté signifie « la liberté de l'individu de toute domination étatique » plus que «sa participation au pouvoir étatique 167 »; quant à l'égalité, seule une part infime de la population jouit de droits politiques. Pendant longtemps, la nationalité importe peu. Politiquement, c'est le

L'importance donnée aux innovations techniques dans la définition des cycles a conduit certains auteurs à prévoir (Mensch, Stalemate In Technology: Innovations Overcome The Depression, Francfort, Umschau Verlag, 1979, p. 73) ou à apercevoir un cinquième cycle de Kondratieff, parfois défini comme celui des technologies de l'information (Freeman K, Louça F., As Time Goes By. From the Industrial Revolutions to the Information Revolution, Oxford, Oxford University Press, 2001, p. 141 ; dans le même sens, dès 1987, Mager N. H., The Kondratieff Waves, New York, Praeger Publisher, p. 159) ; l'importance donnée aux formes d'investissement, à dégager un cinquième cycle caractérisé par le développement de produits financiers. Quelle que soit l'hypothèse - cycle des technologies de l'information, cycle des produits financiers -, les années allant de 1980-1990 à 2008 correspondraient à la phase d'expansion du cinquième cycle de Kondratieff. Deux remarques alors : à la différence de ce qui se produit au XIXe siècle, l'augmentation des taux de détention est postérieure de quelque vingt ans au point de retournement à la baisse qui marque le début de la phase de récession du quatrième cycle; s'il existe un cinquième cycle, l'inflation carcérale correspond non pas à sa phase de récession, mais à sa phase d'expansion.

162. Brion F., "Chiffrer, déchiffrer. À propos de l'incarcération des étrangers en Belgique ", in Palidda S. (ed.), Délit d'immigration. La construction sociale de la déviance et de la criminalité des immigrés en Europe, Communautés européennes, Sciences sociales/Social sciences, COST A2 Migrations, Bruxelles, 1997, pp. 163-223.

163. Foucault indique dans un entretien que ce qu'il « essaie de repérer » sous cette notion est « un ensemble [...] hétérogène, comportant des dicours, des institutions, des aménagements architecturaux, des décisions réglementaires, des lois, des mesures administratives, des énoncés scientifiques, des propositions philosophiques, morales, philanthropiques, bref : du dit, aussi bien que du non-dit [...]. Le dispositif lui-même, c'est le réseau qu'on peut établir entre ces éléments ». Voir M. Foucault, «Le jeu de Michel Foucault» (entretien avec D. Colas, A. Grosrichard, G. Le Gaufey, J. Livi, G. Miller, J.-A. Miller, C. Milot, G. Wajeman), Dits et écrits, III, n 206, Paris, Gallimard, 1994, p. 299.

164. Cf. Foucault M., « La sécurité et l’État » (entretien avec R. Lefort), Dits et écrits, III, n² 213, Paris, Gallimard, p. 385.

165. Foucault M., "Naissance de la biopolitique ", Dits et écrits, III, n² 274, Paris, Gallimard, 1994, p. 646.

166. Cf. Rose N., "Governing 'advanced' liberal democracies", in Barry A., Osborne T., Rose N. (eds), Foucault and Political Reason. Liberalism, Neo-Liberalism and Rationalities of Government, Chicago, The University of Chicago Press, 1996, pp. 37-64.

167. Kelsen H., La Démocratie. Sa nature, sa valeur, trad. C. Eisenmann, Paris Sirey, 1932, p. 9. 


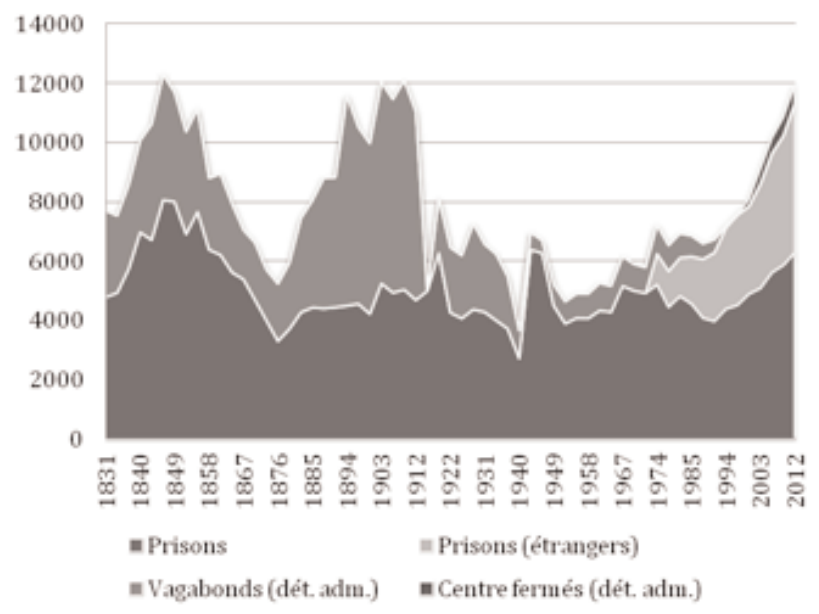

Figure 4 : Établissements pénitentiaires et centres fermés, 1831-2012 ("stock")

cens qui coupe la population en deux : le «peuple-sujet des lois » correspond à la classe dominante, et le «peuple-objet des lois 168 » à la classe dominée. Économiquement, la Belgique est d'abord, comme d'autres États qui se forment alors, «indifférente ou relativement indifférente à l'appartenance spatiale des individus; elle ne s'intéresse pas au contrôle spatial des individus sous la forme de leur appartenance à une terre, à un lieu, mais simplement dans la mesure où elle a besoin que les hommes mettent leur temps à sa disposition 169 ». La « criminalité », pour sa part, divise le « peuple-objet des lois » en une classe laborieuse et une classe dangereuse. Les crises économiques et politiques sont gérées au moyen du droit pénal - droit pénal classique, pour les émeutes de 1845 à $1848{ }^{170}$; droit pénal classique, loi sur la répression du vagabondage et autres lois dites de "défense sociale », de 1886 à la Première Guerre mondiale ${ }^{171}$. Certes, quand la nationalité des membres du «peuple-

168. J'emprunte à Hans Kelsen les concepts de «peuple-sujet des lois » et de «peuple-objet des lois ». Selon le théoricien du droit, la démocratie est, idéalement, « une forme d’État ou de société dans laquelle la volonté générale est formée, ou - sans image - l’ordre social créé par ceux qu'il est appelé à régir - le peuple. Démocratie signifie identité du sujet et de l'objet de pouvoir, des gouvernants et des gouvernés, gouvernement du peuple par le peuple ». Par "peuple ", Kelsen entend l'ensemble des individus soumis au même ordre juridique étatique : cette caractéristique fait son unité, au-delà des oppositions nationales, religieuses et économiques. Or, l'intervention du « peuple » dans la création de l'ordre juridique étatique met en évidence la division de ceux qu'il oblige en deux peuples qui ne coïncident pas, « le peuplesujet (titulaire) du pouvoir, le peuple-législateur, et le peuple-objet du pouvoir, le peuplesujet des lois » (Kelsen H., op. cit., pp. 13-16).

169. Foucault M., "La vérité et les formes juridiques ", art. cit., p. 616. Dans le même sens, voir Melnyk M., Les Ouvriers étrangers en Belgique, Louvain, UCL/IRES et E. Nauwelaerts éd., 1951, p. 21.

170. Vesentini F., Pratiques pénales et structures sociales. L'État belge et la répression du crime en temps de crise économique (1840-1860), Louvain-la-Neuve, PUL./Academia-Bruylant, 2006.

171. Sur ce point, voir Tulkens F., Généalogie de la défense sociale en Belgique (1880-1914). 
objet des lois » le permet, les autorités recourent déjà à l'éloignement ${ }^{172}$. Mais, dans la formule libérale de gouvernement, le principal outil de contrôle du surplus relatif de la population est l'enfermement.

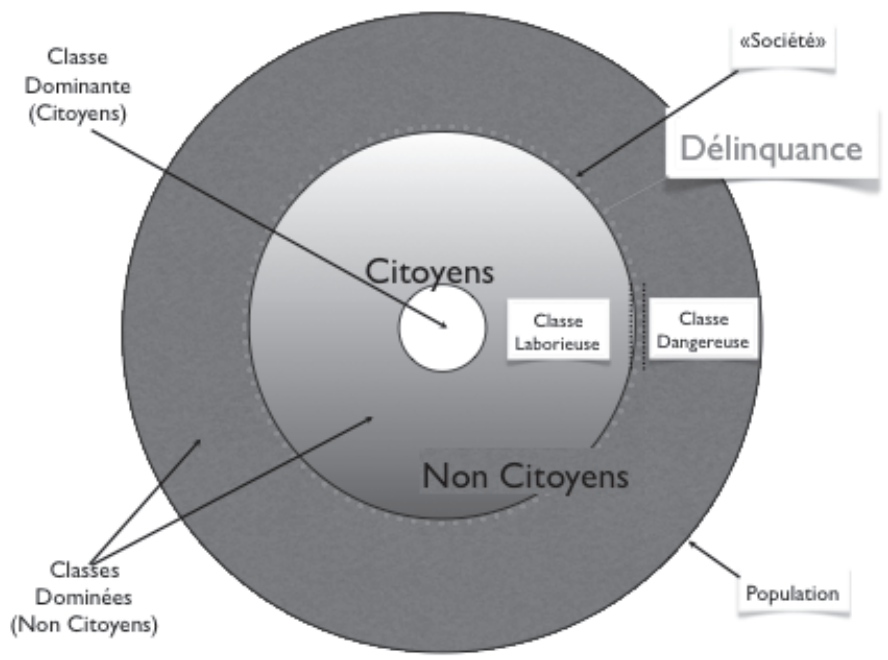

Figure 5 : Population et société (II) : formule libérale de gouvernement

En 1919, le suffrage universel masculin change la donne : c'est la nationalité, non plus le cens, qui définit les limites du «peuple-sujet des lois » et du « peuple-objet des lois »; et c'est la nationalité, non plus la «criminalité », qui divise la classe dominée, sert de référent à la « race », et désarme la lutte des classes. La liberté signifie " participation au pouvoir étatique » autant que « liberté de toute domination politique 173 ». Quant à l'égalité, étendue à l'ensemble de la «communauté nationale », elle a pour contenu les droits civils et politiques, avant d'inclure droits sociaux et économiques ${ }^{174}$. Naissance de « l'État national (et nationaliste) égalitaire 175 »; et, dans la foulée, naissance du problème de la «main-d'œuvre étrangère » et des « immigrés », ces « autres

Travaux du séminaire de recherche qui s'est tenu à l'Université catholique de Louvain sous la direction de Michel Foucault, Bruxelles, Story-Scientia, 1988 ; Brion F., Des classes à la population? Formules de gouvernement et détention, in Harcourt B. (ed.), Carceral Notebook 4 Discipline, Security and Beyond: Rethinking Michel Foucault's 1978 \& 1979, College de France Lectures, Chicago, Carceral.org, 2008, pp. 25 et 40).

172. Godding Ph., «L'expulsion des étrangers en droit belge. Aperçu historique 1831-1952 », Annales de droit, 30, 1970, pp. 301-329.

173. Kelsen H., op. cit., p. 9.

174. Cf. Brion F., « Les menaces d'une forteresse. Citoyenneté, crime et discrimination dans la construction de l'Union européenne », in Tulkens F. et Bosly H.-D. (eds.), op. cit., p. 260.

175. Balibar E., « Racisme et nationalisme », in Balibar E., Wallerstein I. (eds.), Race, nation, classe. Les identités ambiguës, Paris, La Découverte, 1990, p. 72. 
intérieurs $176 »$ du monde ouvrier. La circulation de main-d'œuvre n'est pas une réalité nouvelle; mais, dorénavant, elle se voit distinctement. Pendant un siècle, l'activité professionnelle des étrangers n'avait donné lieu à aucune réglementation particulière : en droit, la liberté de travailler et d'entreprendre était complète. Entre 1930 et 1939, une série d'arrêtés définissent les régimes d'autorisation qui leur sont appliqués; ils complètent le dispositif qui donnera sa forme à l'histoire de l'immigration jusque 1974 - selon Albert Martens, il n'y a « aucune rupture, ni sur le plan juridique, ni sur le plan économico-social entre la politique d'immigration d'avant-guerre et celle d'après-guerre 177 ». Certes, pour reproduire le peuple-objet, la tactique peut changer : laisser venir, aller chercher, organiser sur place sa reproduction en limitant l'attribution de la nationalité. De même, le procédé : lois plutôt qu'arrêtés 178. Mais, quoi qu'il en soit, la fonction de drainage est remplie par l'éloignement; et, pour les membres du peuple-objet, c'est la précarité qui assure l'assujettissement.

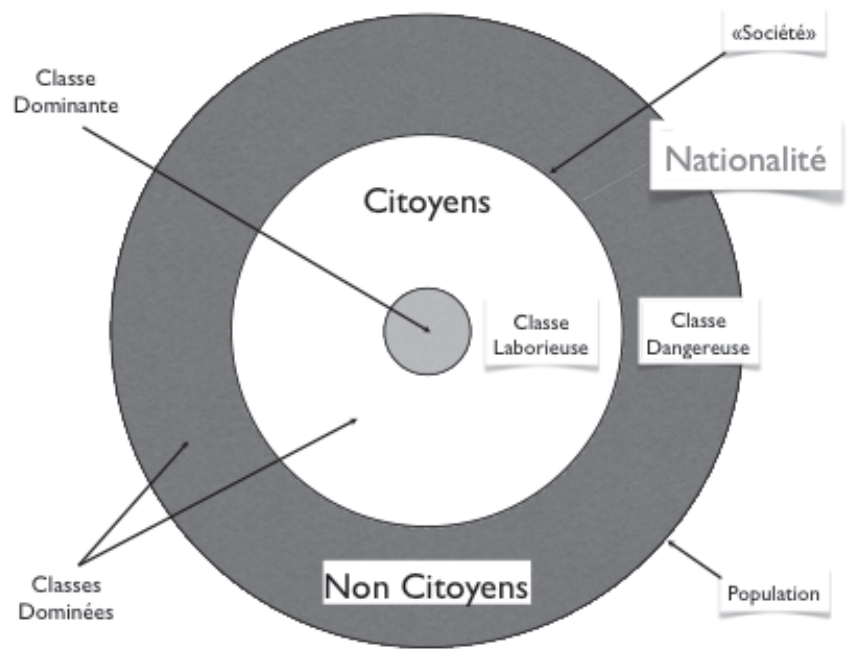

Figure 6 : Population et société (III) : formule sociale de gouvernement

176. Balibar E., « Racisme et nationalisme. Une logique de l'excès », in Wieviorka M. (ed.), Racisme et modernité, Paris, La Découverte, 1993, pp. 79 et 81.

177. Martens A., Les Immigrés. Flux et reflux d'une main-d'oeuvre d'appoint, Louvain, EVOPUL, 1976, p. 41.

178. Ainsi la loi du 19 février 1965 relative à l'exercice, par les étrangers, des activités professionnelles indépendantes remplace-t-elle l'arrêté royal n ${ }^{\circ} 62$ du 16 novembre 1939 portant réglementation de l'activité professionnelle des étrangers. 
Nouveau dispositif dans le dernier quart du $\mathrm{XX}^{\mathrm{e}}$ siècle. Construction européenne, extension des catégories d'étrangers ayant droit à un permis de travail valable pendant une durée illimitée pour toutes les professions salariées : pour les ressortissants des États membres de la Communauté et pour les étrangers de deuxième et troisième générations, le dispositif de régulation du surplus relatif de population par la nationalité perd son efficacité et sa légitimité. Pour ajuster l'offre et la demande de travail et corréler l'accumulation des hommes et l'accumulation du capital, les États européens misent sur une forme, celle du marché. En Belgique, le mécanisme de reproduction du «peuple-objet des lois », grippé, semble en passe d'être abandonné : les conditions d'attribution de la nationalité sont redéfinies, le droit du sol s'ajoutant au droit du sang pour faciliter l'inclusion dans le peuple-sujet des migrants et de leurs descendants ; les procédures d'acquisition de la nationalité se diversifient. En 1992, le traité de Maastricht modifie la forme du couplage de la nationalité et de la citoyenneté. Pour les citoyens européens, la liberté signifie moins "participation au pouvoir » que « liberté de circuler et de séjourner sur le territoire des États membres ». L'égalité a pour contenu les droits de l'homme ainsi que des droits politiques restreints; aux termes de l'accord sur la politique sociale conclu entre les États membres de la Communauté à l'exception du RoyaumeUni, c'est aussi l'égalité entre hommes et femmes en ce qui concerne leurs chances sur le marché du travail et leur traitement dans le travail, ainsi que l'égalité des rémunérations entre travailleurs masculins et féminins pour un même travail.

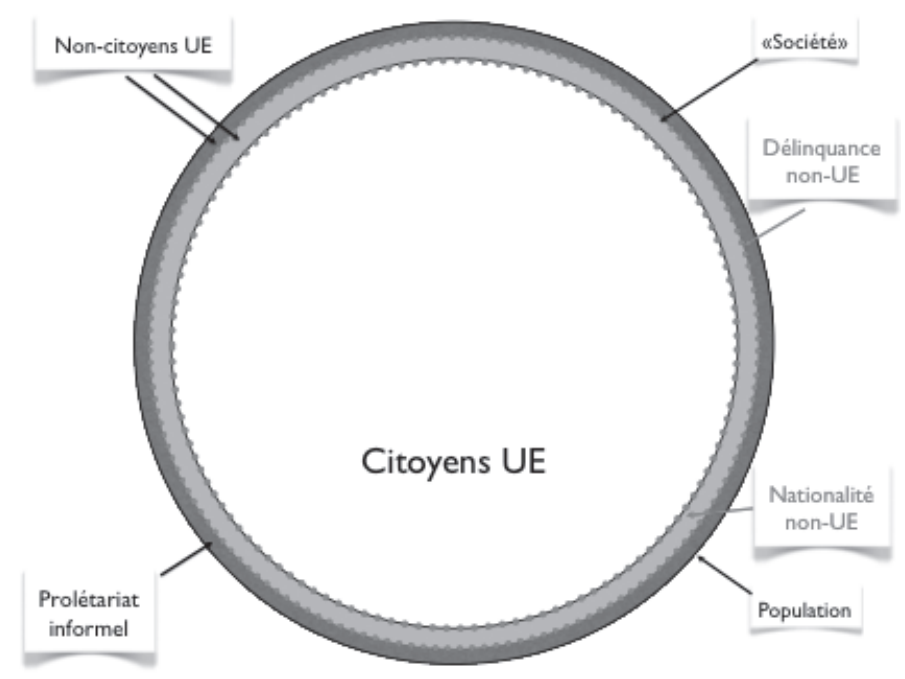

Figure 7 : Population et société (IV) : formule néolibérale de gouvernement (avers) 
Fin de la gestion étatique des flux et des reflux de la main-d'œuvre d'appoint ? Non point. Refonte des mécanismes de production du «peupleobjet »; différenciation des régimes de mobilité ; couplage de la «criminalité » avec certaines nationalités, qui substitue au «peuple-objet des lois » un «peuple-hors la loi », et aux immigrés des «illégaux » et des «délinquants ». Choc pétrolier, récession : en 1974 - au sommet du quatrième cycle économique long, pour la plupart des auteurs qui se réfèrent à Kondradieff ; au début de la quatrième phase du processus de développement du capitalisme, selon Maddison ${ }^{179}$-, la Belgique met un terme à sa politique conventionnelle d'immigration à des fins économiques et démographiques 180. Autre récession, réduction du nombre de postes de travail dans le secteur industriel, chômage des jeunes : en 1983, une loi prolonge l'obligation scolaire de 14 ans à 18 ans ${ }^{181}$. Deux nouveaux problèmes - un nouveau dispositif ? - apparaissent bientôt : l' « illégalité 182 » ou la « criminalité statuaire » des étrangers (la criminalisation de l'immigration) et la « criminalité des immigrés » (la criminalisation des jeunes issus de l'immigration) introduisent dans la population une nouvelle ligne de division entre population officielle et population non officielle. Dans la première, la marge qui distingue la société de la population est réduite au maximum et l’idée démocratique semble quasiment réalisée ; la loi

179. Maddison A., Dynamic Forces in Capitalist Development, op. cit. (une version abrégée du chapitre relatif aux théories des cycles longs est accessible en ligne : Maddison A., "Business cycles, long waves and phases of capitalist development", abbr. version of chapter 4 of Maddison A. : http://wwww.ggdc.nl/maddison/ARTICLES/Business_Cycles.pdf (consulté le 4 décembre 2013).

180. Par politique conventionnelle d'immmigration, j'entends la politique dont les instruments étaient des conventions bilatérales. Ce qui est actuellement défini par certains auteurs comme une absence de politique d'immigration est à mes yeux une autre politique, menée au moyen d'autres instruments ; le passage d'une politique à l'autre - et, plus généralement, le passage de la formule sociale de gouvernement à la formule néolibérale (ou libérale avancée) - est réalisé à travers la redéfinition des agenda et des non-agenda de l'État; une redéfinition qui peut s'analyser comme une nouvelle résolution de ce que Colin Gordon appelle l' «énigme libérale » (Gordon C., "Governement rationality: an introduction”, in Burchell G., Gordon C., Miller P. (eds), The Foucault Effect. Studies in Governmentality, Chicago, University of Chicago Press, 1992, p. 34.

181. Cf. Rea A., Hublet B., Pjetri J., Temps de passage. Jeunes entre l'école et l'entreprise, Bruxelles, FRB, 1990.

182. À nouveau, ce qui est neuf n'est pas l'immigration irrégulière ( $c f$. sur ce point Marie C.-V., «L'immigration clandestine en France », Travail et emploi, 17, 1983, p. 27 : l'auteur écrit, à propos de l'immigration clandestine et du travail étranger clandestin, que « ces deux réalités ne sont pas nouvelles ni non plus spécifiques à la France »). Ce qui est neuf, ce sont les termes dans lesquels l'immigration non autorisée préalablement fait problème (il est successivement question d'immigration de "touristes », de " clandestins » et d' "illégaux ») ; plus radicalement, c'est le fait même qu'elle fasse problème. À cet égard, il est significatif qu'en 1984, le sociologue de l'immigration Abdelmalek Sayad, passant en revue les divers « problèmes sociaux » auxquels des scientifiques ont associé les immigrés - le plus souvent sans se soucier de déconstruire cette "problématique imposée »-, ne mentionne pas une seule fois le problème des « clandestins » ou des «illégaux ». De même, alors qu'il recense les catégorisations dont les personnes définies comme «immigrées » ont fait l'objet (nationalité ou origine nationale, culture, génération...), les catégories liées au statut administratif de l'étranger (« légal » ou « illégal »; CE ou non-CE; réfugié, candidat réfugié, «faux » réfugié...) ne sont jamais mentionnées (Sayad A., « Tendances et courants dans les publications en sciences sociales sur l'immigration en France depuis 1960 », Current Sociology, ISA, 32-3, 1984, pp. 219-304). 
" interpelle » les individus en sujets libres et égaux ${ }^{183}$, et ils se reconnaissent dans cette interpellation. Dans la seconde, les individus sont ravalés au rang de non-personnes ${ }^{184}$; objets de police davantage que sujets de droits, ils peuvent être exploités, enfermés ou éloignés.

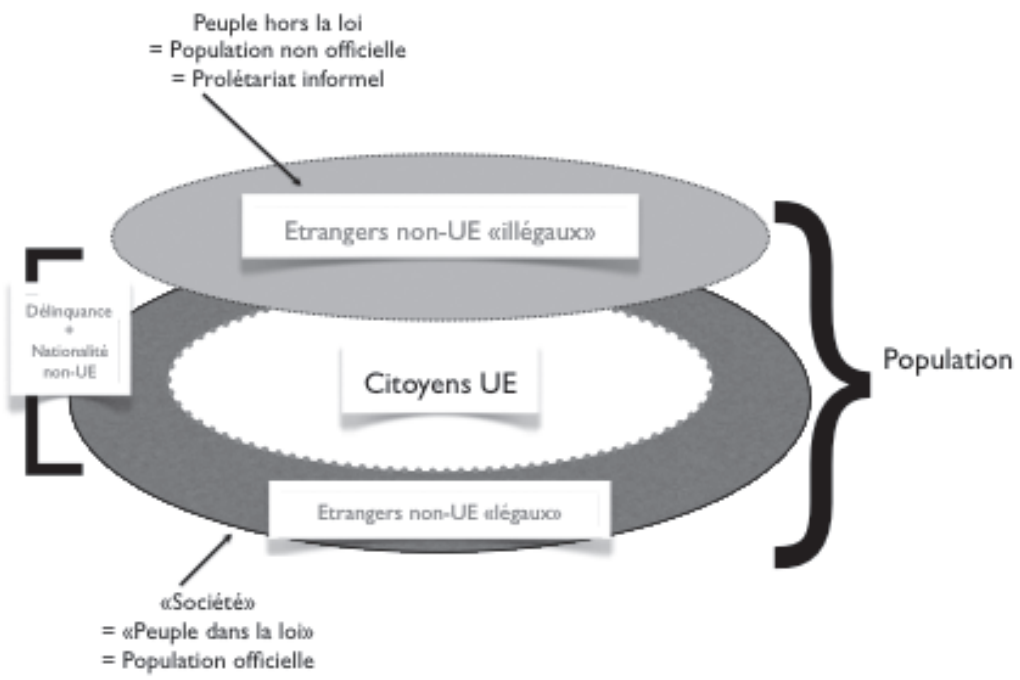

Figure 8 : Population et société (V) : formule néolibérale de gouvernement (revers)

Sur l'avers : démocratie formelle, réelle et non substantielle (ce qui unit le peuple est sa soumission à un même ordre juridique ; ce qui divise la population en deux peuples n'est ni la classe, ni la race, ni la nation, ni la religion, mais la citoyenneté). Sur le revers : dispositif de guerre (ce qui soutient imaginairement la constitution ou l'interpellation d'une partie de la population en société est la référence à un ennemi). La «thanatopolitique », cet « envers de la biopolitique 185 », montre que la population, qui semble à première vue être tout à la fois un «sujet de besoins et d'aspirations » et un « objet entre les

183. Cf. Brion F., «Les menaces d'une forteresse. Citoyenneté, crime et discrimination dans la construction de l'Union européenne », art. cit., pp. 265-267. Sur les trois âges de l'immigration et les partitions successives de la population, Brion F., "Chiffrer, déchiffrer. À propos de l'incarcération des étrangers en Belgique ", art. cit., en particulier pp. 213-223 ; ainsi que Brion F., «Des classes à la population ? Formules de gouvernement et détention », art. cit., pp. 23-44.

184. Brion F., «De la criminalité des immigrés à la criminalisation de l'immigration. Pour une reconstruction d'objet ", Revue de droit pénal et criminologie, 7-8, 1997, pp. 763-775; Brion F., Tulkens F., "Conflit de culture et délinquance. Interroger l'évidence », Déviance et société, 22-3, 1998, pp. 235-262 ; Dal Lago A., Non persone. L'esclusione dei migranti in una società globale, Milan, Feltrinelli, 1999.

185. Foucault M., « La technologie politique des individus », in Dits et écrits, $I V, \mathrm{n}^{\circ} 364$, Paris, Gallimard, 1994, p. 826. 
mains du gouvernement 186 », n'est en fin de compte " jamais que ce sur quoi veille l'État dans son propre intérêt 187 ». La société, par contre, est ce au nom de quoi, dans des États où la rationalisation de la pratique gouvernementale suit la règle libérale de l'économie maximale, « on va chercher à savoir pourquoi il est nécessaire qu'il y ait un gouvernement, en quoi on peut s'en passer, et sur quoi il est inutile ou nuisible qu'il intervienne 188 ». Du moins à première vue, car sous prétexte de "défense », c'est aussi ce au nom de quoi, dans ces États, les exceptions à la règle de l'économie maximale sont justifiées ; ce au nom de quoi, malgré la critique libérale, la « maximalisation sous condition d'optimum 189 » de la pratique gouvernementale propre à la raison d'État est légitimée s'agissant des individus ou des groupes réputés mettre la société en danger.

Analysée du double point de vue de la reproduction (ou de la production) de la force productive et de la reproduction (ou de la transformation) des rapports de force existants, l'évolution de la population détenue suggère que ce sont les fonctions remplies alternativement ou complémentairement par la "délinquance » et la nationalité qui expliquent l'amplitude variable des vagues d'enfermement : la seconde serait, dans la formule sociale de gouvernement, l'équivalent fonctionnel de la première dans la formule libérale ; l'«illégalité » et la « criminalité des immigrés », qui les rabattent l'une sur l'autre, seraient leurs équivalents dans la formule néolibérale. Mutatis mutandis car, dans le cas des immigrés, « l'intégration marginaliste à l'utilité de l'État 190 » passait par l'insertion sur le marché du travail formel ; or, «illégalité » et «criminalité » renvoient sur le marché du travail informel. À la stratification nationale du marché du travail caractéristique de la formule sociale de gouvernement, la formule néolibérale substitue une forme de stratification passant par la coexistence de deux marchés du travail, formel et informel ; parallèlement, en couplant nationalités tierces et délinquance, elle substitue à la division nationale du prolétariat sa division en un « prolétariat formel » et un « prolétariat informel $191 »$.

186. Foucault M., « La “gouvernementalité” ", art. cit., p. 652.

187. Foucault M., « La technologie politique des individus », art. cit., p. 826.

188. Foucault M., « Naissance de la biopolitique », art. cit., p. 820. De là, selon Foucault, « le fait que la critique libérale ne se sépare guère d'une problématisation, nouvelle à l'époque, de la “société” [...]. La réflexion libérale ne part pas de l'existence de l'État, trouvant dans le gouvernement le moyen d'atteindre cette fin qu'il serait pour lui-même ; mais dans la société qui se trouve être dans un rapport complexe d'extériorité et d'intériorité vis-à-vis de l'État ».

189. Idem.

190. Foucault M., « La technologie politique des individus », art. cit., p. 820.

191. Sur le concept de prolétariat informel, voir Neilson D., Stubbs T., "Relative surplus population and uneven deveopment in the neoliberal era: Theory and empirical application”, Capital E Class, 35-3, 2011, pp. 441-442. Cinq formes de travail seraient caractéristiques du prolétariat informel. Les quatre premières concernent l'exercice illégal d'activités légales : travail non rémunéré effectué pour le compte d'une micro-entreprise gérée par des parents assurant en contrepartie un hébergement ; travail «salarié » sous-rémunéré effectué dans le cadre d'une relation employeur-employé non soumise aux conditions et aux contrôles prévus par la loi ; travail « indépendant » et micro-entrepreneuriat non soumis aux conditions et aux contrôles 
La transformation du comportement de la courbe de détention est le corrélat d'une série de mutations. D'une formule de gouvernement à l'autre, la définition de la citoyenneté est modifiée, en extension et en compréhension 192 ; les significations de la liberté et de l'égalité sont changées ; l'importance de la nationalité est réévaluée ; les référents objectifs de la criminalité sont transformés ; les contours de la société sont redessinés ; l'ensemble des individus appelés à la défendre - ses membres - est redéfini ; l'ennemi à refouler aussi. La formule libérale distingue citoyenneté, nationalité et société (chaque notion définit un ensemble différent). La formule sociale les confond (elles désignent un seul et même ensemble). La formule néolibérale les dispose autrement : elle confond « citoyenneté-UE » et «société », érode dans l'ensemble ainsi défini la distinction entre les nationalités, et isole dans la population un reste, qu'elle caractérise par la non-citoyenneté-UE, la non-nationalité-UE et l'illégalité/criminalité. Le passage d'une formule à l'autre est annoncé par la transformation des statistiques enregistrées, et consommé par les redéfinitions de la citoyenneté et les transformations du droit de la nationalité 193 . Il faut attendre 1884 - un an avant la fondation du Parti ouvrier belge, en 1885 ; deux ans avant les soulèvements ouvriers de 1886 - pour que les statistiques d'émigration et d'immigration, collectées depuis 1846, distinguent entre nationaux et étrangers ${ }^{194} .1893$ voit l'abolition du cens et l'attribution de la capacité politique à tous les hommes de nationalité belge ${ }^{195}$;

prévus par la loi. Dans les deux premiers cas, l'hyper-assujettissement à l'employeur s'ajoute à l'absence d'assujettissement aux législations fiscales, sociales et relatives au travail. La cinquième regroupe des activités telles que la vente de stupéfiants, la prostitution, la mendicité ou des petits vols.

192. Brion F., "Les menaces d'une forteresse. Citoyenneté, crime et discrimination dans la construction de l'Union européenne ", art. cit., en particulier pp. 257-267.

193. Marx et Engels avaient anticipé l'importance que prendrait la nationalité dès 1848. Les ouvriers, notaient-ils alors, doivent, pour améliorer leurs conditions d'existence, s'organiser « en classe, et donc en parti politique ». Cette organisation est "sans cesse détruite de nouveau par la concurrence [qu'ils] se font entre eux ». Pour cette raison, leur lutte, «bien qu'elle ne soit pas, quant au fond, une lutte nationale ", doit en revêtir la forme (Marx K., Engels F., Manifeste du Parti communiste, Bruxelles, 1848. En 1848 et en 1886, le gouvernement réagit aux émeutes en réprimant et en élargissant le droit de suffrage. En 1886, les leaders du Parti ouvrier approuvent la répression et revendiquent le suffrage universel : "Si nous voulons le suffrage universel, c'est pour éviter une révolution, car réforme ou révolution, suffrage universel ou bouleversement universel, tel est le dilemme qui se pose au peuple belge en ce moment ", écrit De Paepe (cité in Brion F., " Des classes à la population ? Formules de gouvernement et détention », art. cit., p. 25). Les lois électorales de 1893 et 1919 investissent la ligne de faille ouverte par la concurrence des ouvriers entre eux (idem).

194. Melnyk M., op. cit., pp. 174-175. En son contraire, Eggerickx Th., " Migrations internationales et populations de nationalité étrangère : quelques aspects démographiques ", in Khader B., Martiniello M., Rea A., Timmerman C. (eds.), Penser l'immigration et l'intégration autrement, Bruxelles, Bruylant, 2006, p. 32 : le démographe écrit que jusqu'en 1932 - année où les lois sur la nationalité adoptées entre 1922 et 1932 ont été coordonnées -, les données d'immigration et d'émigration ne distinguent pas la nationalité, mais le lieu de naissance (en Belgique ou à l'étranger). C'est à partir de 1921 que les communes ont dû tenir non seulement un registre de population, mais un registre des étrangers permettant aux autorités communales de " [...] connaître, à tout moment, la présence des étrangers et d'exercer sur eux un contrôle sévère et permanent » (ibid., p. 34).

195. Il est intéressant de noter que Prins, qui jette à partir de 1886 les bases de la doctrine de la défense sociale (cf. Prins A., Criminalité et répression : essai de science pénale, Bruxelles, 
1919, l'abandon du vote plural et, pour les hommes de nationalité belge, la reconnaissance du suffrage universel pur et simple. Entre 1922 et 1932, quatre lois sur l'acquisition, la perte et le recouvrement de la nationalité belge sont adoptées ; coordonnées en 1932, elles font de la Belgique un pays de strict ius sanguinis paterni, et finissent d'instituer les conditions de la formule sociale de gouvernement. Le premier dénombrement des détenus étrangers est effectué en 1974. La citoyenneté européenne est instituée en 1992. Les conditions d'attribution, d'acquisition, de perte et de recouvrement de la nationalité sont redéfinies en 1984, 1991, 1993, 1995, 1998, 2000, 2006 et 2012.

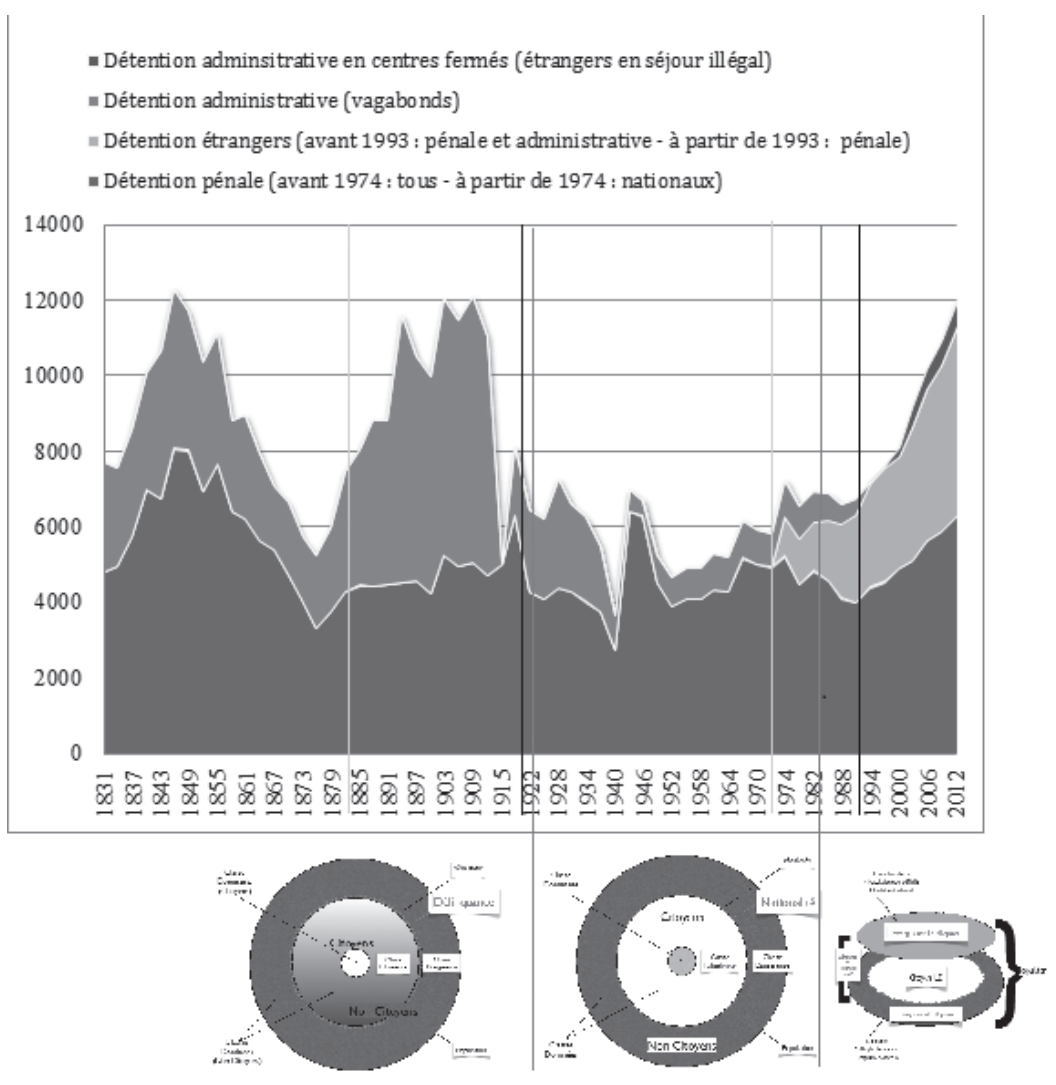

Figure 9 : Établissements pénitentiaires et centres fermés, 1831-2012 ("stock")

Muquardt, 1886 ; Science pénale et droit positif, Burxelles, Bruylant, 1899; La Défense sociale et les transformations du droit pénal, Bruxelles, Misch et Thron, 1910), publie par ailleurs durant ces années troublées plusieurs ouvrages sur la forme démocratique (Prins A., La Démocratie et le régime parlementaire, Bruxelles, Herzbach et Falk, 1884 ; La Démocratie et le régime parlementaire : étude sur le régime corporatif et la représentation des intérêts, Bruxelles, Muquardt, 1886, rééd. augmentée 1887 ; De l'esprit du gouvernement démocratique : essai de science politique, Bruxelles, Misch et Thron, 1905). 
Deleuze écrit que le pouvoir, selon Foucault, «s'exerce avant de se posséder (puisqu'il ne se possède que sous une forme déterminable, classe, et déterminée, État) 196 ». L'histoire des transformations des formes de régulation et des usages de la prison aide à comprendre comment, dans les sociétés libérales, se nouent les relations entre exercice et possession, classes et population. Si le gouvernement y est un art de disposer choses et gens, la fin à laquelle il les conduit convient d'abord aux citoyens. Toujours, le racisme suit la ligne de partage qui, à l'intérieur de la population, vise à spécifier la société : pendant le " long XIXe siècle 197 ", libéral, la population racisée est le Lumpenproletariat ${ }^{198}$; pendant le « court XXe siècle ${ }^{199}$ », national et social, ce sont les travailleurs étrangers; en ce début de XXIe siècle, néolibéral, ce sont les «allochtones » et les musulmans. Toujours, la prison définit les délinquants, que le criminalisme distingue des infracteurs en les liant à leur infraction par diverses déterminations. Pour réaliser l'égalité, le racisme nie l'humanité de certains êtres humains; dans les luttes autour de la loi et des illégalismes, la prison spécifie la délinquance. Racisme et criminalisme sont couplés au passage d'une formule de gouvernement à l'autre : dans les deux cas, le «crime »/la «criminalité » fonctionne comme un synonyme de la « race » (crime is race by another name); mais à l'orée du XXe siècle, ils sont liés par l'ethnicité quand, un siècle plus tôt, ils l'étaient par la dégénérescence.

196. Deleuze G., Foucault, Paris, Minuit, 1986, p. 78. Cf. aussi Foucault M., Surveiller et punir, op. cit., p. 31 : selon le philosophe, l'étude de la microphysique du pouvoir mise en jeu par les appareils et les institutions « suppose que le pouvoir qui s'y exerce ne soit pas conçu comme une propriété, mais comme une stratégie, que ses effets de domination ne soient pas attribués à une "appropriation", mais à des dispositions, à des manœuvres, à des tactiques, à des techniques, à des fonctionnements [...] Il faut en somme admettre que ce pouvoir s'exerce plutôt qu'il ne se possède, qu'il n'est pas le privilège acquis ou conservé de la classe dominante, mais l'effet d'ensemble de ses positions stratégiques - effet que manifeste et parfois reconduit la position de ceux qui sont dominés ».

197. J'emprunte l'expression à l'historien marxiste E. J. Hobsbawn, qui a étudié le long XIXe siècle dans sa trilogie : Hobsbawn E. J., The Age of Revolution, 1789-1848, New York, Vintage Books, 1962; The Age of Capital, 1848-1875, New York, Vintage Books, 1975 ; The Age of Empire, 1875-1914, Londres, New York, Vintage Books, 1989.

198. En 1910, Prins, qui explique certaines formes de criminalité par l'hérédité, pense certes en termes de race, mais établit une équivalence entre race et classe : «l'insuffisance » de ces « infirmes de l'intelligence et de la volonté » que " les Allemands [appellent] Minderwertigen, [et] les Flamands, Minderwaardigen »- littéralement, " [gens] de moindre valeur »- est à ses yeux affaire de race, c'est-à-dire de classe (Prins A., La Défense sociale et les transformations $d u$ droit pénal (1910), rééd. avec une introduction de Tulkens F., Genève, Médecine et Hygiène, 1986, p. 94). À l'exception des «bandes errantes de tziganes ", qu'il mentionne une seule fois, il n'use d'ailleurs jamais ni de catégories nationales ni de catégories ethniques pour caractériser les types - vagabonds, délinquants, défectueux - qui lui semblent menacer la société : le premier âge de l'immigration confond dans l'ouvrier le national et l'étranger (Brion F., Immigration, crime et discrimination. Essai de criminologie réflexive sur les usages politiques du crime et de la science qui le prend pour objet, Louvain-la-Neuve, École de criminologie (ronéo), 1995, chapitre 2).

199. Cf. Hobsbawn E.J., L'Âge des extrêmes : histoire du court XXe siècle, Bruxelles, Complexe, 2003 [1999]. 
Et la discipline, cette technologie de pouvoir qui investit le « corps dressable » des individus ? La prison est sans doute, à cette échelle, une «institution d'assujettissement ». Encore faut-il voir, avec Foucault, que « [d]ans le grand panoptisme social, dont la fonction est précisément celle de transformer la vie des hommes en force productive, [elle] exerce une fonction beaucoup plus symbolique et exemplaire que réellement économique, pénale ou corrective 200 ». Voir, aussi, que la formule sociale de gouvernement lui a, dans cette fonction, donné un équivalent, la précarité devenant pour une partie de la population le ressort de l'assujettissement 201 . Voir ou entrevoir enfin, avec Alessandro De Giorgi, que la discipline n’était peut-être que la technologie de transformation des corps en « corps productifs » et en « corps assujettis » adéquate au capitalisme industriel ${ }^{202}$. Si tel est le cas, la prison et la plupart des alternatives à la détention - y compris la surveillance électronique - sont des « machines disciplinaires » tournant à vide ou remplissant d'autres fonctions. Production de cet au-delà de l'obéissance que Foucault appelle "l'état d'obéissance »-forme d'obéissance " auto-référée », qui est à elle-même sa propre fin, et qui se manifeste dans l'humilité, la patience et la soumission 203. Ou production de fautes, qui le plus souvent prennent la forme d'infractions disciplinaires, et qui étendent infra-pénalement la surveillance et les possibilités de réintégration en prison ${ }^{204}$.

\section{Fragment 4. Melossi vs Foucault : avatars ou mort du deus ex machina}

Retour au problème de l'idéologie. Soit l'hypothèse que l'inflation carcérale et le « grand renfermement » des étrangers procèdent à (et de) la restructuration de la population vivant sur le territoire de l'État, à (et de) la reconfiguration du marché du travail, à (et de) la transition de la formule sociale à la formule néolibérale de gouvernement - «à (et de)» : ils leur sont immanents. Comment penser concrètement les rapports entre infrastructure et superstructure ? Trois hypothèses - économique, politique, idéologique - ont été avancées par Theodore Chiricos et Miriam Delone ${ }^{205}$, qui expliquent les

200. Foucault M., « La vérité et les formes juridiques », art. cit., p. 621.

201. Le dispositif de régulation du travail et du séjour des étrangers forgé dans l'entre-deuxguerres ne spécifie pas un lieu clos hétérogène à tous les autres, pas davantage qu'il ne divise un espace disciplinaire, y détermine des emplacements fonctionnels ou n'y range des corps. Il n'enferme pas dans un lieu, mais dans un statut ; il n'architecture pas à coups de bâtiments, mais de règlements. Il ne quadrille pas un espace réel, mais un espace fictionnel. Pour transformer la vie des hommes en force productive, il mise sur l'ex-corporation : il menace d'expulser du territoire ces corps qu'il définit comme étrangers au corps social ( $c f$. Brion F., «Des classes à la population ? Formules de gouvernement et détention », art. cit., pp. 36-37 ; Immigration, crime et discrimination, op. cit.).

202. De Giorgi A., "Toward a political economy of post-Fordist punishment", in Lynch M. J., Streteski P.B. (eds), Radical and Marxist Theories of Crime, Farnham, Ashgate, 2011, p. 485.

203. Foucault M., Mal faire, dire vrai. Fonction de l'aven en justice. Cours de Louvain (1981), op. cit., pp. 135-136.

204. Simon J., Poor Discipline. Parole and the Social Contraol of the Underclass, 1890-1990, Chicago/Londres, The University of Chicago Press, 1993.

205. Chiricos T. G., Delone M., "Labor Surplus and Punishment: A Review and Assessment of Theory and Evidence”, Social Problems, 39-4, 1992, pp. 421-446. 
variations des taux de détention par les fonctions remplies par les prisons dans la production et la reproduction de la force productive et des rapports de production. Nouveau détour théorique, en deux temps et deux tableaux. Le premier représente Dario Melossi, longtemps partisan de l'explication «idéologique 206 »; le second, Foucault, plus proche des partisans de l'explication politique.

Sur le tableau de droite : Dario Melossi, co-auteur avec Massimo Pavarini de la traduction italienne de Punishment and Social Structure 207 et de Carcere e fabbrica : alle origine del sistema penintenziario (XVI-XIX secolo), tous les deux publiés en 1978, trois ans après Surveiller et punir 208. Dans une série d'articles publiés entre 1985 et 1992, il observe que les taux de chômage et de détention "semblent bouger ensemble ", indépendamment des taux de criminalité 209. Passent pour des explications de cette corrélation, écrit-il, "quelques formules structuralistes magiques sur "les besoins du capital” ou "le besoin de contrôle social", qui hypostasient le comportement d'entités collectives indépendamment des actions motivées des agents effectivement impliqués 210 »; « des comptes rendus de type fonctionnaliste similaires, [tout aussi] insatisfaisants 211 »; des « hypothèses [tenant] d'une vision plutôt conspiratrice des rapports sociaux 212 ». En arrière-plan : la foule nombreuse de ceux

206. Dans une série de publications récentes, consacrées à l'histoire des pratiques d'enfermement et à la criminalisation de l'immigration, Melossi délaisse l'étude des « vocabulaires de la motivation punitive » et, à la suite de sociologues tels que Salvatore Palidda ou Alessandro Del Lago, fins connaisseurs de l'œuvre de Foucault et d'Abdelmalek Sayad, sociologue des migrations et de la "pensée d'État ", s'intéresse à la reconfiguration du marché du travail ainsi qu'aux pratiques policières et judiciaires. Ainsi avance-t-il l'hypothèse que " [...] l'émigration et l'immigration sont toutes deux liées aux changements profonds de la structure de l'économie. [...] En d'autres termes, les processus d'expulsion des milieux ruraux, qu'ils se déroulent dans le sud de l'Italie de 1890 à 1915 ou en Afrique du Nord beaucoup plus récemment, tendent à produire un surplus de main-d'œuvre qui est, pour ainsi dire, canalisée, du moins dans un premier temps, à la fois dans les mouvements migratoires et dans le système pénal » (Melossi D., "Le crime de la modernité : sanctions, crime et migration en Italie (1863-1997) ", Sociologie et sociétés, 33-1, 2001, p. 103). Voir aussi Melossi D., “'In a Peaceful Life': Migration and the Crime of Modernity in Europe/Italy", Punishment and Society, 5-4, 2003, pp. 371-397 ; Melossi D., "Punishment and Migration Between Europe and the USA: A Transnational 'Less Eligibility'?”, in Simon J., Sparks R. (eds), The Sage Handbook of Punishment and Society, Londres, Sage, 2013, pp. 416-432. Pour d'autres explications «idéologiques » de la corrélation entre l'évolution des taux de chômage et des taux de détention, $c f$. Chiricos T.G., Hales W. D., "Unemployment and punishment: an empirical assessment", Criminology, 29-4, 1991, pp. 701-724.

207. Rusche G., Kirchheimer O., Pena e struttura sociale, trad. D. Melossi, M. Pavarini, Bologne, Il Mulino, 1978.

208. Melossi D., Pavarini M., Carcere e fabbrica : alle origine del sisteme penitenziaro (XVI-XIX secolo), Bologne, Il Mulino, 1978.

209. Melossi D., "Overcoming the crisis in critical criminology: toward a grounded labeling theory", Criminology, 23-2, 1985, p. 205 : «In fact, while unemlpoyement and imprisonment rates seem to move together with great synchrony, crime does not ».

210. Idem: "What pass for explanations are some magic structuralist formulas about 'the needs of capital' or 'the need for social control', magic because they hypostasize collectivities' behavior in a way which is independent from the motivated actions of the actual personnel involved».

211. Melossi D., "Political business cycles and imprisonment rates in Italy: report on a work in progress", The Review of Black Political Economy, 16-1/2, 1987, p. 214. 
qui ont reproché à « la pensée 68213 » tantôt de céder à la facilité des théories du complot, tantôt de pratiquer un structuro-fonctionnalisme qui réduit les êtres humains à l'impuissance et anéantit toute possibilité de résistance.

Selon Dario Melossi, les cycles économiques longs étant doublés de cycles politiques (les «political business cycles 214 »), le «climat moral » des sociétés oscille selon un mouvement pendulaire ${ }^{215}$. De manière générale, la croissance de la population détenue " coïncide avec des situations perçues comme cruciales pour le maintien de l'hégémonie des élites». Certes, il arrive que les «difficultés économiques » ne donnent pas lieu à des "crises hégémoniques 216 ». C'est qu'en l'occurrence, « la situation de crise prétendument “objective” »- soit « une situation jugée telle par un observateur neutre (un sociologue, par exemple) $217 »-$ est moins déterminante que les perceptions et les interprétations des « élites morales 218 » («la perception de panique morale 219 ", suivant Theodore Chiricos et Miriam Delone). Ces élites morales - « ceux qui sont autorisés à identifier et à étiqueter les problèmes sociaux »ont en effet " une propension à réagir à des situations qu'[elles] perçoivent comme menaçantes pour les structures [...] qu'[elles] associent à la défense et à la promotion de leur propre hégémonie 220 ».

Nul besoin d'invoquer l'État - ce commode Léviathan 221 - pour expliquer la corrélation entre les taux de chômage et de détention : si leurs variations sont synchrones, c'est que " quelque chose se passe dans les constructions des motivations des agents du contrôle social », qui « de quelque façon, lie l'état de l'économie à leurs activités professionnelles 222 ». La corrélation observée dépend d'une «variable intervenante 223 », les «vocabulaires à moti-

212. Melossi D., «L’hégémonie et les vocabulaires de la motivation punitive : la gestion discursive des crises sociales », Criminologie, 25-2, p. 99.

213. Ferry L., Renaut A., La Pensée 68. Essai sur l'anti-humanisme contemporain, Paris, Gallimard, 1985.

214. Melossi D., "Punishment and social action: changing vocabularies of punitive motive within a political business cycle", Current Perspectives in Social Theory, 6, 1985, p. 169 ; "Political business cycles and imprisonment rates in Italy ", art. cit., p. 211.

215. Melossi D., «An introduction. Fifty years later, Punishment and Social Structure in comparative analysis ", art. cit., p. 320.

216. Melossi D., «L’hégémonie et les vocabulaires de la motivation punitive: la gestion discursive des crises sociales », art. cit., pp. 95 et 108.

217. Idem.

218. Dario Melossi précise que le concept est plus large que celui d'entrepreneur de morale d'Howard Becker (Melossi D., "L'hégémonie et les vocabulaires de la motivation punitive : la gestion discursive des crises sociales », art. cit., p. 101).

219. Chiricos T. G., Delone M., art. cit., en particulier p. 426.

220. Melossi D., «L'hégémonie et les vocabulaires de la motivation punitive : la gestion discursive des crises sociales ", art. cit., p. 95.

221. Melossi D., "Political business cycles and imprisonment rates in Italy: report on a work in progress", art. cit., p. 214 : "Leviathan in fact is the ideal stand-in for the real culprits in the script of a conspirational functionalism », Melossi D., "An introduction. Fifty years later", art. cit., p. 319.

222. Melossi D., "Overcoming the crisis in critical criminology: toward a grounded labeling theory”, art. cit., p. 205. 
vation punitive 224 ». Il faut donc " établir une chaîne discursive allant des rationalisations et des explications des conflits politiques et sociaux qui entourent le cycle économique, aux vocabulaires à motivation punitive qui sont à la disposition des agences de contrôle social, vocabulaires à partir desquels ces agences rendent raison de leurs actions 225 ». Concrètement, le sociologue propose d'analyser des textes faisant autorité en matière de politique criminelle, tels les discours des procureurs généraux; il y voit des « indicateurs directs » de la gestion discursive des crises, un des « maillons » de la chaîne à établir (il cite aussi « les documents législatifs, les reportages des médias, les articles dans les magazines et les journaux spécialisés ») 226.

Foucault, poursuit-il, a bien montré combien les fonctions latentes des prisons étaient éloignées de leurs fonctions manifestes ; aussi lui paraît-il difficile de les réduire à « un nouveau but instrumental et intentionnel : le contrôle de la classe ouvrière 227 ». Aux yeux du sociologue, le philosophe considérerait, à l'instar de Durkheim, que le « projet central de la pénalité » est «son usage symbolique comme une pièce de théâtre moralisatrice ou [...] comme une gazette officielle de moralité 228 »; il considérerait, en d'autres mots, qu'entre les fonctions des méthodes pénales et les « techniques d'assujettissement 229 » des sociétés d'Ancien Régime et de la société de surveillance, il n’y a pas de différence. De là, une série d'hypothèses : le système d'administration de la justice pénale viserait à contenir la criminalité dans les limites « accepta-

223. Melossi D., "Political business cycles and imprisonment rates in Italy: report on a work in progress", art. cit., p. 215 ; “An introduction. Fifty years later”, art. cit., p. 320.

224. Melossi D., "Punishment and social action: changing vocabularies of punitive motive within a political business cycle”, art. cit., pp. 169-197; «L'hégémonie et les vocabulaires de la motivation punitive : la gestion discursive des crises sociales ", art. cit., pp. 93-114 (l'auteur dit plus fréquemment «vocabulaires à motivation punitive»).

225. Melossi D., "Political business cycles and imprisonment rates in Italy: report on a work in progress", art. cit., p. 215.

226. Melossi D., "L'hégémonie et les vocabulaires de la motivation punitive : la gestion discursive des crises sociales ", art. cit., pp. 109-110.

227. Ibid., p. 104. L'auteur renvoie à Garland D., "Frameworks of Inquiry in the Sociology of Punishment", art. cit., p. 6. Selon David Garland, «Foucault's analysis of the latent functions of the prison stands as a model of how the appearence of failure can be turned into success by this search for hidden utility. He refuses to accept that a dysfunctional, counter-productive institution - the prison - could survive for centuries, so he asks what positive functions such futility could conceal. Having put the question thus, he produces an answer of sorts - the prison doesn't control the criminal, it controls the working class by creating criminals ».

228. Idem. L'article de Dario Melossi est antérieur à la publication des Dits et écrits, de sorte que sa lecture ne peut tenir compte d'une série d'hypothèses formulées par Foucault à l'occasion de cours ou de conférences. En 1973, dans « La vérité et les formes juridiques », le philosophe insiste, dans son commentaire des Leçons sur les prisons, sur « le phénomène d'inversion du spectacle en surveillance » qui, selon lui, marque la naissance, au XVIII siècle, de la société panoptique ; il relève que l'auteur des Leçons - Julius, un collègue de Hegel - voit dans cette inversion un corrélat de l'apparition de sociétés étatiques ; il attire l'attention sur les institutions " propres à la société moderne, industrielle, capitaliste » dans lesquelles les caractéristiques du panoptisme sont actualisées ; enfin, pour appréhender ce panoptisme ou cette surveillance à la base, il lit à ses auditeurs le règlement d'une usine (Foucault M., «La vérité et les formes juridiques", art. cit., pp. 608-611).

229. Melossi D., «L'hégémonie et les vocabulaires de la motivation punitive : la gestion discursive des crises sociales ", art. cit., p. 104. 
bles » pour une société donnée à un moment donné ; l'incarcération serait l'un des spectacles destinés à «engendrer l'hégémonie »; elle «montrerait à un plus large public à la fois le comportement social acceptable dans un contexte historique donné et l'infamie de ceux qui ne s'y conforment pas 230 ». À la régie : des «élites morales » tantôt sévères, tantôt magnanimes (Dario Melossi cite les propos lénifiants d'Andreotti après les assassinats de plusieurs candidats aux élections, dans le Sud de l'Italie ${ }^{231}$ ).

Problème : l'explication «idéologique " proposée par le sociologue de la pénalité détourne l'attention des formes d'ajustement de la corrélation de l'accumulation des hommes et de l'accumulation du capital 232 ; ce faisant, elle protège dispositifs et dispositions, en ce compris le système des infractions. Suivant Marx, l'ensemble des rapports de production constitue « la structure économique de la société, la base concrète sur laquelle s'élève une superstructure juridique et politique et à laquelle correspondent des formes de conscience sociales déterminées » (ce n'est pas, écrit-il, «la conscience des hommes qui détermine leur être », mais « inversement, leur être social qui détermine leur conscience ») ; la structure économique se transforme quand, de «formes du développement des forces productives qu'ils étaient », les rapports de production existants deviennent « des entraves »; les changements dans l'infrastructure bouleversent alors " plus ou moins rapidement toute l'énorme superstructure 233 ». Tout se passe comme si Dario Melossi, dans les articles étudiés, considérait que les indicateurs économiques, le « climat moral » de la société et les chiffres des prisons co-varient toutes choses égales par ailleurs. L'histoire concrète des transformations dans l'infrastructure est remplacée par la référence aux cycles économiques modélisés par Kondratieff ${ }^{234}$; l'histoire concrète de la superstructure juridico-politique est ignorée.

Pourtant, du côté des économistes, des théoriciens marxistes ont déjà critiqué l'hypothèse d'invariance structurelle qui sous-tend l'application des méthodes économétriques à des séries historiques concrètes uni- ou pluridécennales ${ }^{235}$, et insisté sur la nécessité de combiner analyse historique et ana-

230. Ibid., pp. 105-106.

231. Ibid., pp. 106-107.

232. Foucault M., Surveiller et punir, op. cit., pp. 220 sq.

233. Marx K., Introduction à la critique de l'économie politique (1857), Paris, L'Altiplano, 2008, pp. 11-13 (http://www.laltiplano.fr/introduction-a-la-critique-de-leconomie-politique.pdf, consulté le 25 avril 2014).

234. Melossi D., "An introduction. Fifty years later, Punishment and Social Structure in comparative analysis", art. cit., p. 320.

235. Cf. Louça F., «Ernest Mandel et la pulsation de l'histoire », in Achcar G. (ed.), Le Marxisme d'Ernest Mandel, Paris, PUF, 1999 (http://www.ernestmandel.org/new/sur-la-vie-et-l-oeuvre/article/ernest-mandel-et-la-pulsation-de-l, consulté le 27 avril 2014). Francisco Louça (idem, n. 6) attire l'attention sur le fait que d'autres économistes, non marxistes, ont vivement critiqué l'utilisation de méthodes économétriques appliquée à des séries historiques concrètes. Parmi ces critiques, J. M. Keynes. 
lyse statistique 236. Ainsi, Mandel 237, qui a rouvert le débat sur les cycles de Kondratieff au milieu des années 1960238 : selon le savant trotskiste, les ondes longues du capitalisme ne sont pas de «simples mouvements de hausse et de baisse du taux de croissance des économies capitalistes », mais « au sens plein du terme, des périodes historiques spécifiques 239 »; le retournement des ondes longues à la hausse et le passage d'un cycle à un autre nécessitent par ailleurs des transformations dans la base économique et dans la superstructure juridique et politique ${ }^{240}$. Ou encore David Gordon, à qui Mandel reproche l'économisme de sa théorie : il voit les ondes longues comme « une succession de structures sociales d'accumulation 241 », la lutte des classes forgeant les conditions institutionnelles de nouvelles expansions lors des crises structurelles. Sur ces critiques, le sociologue de la pénalité fait l'impasse. De même, il fait l'impasse sur la critique de Maddison 242, qui reproche aux théoriciens des cycles longs de confondre modèle et réalité 243 et de minimiser systématiquement - de Kondratieff à Schumpeter, du marxisme au libéralisme - le rôle de ce qu'il appelle l' «institutional-policy mix 244 » dans l'essor et le déclin de chacune des phases du processus de développement du capitalisme ${ }^{245}$.

236. Cf. Louça F., "Ernest Mandel and the Pulsation of History”, in Achcar G. (ed.), The Legacy of Ernest Mandel, Londres, Verso, 1999, p. 116, n. 8 : selon l'auteur, les méthodes économétriques ne permettent pas de prouver l'existence de cycles économiques longs.

237. Ernest Mandel (1923-1995), économiste mondialement reconnu, chef de file de la Capitalist Crisis School (cf. Goldstein J., op. cit., p. 40). Marxiste, trotskiste, il est l'auteur de nombreux livres, parmi lesquels Le Troisième âge du capitalisme, Paris, UGE, 1976 ; Long Waves of Capitalist Development. A Marxist Interpretation, Cambridge, Cambridge University Press/Paris, Éditions de la Maison des Sciences de l'Homme, 1980 [rééd. Londres, Verso, 1995 ; trad. française : Les ondes longues du développement capitaliste. Une interprétation marxiste, Paris, Page Deux, 1998].

238. Sur ce point, $c f$. Goldstein J., op.cit., p. 40, ainsi que Louça F., « Ernest Mandel et la pulsation de l'histoire » (http://www.ernestmandel.org/new/sur-la-vie-et-l-oeuvre/article/ernest-mandel-et-la-pulsation-de-l). Le premier article de Mandel sur le sujet fut publié en 1964 ; il y analyse les textes publiés par Kondratieff en 1922, 1924 et 1926, le débat de Trotsky avec Kondratieff, ainsi que Business Cycles de Schumpeter, publié en 1939.

239. Mandel E., Long Waves of Capitalist Development. A Marxist Interpretation, cité in Louça F., idem.

240. Goldstein J., op. cit., p. 42.

241. Ibid., p. 44. L'auteur se réfère à Gordon D. M., "Up and Down the Long Roller Coaster", in Union for Radical Political Economics (eds.), U.S. Capitalism in Crisis, New York, Union for Radical Political Economics, pp. 22-35 ; Gordon D. M., "Stages of Accumulation and Long Economic Cycles", in Hopkins T., Wallerstein I. (eds), Processes of the World System, Beverly Hills, Sage Publications, 1980, pp. 9-45 ; Gordon D. M., Edwards R., Reich M., Segmented Work, Divided Workers, Cambridge, Cambridge University Press, 1982.

242. Angus Maddison (1926-2010), économiste et historien britannique, spécialiste de macro-économie et de l'histoire du développement du capitalisme. Longtemps directeur-adjoint de la division du développement économique de l'OCDE, il est l'auteur de plusieurs ouvrages, parmi lesquels Maddison A., Les Phases du développement capitaliste, Paris, Economica, 1981 ; Maddison A., op. cit., Oxford/New York, Oxford University Press, 1991.

243. Ibid., en particulier pp. 85-111.

244. Ibid., p. 85.

245. Dès 1981, Maddison distingue quatre phases dans le processus de développement du capitalisme, la quatrième commençant en 1973. Chaque phase est caractérisée au moyen d'un jeu de cinq variables : 1) priorité accordée à l'emploi ou à la stabilité des prix ou à la stabilité du commerce extérieur ; 2) nature du système international de paiement ; 3) comportement du marché du travail ; 4) degré de liberté du commerce international ; 5) degré de liberté des capitaux 
De facto, Dario Melossi réduit dans ces articles l'État à son appareil répressif, l'appareil répressif à ses prisons, et les prisons à la taille de leur population. D'Althusser - qu'il mentionne ${ }^{246}$-, il ne retient ni la volonté de « penser ce que la tradition marxiste désigne sous les termes conjoints d'autonomie relative de la superstructure et d'action en retour de la superstructure sur la base 247 », ni les thèses relatives à l'assujettissement. Résultat : si les cycles longs existent - ce qui est discuté 248 -, leurs effets sont surestimés, tandis que les effets de la structure juridico-politique sont sous-estimés. Trop de nécessité : ainsi que Raymond Michalowski et Susan Carlson l'ont montré aux États-Unis, la corrélation entre le taux de chômage et le taux de détention est « historiquement contingente 249 ». Trop de représentations : pour expliquer qu'ils ne sont pas nécessairement liés, il ne suffit pas d'évoquer les perceptions des «élites morales »; il faut mentionner aussi la succession des «structures sociales d'accumulation $250 »$. Trop peu de biopolitique : les effets de la pro-

et du travail) (pp. 120-121). Les modalités changent d'une phase à l'autre, à la suite de chocs systémiques. La troisième phase (1950-1973) se caractérise selon lui par 1) la priorité donnée au plein emploi ; 2) des taux de change fixes (mais non rigides) à l'échelle internationale, de larges facilités de crédit ; 3) des syndicats puissants, faisant obstacle à la flexibilité des salaires vers le bas ; 4) la libération du commerce par la création d'unions douanières ; 5) la libération progressive des mouvements du travail et du capital. La quatrième phase (1973-...) est caractérisée comme suit : 1) priorité donnée à la stabilité des prix ; 2) effondrement du système financier, puis taux flottants et zones croissantes de stabilité dans le système monétaire mondial ; 3) affaiblissement des syndicats ; 4) maintien de la liberté des échanges commerciaux ; 5) augmentation de la liberté des mouvements du capital, restriction de la liberté des mouvements du travail (Cf. Maddison A., Les Phases du développement capitaliste, op. cit. ; Maddison A., Dynamic Forces in Capitalist Development. A Long-Run Comparative View, op. cit., en particulier pp. 120-121, où l'auteur résume sous forme de tableau les caractéristiques des diverses phases). L'histoire subséquente montre qu'il faut, par restriction légale des mouvements du travail, entendre l'institution de régimes différenciés de mobilité.

246. Cf. Melossi D., "An introduction. Fifty years later", art. cit., p. 319 : «In the 1960 s and early 1970s, Leviathan seemed in fact to be the ideal stand-in for the real culprits in a script that was quite popular at the teime and whose most celebrated model was probably Louis Althusser's famous essay on the State "ideological" and "repressive" apparatuses (1970). Thanks to the artificial man, analysts did not need to reconstruct the causal chain of typical orientations and actions relatif changes in economic indicators to criminal and penal policy decisions and actual rates of imprisonment. They had a Deus ex-machina called "state" descend and take care of it all. » Pour une autre discussion du thème du Léviathan (« en tant qu'homme fabriqué » ou en tant qu'âme) et une présentation des « précautions de méthode » prises dans l'analyse du pouvoir - précautions incluant le déplacement, commun à Althusser et à Foucault, du thème de l'âme du Léviathan à celui de la constitution des sujets - , $c f$. Foucault M., "Il faut défendre la société ". Cours an Collège de France, 1976, Paris, Gallimard/Seuil, 1997, p. 26 et, plus généralement pp. 21-36.

247. Althusser L., «Idéologie et appareils idéologiques d'État (Notes pour une recherche) », La Pensée, 151, juin1970 [rééd. in Althusser L., Positions (1964-1975), Paris, Les éditions sociales, 1976, p. 76].

248. Maddison A., Dynamic Forces in Capitalist Development. A Long-Run Comparative View, op. cit., en particulier pp. 85-111.

249. Cf. Michalowski R. J., Carlson S. M., «Unemployment, imprisonment, and social structures of accumulation: historical contingency in the Rusche-Kirchheimer hypothesis ", Criminology, 37-2, 1999, pp. 217-250. Les auteurs étudient l'effet, aux États-Unis, des transformations des structures sociales d'accumulation (reconfiguration du marché du travail ; stratégies étatiques de gestion du surplus relatif de la population; à l'échelle internationale, rapports entre phases et structures sociales d'accumulation) sur la relation entre chômage et détention.

250. Rose N., "Governing 'advanced' liberal democracies”, in Barry A., Osborne T., Rose N. 
duction, de la reproduction et de la structuration de la population et de la société sont ignorés. Trop peu d'histoire des transformations dans l'infrastructure et la superstructure juridico-politique : Dario Melossi, qui reproche aux tenants de l'explication " politique » leur vision conspiratrice des rapports sociaux, adopte dans les articles étudiés la version la plus conspiratrice de la théorie des paniques morales, le modèle des paniques morales orchestrées par les élites (elite engineered model) 251 . Il ne tue pas le personnage du deus ex machina : il attribue au marché et aux «élites morales »- des magistrats aux médias - le rôle qu'il a retiré à l’État.

À gauche : Foucault, parfois décrit par ses contempteurs comme structuro-fonctionnaliste. Est-il structuraliste ? Tout au plus admet-il, rieur, en avoir été brièvement « l'enfant de chœur 252 », avant de préciser dans un texte ultérieur que le point du débat et le point de résistance sont ailleurs ${ }^{253}$. Dans la philosophie structuraliste, il voit le moyen de "diagnostiquer ce qu'est “aujourd'hui" 254 ». Comme le structuralisme, elle analyse «non pas tellement des choses, des conduites et leur genèse ", mais « des rapports qui régissent un ensemble d'éléments ou un ensemble de conduites »- « des ensembles dans leur équilibre actuel, beaucoup plus que des processus dans leur histoire ». Mais elle ne se limite pas à un domaine scientifique précis, et concerne « l'ensemble des relations pratiques ou théoriques qui définissent notre modernité 255 ». Un philosophe structuraliste « peut être marxiste ou pas, mais il le sera toujours un peu dans la mesure où il se donnera pour tâche de diagnostiquer les conditions de notre existence ». Inversement, un marxiste sera toujours « au moins un peu structuraliste s'il veut avoir entre les mains un instrument rigoureux [...] $256 »$. Après tout, le marxisme pense l'infrastructure et la superstructure comme des structures. Et, suivant Lévi-Strauss, une structure « consiste en éléments tels qu'une modification quelconque de l'un d'eux entraîne une modification de tous les autres 257 ».

Est-il fonctionnaliste ? Comme il est ou n'est pas structuraliste : l'analyse fonctionnelle est entre ses mains un instrument qui permet de diagnostiquer ce qu'est notre présent. Deleuze évoque un «nouveau fonctionnalisme 258 »;

(eds), Foucault and Political Reason. Liberalism, Neo-Liberalism and Rationalities of Government, Chicago, The University of Chicago Press, 1996, pp. 37-64. Il serait utile de préciser les relations entre le concept de «structure sociale d'accumulation ", utilisé par des sociologues marxistes, et le concept de "formule de gouvernement », utilisé par des sociologues foucaldiens.

251. Goode E., Ben Yehuda N., "Moral Panics: Culture, Politics, and Social Construction", Annual Review of Sociology, 20, 1994, pp. 164-165.

252. Foucault M., "La philosophie structuraliste permet de diagnostiquer ce qu'est "aujourd'hui" ", Dits et écrits, I, n 47, Paris, Gallimard, 1994, p. 581.

253. Foucault M., L'Archéologie du savoir, Paris, Gallimard, 1969, p. 263.

254. Foucault M., "La philosophie structuraliste permet de diagnostiquer ce qu'est "aujourd'hui" ", art. cit., p. 580.

255. Ibid., p. 581.

256. Ibid., p. 583.

257. Lévi-Strauss C., Anthropologie structurale, Paris, Plon, 1958, p. 306. 
peut-être faudrait-il parler d'un fonctionnalisme à l'envers, cherchant non pas à améliorer, mais à « enrayer 259 » les fonctionnements. Du fonctionnalisme, Foucault reprend parfois des notions, des questions, des formes de raisonnement 260 ; il lui arrive aussi de chercher l'explication d'un phénomène non pas « du côté de ce qui le précède », mais « du côté de ce qui le suit 261 ». Mais il dit vouloir « retrouver le clivage des affrontements et des luttes que les aménagements fonctionnels ou les organisations systématiques ont pour but [...] de masquer 262 »; il explore les « contenus historiques [...] ensevelis [...] dans des cohérences fonctionnelles »; alors qu'il voit dans le système une «forme majeure d'honnêteté 263 » quand il raisonne en structuraliste, il privilégie dans son fonctionnalisme inversé la localité par rapport à la totalité. Sommairement dit : il garde les outils, mais refuse l'esprit. Au reste, il discute la thèse marxiste de la «fonctionnalité économique du pouvoir » et se demande si l'indissociabilité de l'économie et du politique est de l'ordre de « la subordination fonctionnelle »- on pense à Rusche et Kirchheimer -, de «l'isomorphie formelle » - on pense à Pashukanis -, ou d'un autre ordre encore, qu'il faudrait dégager 264 .

De manière générale, le propos n'est pas tant d'expliquer que de diagnostiquer et d'armer la critique. L'enjeu est pratique : « [...] contribuer à ce que certaines choses changent dans les façons de percevoir et les manières de faire, prendre part à ce difficile déplacement des formes de sensibilité et des seuils de tolérance $[\ldots]^{265}$ ». L'exercice est théorique : il se demande « dans quelle mesure le travail de penser sa propre histoire peut affranchir la pensée de ce qu'elle pense silencieusement et lui permettre de penser autrement 266 ». Le temps est investi comme un objet: Foucault ne fait pas siennes les notions de

258. Deleuze G., op. cit., p. 33.

259. Sur ce point, cf. Foucault M., "Il faut défendre la société ». Cours au Collège de France, 1976, op. cit., p. 6.

260. Foucault M., Surveiller et punir, op. cit., p. 276. De manière critique, Garland D., "Frameworks of Inquiry in the Sociology of Punishment", art. cit., p. 4, où l'auteur écrit qu'une limite évidente de l'œuvre de Foucault est le « fonctionnalisme dogmatique » auquel il soucrirait ; Garland D., Punishment and Modern Society. A Study in Social Theory, Oxford, Clarendon Press, 1990, p. 5.

261. Foucault M., «La poussière et le nuage », Dits et écrits, IV, n² 277, Paris, Gallimard, 1994, p. 12.

262. Ibid., p. 8 .

263. Foucault M., « La philosophie structuraliste permet de diagnostiquer ce qu'est “aujourd'hui”", art. cit., p. 580.

264. Foucault M., "Il faut défendre la société ». Cours au Collège de France, 1976, op. cit., pp. 1415.

265. Cf. Foucault M., « Table ronde du 20 mai 1978 », Dits et écrits, $I V, \mathrm{n}^{\circ}$ 278, Paris, Gallimard, 1994, pp. 30-31 : « [...] Mon projet, lui, est loin d'avoir une telle envergure. Aider d'une certaine manière à ce que s'écaillent quelques “évidences”, ou "lieux communs” [...], faire en sorte, avec bien d'autres, que certaines phrases ne puissent plus être dites aussi facilement ou que certains gestes ne soient plus faits au moins sans quelque hésitation, contribuer à ce que certaines choses changent dans les façons de percevoir et les manières de faire, prendre part à ce difficile déplacement des formes de sensibilité et des seuils de tolérance [...] ». Et le philosophe poursuit : «Si seulement ce que j'ai essayé de dire pouvait, d'une certaine façon, et pour une part limitée, n'être pas entièrement étranger à quelques-uns de ces effets dans le réel... »

266. Foucault M., L'Usage des plaisirs. Histoire de la sexualité (2), Paris, Gallimard, 1984, p. 15. 
cycle économique ou politique ; il étudie les conceptions du temps présupposées par divers arts de gouverner et jeux de vérité ${ }^{267}$. C'est aussi une arme : là où « on serait assez tenté de se référer à une constante historique ou à un trait anthropologique immédiat », le philosophe "événementialise 268 ", donnant à voir singularités et «bibelots politiques d'époque 269 »; pour souligner la nonnécessité, il ajoute l'histoire du présent à l'archéologie (à « l'anarchéologie 270 », dit-il en 1980) ; pour que s’écaillent les évidences, il écrit des généalogies. En retrait : Althusser, écrivant que « la philosophie n’intervient dans la réalité qu'en produisant des effets en elle-même ${ }^{271}$ ». C'est abstrait ? Pour illustrer, il suffit de songer à l'historicité - à la non-nécessité - du couplage de la citoyenneté et de la nationalité.

De son propre aveu, Foucault « ne [s']intéresse pas beaucoup [aux] dénonciations faciles du discours [...] oppressif, idéologique » : ce qui « [lui] semble intéressant », c'est la «pensée dense, importante » qui sert de « support, de condition d'existence et aussi de condition de fonctionnement » aux pratiques ${ }^{272}$. À la notion d'idéologie dominante, il fait trois objections : elle postule « une théorie mal faite, ou [...] pas faite du tout de la représentation »; elle est « indexée, au moins implicitement [...] à une opposition du vrai et du faux, de la réalité et de l'illusion, du scientifique et du non-scientifique, du rationnel et de l'irrationnel »; et elle fait « l'impasse sur tous les mécanismes réels d'assujettissement ». La notion de pouvoir permet de déplacer l'attention du système de représentations dominantes vers les procédures et les techniques par lesquelles les relations de pouvoir «s'effectuent effectivement »; celle de savoir a pour fonction de « mettre hors champ l'opposition du scientifique et du non-scientifique, la question de l'illusion et de la réalité, la question du vrai et du faux 273 ». L’hégémonie est définie - équivoquement comme le fait de «se trouver en tête des autres, de les conduire et de conduire en quelque sorte leur conduite "; elle ne va pas sans alêthurgie, c'est-à-dire sans quelque rituel de production du vrai 274 .

267. Cf. Foucault M., Mal faire, dire vrai. Fonction de l'aven en justice, op. cit., p. 74, n.3.

268. Foucault M., «Table ronde du 20 mai 1978 », art. cit., p. 23.

269. Veyne P., «Foucault révolutionne l'histoire », art. cit., p. 389.

270. Foucault M., Du gouvernement des vivants. Cours au Collège de France, 1979-1980, op. cit., p. 77.

271. Cf. Althusser L., Philosophie et philosophie spontanée des savants, Paris, Maspero, 1974, p. 64. Je suis ici l'analyse de Warren Montag (Montag W., art. cit., pp. 57-58).

272. Foucault insiste, à Louvain-la-Neuve, sur le fait que « la pensée ne pense pas seulement là où elle se pense elle-même, dans la forme de la philosophie ou de la réflexion sur soi ». «Dans une institution psychiatrique, il y a, dit-il, une pensée qu'il faut rechercher »; de même, il y a «de la pensée dans une prison, aussi bête que soit la prison » (Foucault M., "Entretien de Michel Foucault avec Jean François et John De Wit (22 mai 1981) ", Mal faire, dire vrai. Fonction de l'aveu en justice, op. cit., p. 250).

273. Foucault M., Du gouvernement des vivants. Cours au Collège de France (1979-1980), op. cit., pp. 12-13.

274. Ibid., p. 8 . 
Comment le pouvoir s'exerce-t-il ? La réponse à cette question prend communément la forme d'une alternative, violence ou idéologie : «tantôt il réprimerait, tantôt il tromperait ou ferait croire 275 ». Réponse réductrice, selon Foucault 276. De la répression et de l'idéologie, écrit Deleuze, il «n'ignore rien [...] ; mais, comme Nietzsche l'avait déjà vu, elles sont seulement la poussière soulevée par le combat 277 ». Les procédures et les techniques par lesquelles les relations de pouvoir s'effectuent effectivement » sont plus variées ; par ailleurs, elles ne sont pas extérieures aux rapports de production (elles ne leur sont ni surimposées ni superposées) 278. "Un pouvoir, commente Deleuze, ne procède pas par idéologie, même quand il porte sur les âmes ; il n'opère pas nécessairement par violence et répression, au moment où il pèse sur les corps 279 ». Ainsi la discipline procède-t-elle par répartition des corps, organisation des genèses, composition des forces 280 . La biopolitique agence, dispose, façonne, structure, configure, aménage des probabilités. Quant aux savoirs technologique et d'observation qui leur sont associés : les connaissances présentées sont parfois faussées ; mais, plus encore que la production du faux, c'est la production du vrai qui assure aux relations de pouvoir leur effectivité.

Dès l'Introduction à l'anthropologie, le philosophe a établi une équivalence entre les «synthèses de la vérité » et « la constitution du nécessaire dans le domaine de l'expérience 281 ». Produire du vrai, ce serait, à travers divers jeux de vérité, produire ces synthèses et ces nécessités ; lier, "d'une manière non pas analytique, mais synthétique ", les êtres humains à ce qui est donné - constitué et présenté - comme leur essence. Des exemples ? La prison et le dispositif carcéral lient synthétiquement certains infracteurs à leur infraction en ajoutant à la prévention ou à la condamnation ce supplément d'essence qu'est la délinquance : «synthèse de la vérité ». La discipline et la biopolitique lient synthétiquement les hommes à l'appareil de production pour lequel ils travaillent, mais aussi au travail donné comme leur essence 282 : "synthèse de la vérité ». La toute première "synthèse de la vérité » produite par la science (cette " alêthurgie » définie par Foucault comme « la production du vrai dans les consciences des individus par des procédés logico-expérimentaux $283 »$ ) est que l'essence des individus qui s'en font les sujets est l'objectivité - fiction qui

275. Deleuze G., op. cit., p. 36.

276. Il en va de même d'Althusser, contrairement à ce qu'une lecture trop rapide d'Idéologie et appareils idéologiques d'État pourrait suggérer. Sur ce point, $c f$. Montag W., art. cit., en particulier pp. 69-74.

277. Idem.

278. Foucault M., « La vérité et les formes juridiques », art. cit., p. 623.

279. Deleuze G., op. cit., p. 36.

280. Sur ce point, $c f$. Foucault M., Surveiller et punir, op. cit., pp. 137-171.

281. Sur ce point, cf. Foucault M., Introduction à l'Antbropologie, Paris, Vrin, 2008, p. 65.

282. Foucault M., "La vérité et les formes juridiques ", art. cit., pp. 621-622 : "Ce que j'aimerais montrer, c'est que le travail n'est absolument pas l'essence concrète de l'homme [...]. La liaison de l'homme au travail est synthétique, politique ».

283. Foucault M., Du gouvernement des vivants. Cours au Collège de France (1979-1980), op. cit., pp. 8-9. 
les dote de pouvoirs considérables, et les habilite à produire, d'autorité, d'autres «synthèses de la vérité ». Théoriquement, la question soulevée est celle du "gouvernement par la vérité 284 ». Pratiquement, dès lors que la vérité est synthétique, c'est celle de savoir comment - au moyen de quelle analytique de la vérité - armer la lutte : car, dit le philosophe, il est possible de détruire politiquement ce qui a été historiquement constitué 285 .

\section{Fragment 5. Stratégie et tragédie}

Ultime reprise. Au «constat que la prison échoue à réduire les crimes », Foucault proposait en 1975 de substituer l'hypothèse qu'elle a « fort bien réussi à produire la délinquance, type spécifié, forme politiquement ou économiquement moins dangereuse - à la limite utilisable - d'illégalisme ; à produire les délinquants, milieu apparemment marginalisé mais centralement contrôlé ; à produire le délinquant comme sujet pathologisé 286 ». Quelle hypothèse faut-il substituer aujourd'hui au constat que, de surcroît, la lutte contre la surpopulation carcérale échoue à réduire le nombre de détenus ? Elle a accrédité l'idée que la prison est inhumaine et dégradante du seul fait de la surpopulation et de ses effets sur les conditions de détention; elle a réussi à transformer le système et le régime des peines, les usages de la prison, et sa population. Le " grand renfermement» des étrangers soulève plusieurs questions. Au niveau idéologique de la superstructure, dans « la forme sociale de conscience » qui est la nôtre : la question des relations entre l'ethnicité et la délinquance. Au niveau juridico-politique : celle des mécanismes et des processus contribuant à la croissance des taux de détention des individus ayant la nationalité d'un État qui n'est pas membre de l'Union. Plus généralement : celle de ses relations avec l'infrastructure et de ses fonctions.

284. Ibid., pp. 12-13 ; Foucault continue d'élaborer la notion de gouvernement par la vérité dans Foucault M., Mal faire, dire vrai. Fonction de l'aven en justice, op. cit., p. 13.

285. Cf. sur ce point Foucault M., "Entretien de Michel Foucault avec André Berten (7 mai 1981) », ibid., p. 243 : «Il s'agit donc de rendre les choses plus fragiles par cette analyse historique ou plutôt, de montrer à la fois pourquoi et comment les choses ont pu se constituer ainsi, mais [de] montrer en même temps qu'elles se sont constituées à travers une histoire précise. Il faut donc montrer et la logique des stratégies à l'intérieur desquelles les choses se sont produites, et montrer que ce ne sont pourtant que des stratégies et que, du coup, en changeant un certain nombre de choses, en changeant de stratégie, en prenant les choses autrement, du coup, ce qui nous paraissait évident ne l'est pas. Notre rapport à la folie, c'est un rapport qui est historiquement constitué. Et du moment qu'il est historiquement constitué, il peut être politiquement détruit - je dis "politiquement" en donnant au mot "politique" un sens très large. En tout cas, il y a des possibilités d'action, puisque c'est à travers un certain nombre d'actions, de réactions, à travers un certain nombre de luttes, de conflits, pour répondre à un certain nombre de problèmes, qu'on a choisi ces solutions-là. J'ai voulu réintégrer beaucoup des évidences de notre pratique dans l'historicité même de ces pratiques. Et du coup, les déchoir de leur statut d'évidence pour leur redonner la mobilité qu'elles ont eue et qu'elles doivent toujours avoir dans le champ de nos pratiques. ».

286. Foucault M., Surveiller et punir, op. cit., p. 282. 
Dans Idéologie et appareils idéologiques d'État, Althusser pose que l'idéologie est immanente aux appareils, rituels, pratiques et actes dans lesquels elle existe ${ }^{287}$; selon Warren Montag, les idées sont « en ce sens, des causes qui ne peuvent jamais être constituées qu'après-coup, nachträglich, comme un effet de leurs effets matériels 288 ». De la même façon, la délinquance est, suivant Foucault, immanente à la prison : elle est ce qui, après-coup, est donné comme la cause et la justification de ce dont elle est l'effet, la pénalité de détention; ce que nous attribuons, non pas à tout auteur d'infraction, mais à tout individu qui est ou a été détenu en prison ; ce qu'en quelque sorte, nous devons lui attribuer pour y voir une solution et pouvoir la supporter (et nous supporter, par la même occasion). Et la « criminalité des immigrés » ? Elle est immanente au « grand renfermement» des étrangers. L'ethnicité, quant à elle, est ce que nous supposons pour expliquer et justifier la surreprésentation des étrangers en prison, et fonder en réalité et en nécessité la sélectivité dont elle est l'effet.

$\mathrm{Au}$ risque d'insister : le taux de détention des nationaux est stable, quand bien même le nombre et la proportion de Belges d'origine étrangère dans la population recensée ne cessent d'angmenter; à l'inverse, le taux de détention des étrangers ne cesse d'angmenter, quand bien même le nombre et la proportion des étrangers dans la population recensée tendent à diminuer 289 , y compris s'agissant des nationalités les plus représentées parmi les prisonniers ${ }^{290}$. Si la cause de la surreprésentation des étrangers en prison était leur origine, ou leur culture, ou leur religion, leur inclusion dans la population nationale devrait entraîner une augmentation du taux de détention des nationaux. Ce n'est pas le cas : l'ethnicité n'est, en l'occurrence, que le nom donné à l'un des systèmes de détermination par lesquels des infracteurs sont liés à leur infraction. Là encore, il s'agit d'une « cause absente qui n'existe que dans ses effets 291 »; là

287. Althusser précise que, s'agissant d'idéologie, être spinoziste ou marxiste, c'est « exactement la même position ». Selon Warren Montag, il reprend d'ailleurs à Spinoza la stratégie du sive «Deus, sive Natura » (Dieu, c'est-à-dire la Nature) - se transformant en « l'idéologie, c'est-àdire les appareils, rituels, pratiques et actes dans lesquels elle existe... »). Cf. Alhtusser L., "Idéologie et appareils idéologiques d'État. Notes pour une recherche ", art. cit. ; Montag W., art. cit., p. 63.

288. Ibid. La référence à Freud, précise Warren Montag, est « entièrement en phase avec Spinoza et Althusser ».

289. Le nombre de Belges d'origine marocaine est passé de 151265 en 1991 à 279694 en 2010. Le nombre de Marocains, quant à lui, est passé de 142098 en 1991 à 81943 en 2010. Le nombre de détenus marocains est passé de 740 en 1991 (population en fin d'année) à 1132 en 2010 (population journalière moyenne). L'augmentation du taux de détention des Marocains s'explique et par l'augmentation du nombre de détenus marocains, au numérateur, et par la diminution du nombre d'habitants, au dénominateur.

290. Ainsi les Marocains : au 1er janvier 2013, ils représentaient 28,5\% des étrangers non européens en Belgique. Sous l'effet des réformes du droit de la nationalité, leur nombre a diminué de $47 \%$ depuis 1992 (année de son maximum historique), malgré un solde migratoire positif (cf. Vause S., Eggerickx T., Dal L., Migrations et populations issues de l'immigration en Belgique, LLN/Bruxelles, UCL/Demo/CECLR, 2013, pp. 103 et 140 (http://www.diversite.be/sites/default/files/documents/publication/rapport_statistique_et_ demographique.pdf, consulté le 25 avril 2014).

291. Idem. La référence à Freud, précise Warren Montag, est « entièrement en phase avec Spinoza et Althusser». 
encore, cette cause est constituée après coup, comme un effet des effets matériels produits par les appareils, les rituels, les pratiques et les actes dans lesquels elle existe.

Ensemble, la délinquance et l'ethnicité participent à la construction d'une nouvelle classe dangereuse. La délinquance élargit la suspicion à l'ensemble de la classe sociale où les détenus sont prélevés. L'ethnicité l'étend à l'ensemble des groupes ou des communautés auxquels les détenus étrangers sont renvoyés, que leurs membres soient étrangers, binationaux ou nationaux d'origine étrangère ; en termes goffmaniens ${ }^{292}$, elle diffuse les effets du stigmate pénal à l'ensemble des membres du groupe affecté d'un stigmate tribal ${ }^{293}$, comme le faisait la dégénérescence au tournant des XIX et $\mathrm{XX}^{\mathrm{e}}$ siècles, quand le groupe tribalisé 294 était défini en termes de classe, et non en termes de nationalité, d'origine nationale ou de défaut de laïcité. Cette extension produit, le cas échéant, des effets d'identification, au sens policier comme au sens psychanalytique du terme, tant il est vrai, comme Althusser l'écrivait (mais aussi Genêt), que ce qui constitue un individu en sujet est une interpellation dans laquelle il se reconnaît.

Certes, à côté de la lutte contre la surpopulation carcérale et du « grand renfermement » des étrangers, d'autres mécanismes et processus contribuent à produire et à reproduire l'appartenance entre nationalités tierces et délinquance. La famille $\mathrm{R}$ 'ha compte un fils qui a été déchu de la nationalité belge. De nombreuses familles issues de l'immigration comptent un fils qui n'a pas pu l'acquérir en raison de ses antécédents judiciaires : tous leurs membres appartiennent à la population nationale, à l'exception de celui qui, « délinquant ", appartient à la population étrangère. Ce n'est pas tout. Selon Foucault, « si les châtiments légaux sont faits pour sanctionner les infractions, [...] la définition des infractions et leur poursuite sont faites en retour pour entretenir les mécanismes punitifs et leurs fonctions 295 ». Au tournant des $\mathrm{XIX}^{\mathrm{e}}$ et XX $\mathrm{XX}^{\mathrm{e}}$ siècles - au passage de la formule libérale à la formule (nationale et) sociale -, plusieurs lois ont étendu la répression au-delà du droit pénal classique, et organisant enfermement ante delictum des vagabonds et surveillance des classes réputées dangereuses au prétexte de «défendre la société 296 ». Au

292. Goffman E., Stigma. Notes on the management of spoiled identity, New York, Simon \& Schuster, 1986 [1963], p. 3. «Le terme stigmate, écrit le sociologue, est utilisé pour désigner un attribut profondément discréditant; il faut bien voir, toutefois, que c'est en termes de relations, et non d'attributs, qu'il convient en réalité de parle. »

293. Cf. Brion F., « Les menaces d'une forteresse. Citoyenneté, crime et discrimination dans la construction de l'Union européenne ", art. cit., pp. 268-269.

294. Brion F., «Pour une éthique de l'action interculturelle. Blessures morales et attentes de reconnaissance ", in Larouche J.-M. (ed.), Reconnaissance et citoyenneté. Au carrefour de l'éthique et du politique, Québec, Presses universitaires de Québec, 2003, pp. 111-131.

295. Foucault M., Surveiller et punir, op. cit., p. 29.

296. Tulkens F., Digneffe F., "La notion de dangerosité dans la politique criminelle en Europe occidentale », in Debuyst C. (ed.), Dangerosité et justice pénale. Ambiguïté d'une pratique, Genève, Médecine et Hygiène, pp. 191-207 ; Tulkens F. (ed.), Généalogie de la défense sociale 
tournant des $\mathrm{XX}^{\mathrm{e}}$ et $\mathrm{XXI}^{\mathrm{e}}$ siècles - au passage de la formule sociale à la formule néolibérale -, d'autres lois ont élargi les possibilités de surveiller, enfermer ou éloigner les ressortissants des pays tiers au nom de la nécessité de défendre la société européenne ${ }^{297}$.

Le traité signé à Maastricht le 7 février 1992 n’institue pas seulement une citoyenneté européenne ; à l'article K.I. du titre VI, il définit aussi les dangers qui menacent l'Europe, et ses ennemis ${ }^{298}$. Toute la politique migratoire tombe dans les questions d'intérêt commun : les conditions d'entrée et de circulation des ressortissants des pays tiers ; les conditions de leur séjour, y compris le regroupement familial et l'accès a l'emploi ; la lutte contre l'immigration, le séjour et le travail irréguliers sur le territoire des États membres. D'intérêt commun de même, la coopération en vue de la prévention et de la lutte contre le terrorisme, le trafic illicite de drogue et d'autres formes graves de criminalité internationale. Dans l'ordre juridique étatique, diverses lois ont inséré des dispositions créant de nouvelles infractions dans le Code pénal ou la loi du 15 décembre 1980 sur l'accès au territoire, le séjour, l'établissement et l'éloignement des étrangers : en 1995 et en 2005, les articles relatifs à la traite et au trafic des êtres humains 299 ; en 1999 et en 2005, les dispositions relatives aux organisations criminelles 300 ; en 2007 et en 2013, les dispositions sur le

en Belgique (1880-1914). Actes du séminaire de recherche dirigé par Michel Foucault à l'Université catholique de Louvain, Bruxelles, Story-Scientia, 1988.

297. Sur ce point, $c f$. Enriquez E., «Tolérance à l'altérité et problèmes de la démocratie dans la construction de la CE ", in Mappa S. (ed.), Les Deux sources de l'exclusion. Économisme et replis identitaires, Paris, Karthala, 1993, pp. 59-83; selon cet auteur, «le socle de l'unité européenne reste l'homogénéisation par l'argent comme l'homogénéisation par la guerre » (p. 78).

298. Sur ce point, $c f$. Brion F., «Les menaces d'une forteresse. Citoyenneté, crime et discrimination dans la construction de l'Union européenne ", art. cit., pp. 327-335.

299. La loi du 13 avril 1995 a introduit dans la loi du 15 décembre 1980 sur l'accès au territoire, le séjour, l'établissement et l'éloignement des étrangers un article 77bis sur la traite des êtres humains. La loi du 10 août 2005 modifiant diverses dispositions en vue de renforcer la lutte contre la traite et le trafic des êtres humains et contre les pratiques des marchands de sommeil, et transposant en droit belge la décision-cadre de l'Union européenne du 19 juillet 2002 relative à la lutte contre la traite des êtres humains, la directive 2002/90/CE du Conseil de l'Union européenne définissant l'aide à l'entrée, au transit et au séjour irrégulier ainsi que la décisioncadre du Conseil de l'Union européenne du 28 novembre 2002 visant à renforcer le cadre pénal pour la répression de l'aide à l'entrée, au transit et au séjour irréguliers a transformé le dispositif. Elle insère dans le code pénal un chapitre IIIter relatif à la traite. Dans la loi du 15 décembre 1980, elle insère plusieurs articles relatifs au trafic des êtres humains, défini comme « le fait de contribuer, de quelque manière que ce soit, soit directement, soit par un intermédiaire, à permettre l'entrée, le transit ou le séjour d'une personne non ressortissante d'un État membre de l'Union européenne sur ou par le territoire d'un tel État [...] en violation de la législation de cet État, en vue d'obtenir, directement ou indirectement, un avantage patrimonial ». Plusieurs affaires de mariages de complaisance ont été qualifiées de trafic d'êtres humains (cf. CECLR, La traite et le trafic des êtres humains. Rapport annuel 2010, Bruxelles, CECLR, pp. 78-79).

300. Cf. les dispositions insérées dans le Code pénal par la loi du 10 janvier 1999 sur les organisations criminelles et par la loi du 10 août 2005 modifiant diverses dispositions en vue de renforcer la lutte contre la traite et le trafic des êtres humains et contre les pratiques des marchands de sommeil ; parmi les dispositions insérées, voir notamment l'article 324ter, aux termes duquel la personne qui, sciemment et volontairement, fait partie d'une organisation criminelle, peut être punie d'un emprisonnement d'un an à trois ans, même si elle n'a pas l'intention de commettre une infraction dans le cadre de cette organisation ni de s'y associer. 
mariage forcé ${ }^{301}$, la cohabitation légale forcée, ou le mariage et la cohabitation légale de complaisance ${ }^{302}$. Nombre de ces infractions sont visées à l'article 23/1 sur la déchéance de la nationalité inséré dans le Code de la nationalité en 2012.

Quelles sont les fonctions de la prison, de la lutte contre la surpopulation, $\mathrm{du}$ « grand renfermement » des étrangers et de la criminalisation de l'immigration ? Selon Maddison, la quatrième phase du processus de développement du capitalisme se caractérise notamment par le maintien de la liberté des échanges commerciaux, l'augmentation de la liberté de circulation des capitaux et la restriction de la liberté de circulation des travailleurs ; l'auteur mentionne aussi l'affaiblissement des syndicats ${ }^{303}$. Selon Michel Husson, économiste marxiste que ses travaux sur les ondes longues rattachent à l'école de la crise du capitalisme (Capitalist Crisis School), quatre «faits stylisés » caractérisent le capitalisme dans sa phase néolibérale : stagnation du taux d'accumulation, hausse du taux de profit, baisse de la part des salaires, augmentation de la part des dividendes ${ }^{304}$. Si plusieurs économistes marxistes ont contesté la hausse du taux de profit ${ }^{305}$, il semble que l'augmentation de la productivité par la réduction de la part des salaires ne fait pas débat. Selon David Neilson et Thomas Stubbs ${ }^{306}$, la compétition globale des firmes, des États et des forces de travail propre au modèle néolibéral de développement a nivelé les normes de productivité par le haut et la rémunération du travail peu qualifié par le bas.

Le « grand renfermement » des étrangers réussit-il - question funeste - à «siphonner » efficacement les individus « redondants »? C'est douteux, tant les effectifs de l'armée de réserve des travailleurs sont désormais nombreux :

301. Cf. la loi du 25 avril 2007 insérant un article 391sexies dans le Code pénal et modifiant certaines dispositions du Code civil en vue d'incriminer et d'élargir les moyens d'annuler le mariage forcé (Moniteur belge, 15 juin 2007, p. 32654).

302. Cf. la loi du 2 juin 2013 modifiant le Code civil, la loi du 31 décembre 1851 sur les consulats et la juridiction consulaire, le Code pénal, le Code judiciaire et la loi du 15 décembre 1980 sur l'accès au territoire, le séjour, l'établissement et l'éloignement des étrangers, en vue de la lutte contre les mariages de complaisance et les cohabitations légales de complaisance (Moniteur belge, 23 septembre 2013, p. 67119).

303. Maddison A., Dynamic Forces in Capitalist Development. A Long-Run Comparative View, op. cit., en particulier pp. 120-121.

304. Cf. Husson M., "Le débat sur le taux de profit », site internet du Nouveau parti anticapitaliste (NPA), 9 juin 2010 (http://www.npa2009.org/content/le-debat-sur-le-taux-de-profitpar-michel-husson, consulté le 3 avril 2014). Michel Husson est économiste et statisticien à l'institut de recherches économiques et sociales (IRES). Créé en 1982 par l'ensemble des organisations syndicales représentatives avec l'appui du gouvernement français, l'Institut a pour fonction de répondre aux besoins exprimés par les organisations syndicales représentatives dans le domaine de la recherche économique et sociale.

305. Cf. sur ce point l'analyse de Louis Gill, économiste, professeur émérite à l'Univeristé de Québec à Montréal, ainsi que la littérature qu'il passe en revue, in Gill L., " Les faux-pas d'Alain Bihr, les dérives de Michel Husson ", Carré ronge, 43, mars 2010, pp. 51-66 (http://classiques.uqac.ca/contemporains/gill_louis/faux_pas_alain_bihr/faux_pas_alain_bih r.pdf, consulté le 3 avril 2014).

306. Neilson D., Stubbs T., "Relative surplus population and uneven development in the neoliberal era. Theory and empirical application », Capital E Class, 35-3, 2011, p. 438. 
en 2012, l'Office national de l'emploi (ONEM) recensait en moyenne mensuelle 417250 chômeurs complets indemnisés demandeurs d'emploi 307 ; la même année, la population journalière moyenne des établissements pénitentiaires s'établissait à 11300 détenus, dont quelque 3300 étrangers sans titre de séjour, "prélevés » dans une population qui n'est pas celle des chômeurs indemnisés ${ }^{308}$. Certes, d'autres mécanismes ont été branchés sur les prisons et sur les centres fermés : éloignements, transfèrements, déchéances de la nationalité ; mais, à première vue, il semble que la fonction du dispositif n'est pas de «drainer » - tout au plus de procéder à une forme de « neutralisation sélective».

Réussit-il à dissuader des étrangers d'immigrer ? Non plus. Selon David Neilson et Thomas Stubbs ${ }^{309}$, le modèle néolibéral de développement met en concurrence des pays où le capitalisme est inégalement développé, générant chômage dans les pays d'ancienne industrialisation et prolétarisation dans les pays en voie d'industrialisation. Le rapport entre surplus relatif de la population et « armée active des travailleurs 310 » varie en fonction inverse du niveau de développement ; de même, le pourcentage de travailleurs en situation de précarité ${ }^{311}$. La «brutale tectonique de la globalisation néolibérale 312 » a jeté sur les routes de l'exil des milliers d'hommes, de femmes et d'enfants que le risque de mourir durant leur voyage n'a pas arrêtés 313 : penser que le risque pénal peut le faire est, au mieux, de la naïveté.

La restriction de la liberté de circulation des travailleurs réussit-elle à arrêter l'immigration ? Non. À la canaliser ? D’une étrange façon. La fermeture du canal principal a occasionné le surinvestissement des canaux restés ouverts ainsi que le développement d'autres canaux ou d'autres «filières ». Comme chaque fois que des biens ou des services sont interdits alors qu'ils font l'objet d'une demande peu élastique, la prohibition a favorisé l'essor de marchés cri-

307. SPF Emploi, Travail et Concertation sociale, "L’ONEM publie son rapport annuel ", Actualités, 25 mars 2013,(http://www.emploi.belgique.be/defaultNews.aspx?id=38637, consulté le 30 avril 2014).

308. SPF Justice, DG EPI, Rapport d'activités 2012, p. 104 (http://justice.belgium.be/fr/binaries/jaarverslag\%20fr_spread_tcm421-225154.pdf, consulté le 30 avril 2014).

309. Neilson D., Stubbs T., "Relative surplus population and uneven development in the neoliberal era. Theory and empirical application”, art. cit., pp. 435-453.

310. Il est égal à 1,3 en Allemagne et en Grande-Bretagne, à 4 en Turquie et à 5,3 au Maroc (Ibid., p. 446).

311. 13,3 \% en Grande-Bretagne, 6,9\% en Allemagne, 21,4 \% en Turquie et 30,9\% au Maroc (Idem).

312. Davis, M., "Planet of Slums. Urban Involution and the Informal Proletariat", New Left Review, 26, 2004, p. 23. Selon David Neilson et Thomas Stubbs, le capitalisme mondialisé a généralisé la compétition des entreprises, des États et des forces de travail ; la globalisation met en concurrence des phases différentes du processus de développement du capitalisme, concurrence qui accentue encore les inégalités. Le rapport entre le surplus relatif de la population et l' " armée active » des travailleurs varie en fonction du niveau de développement, de même que la part des individus «surnuméraires » exerçant un travail à titre précaire.

313. Laacher S., « Éléments pour une sociologie de l'exil », Politix, 69, mars 2005, pp. 101-128. 
minels et le développement d'organisations criminelles spécialisées dans l'offre des biens et des services interdits. Elle a stimulé le détournement d'institutions telles que l'asile, le mariage, la cohabitation légale ou l'adoption. Elle a, autrement dit, contribué à faire exister une partie des dangers contre lesquels, dès 1992, les gouvernements des États parties au traité instituant l'Union avaient anticipé qu'ils devraient lutter, et définis par les dispositions sur la coopération dans les domaines de la justice et des affaires intérieures du traité instituant l'Union.

La prison « échoue à réduire les crimes 314 », la lutte contre la surpopulation carcérale échoue à réduire le nombre de détenus, le grand renfermement des étrangers échoue à réduire le nombre de chômeurs, la criminalisation de l'immigration échoue à réduire le nombre de migrants. Ne faut-il pas, à ces constats d'échec, substituer l'hypothèse qu'ils réussissent fort bien à faire, du temps et du corps de certains hommes, quelque chose qui n'est plus que du temps et de la force de travail, et de leur vie quelque chose qui n'est plus qu'une «vie nue 315 »; à compenser la redéfinition des conditions d'attribution et d'acquisition de la nationalité et l'extension de la citoyenneté à tous les ressortissants des États membres de l'Union ; à intriquer «l'opération politique qui dissocie les illégalismes et en isole la délinquance 316 » à celle qui constitue la société en divisant la population; à donner à cette opération la légitimité du tri séparant le bon grain de l'ivraie ; à substituer à la division du demos en un peuple-sujet des lois et un peuple-objet des lois sa division en un peuple-dans la loi et un peuple-hors la loi, et à la stratification du marché du travail par la nationalité sa stratification par la légalité ou l'illégalité, les deux marchés du travail ainsi constitués étant l'un à l'autre solidement arrimés ?

En 1976, Sellin montrait dans Slavery and the Penal System comment, après l'abolition de l'esclavage aux États-Unis, le système pénal avait permis de reconstituer en moins d'une décennie la force de travail requise par l'économie esclavagiste des États du Sud, substituant une forme pénale de réduction en esclavage à celle qui venait d'être abolie, forme plus meurtrière encore puisqu'il suffisait de faire tourner la machine pénale pour remplacer les condamnés morts au travail ${ }^{317}$. Différence par rapport à l'analyse sellinienne : la fonction assignée au système pénal fut en l'occurrence d'assurer la pérennité du mode de production esclavagiste ; elle serait aujourd'hui d'assurer celle du mode de production capitaliste, et d'opérer les reconfigurations de la

314. Foucault M., Surveiller et punir, op. cit., p. 282.

315. Agamben G., Homo sacer. Le pouvoir souverain et la vie nue, Paris, Seuil, 2008.

316. Idem.

317. Sellin J. T., Slavery and the Penal System, op. cit., en particulier pp. 145-162 (« The Convict Lease System ») et pp. 163-176 ("Chain Gangs and Prison Farms »); pour le statut et les châtiments des esclaves avant l'abolition de l'escavage et la guerre de sécession, pp. 133-144 («The Antebellum South»); Brion F., Sociologie de la pénalité, op. cit. En Caroline du Sud, durant le dernier quart du XIXe siècle, la durée moyenne de survie des individus réduits en esclavage pénal était en moyenne de deux ans. 
population requises par le passage de la formule sociale à la formule néolibérale de gouvernement. Aux «immigrés », dont la condition était de convenir ou de contrevenir, la prison, la lutte contre la surpopulation des prisons, le " grand renfermement » des étrangers et la criminalisation de l'immigration substituent des individus qui, « illégaux » ou « délinquants », ne conviennent qu'en tant qu'ils contreviennent.

David Garland reproche à la « conception foucaldienne des institutions pénales » d'être « indûment instrumentale et intentionnelle, ou pour utiliser [les] mots [de Foucault], indûment "stratégique" ». Surveiller et punir aurait donné naissance à une sociologie qui soit « écarte les aspects de la pénalité qui ne sont pas utilitaristes (utilitarian) ou fonctionnels », soit les rapporte pour en rendre raison à « des fonctions latentes ou à des utilités cachées, c'est-à-dire à des objectifs qu'aucune agence ne pourrait prendre en compte ou délibérément viser »; qui ignore la passion ou la déraison où Durkheim voyait l'âme de la peine, et se focalise sur la rationalité des stratégies pénales ; qui, à l'instar de Foucault, surestime leur « utilité politique positive » et est incapable de reconnaître leurs « aspects tragiques » 318 .

Faut-il le préciser ? En aucune façon, le concept de fonction ne se confond pas avec les notions d'objectif ou d'intention. Le structuro-fonctionnalisme (si tel est son nom) recherche les processus et les mécanismes de production de faits qu'il voit comme des effets, avant de se demander quels besoins ils satisfont ${ }^{319}$. Poser que l' «illégalité » et la «criminalité des immigrés »sont dans la formule néolibérale de gouvernement des équivalents fonctionnels de la nationalité dans la formule sociale, ce n'est pas poser que c'est là ce que veulent les agents du système pénal. C’est observer que le dispositif qui relègue une partie de la population à des formes de travail irrégulières, souvent dangereuses et parfois meurtrières, combine désormais des dispositions relatives au séjour et au travail des étrangers et des dispositions pénales ; observer que les antécédents judiciaires produisent dans la vie de fils - et le foulard dans la vie de filles - les effets que la nationalité produisait dans la vie des pères et des mères. De même, soutenir que la « criminalité des immigrés » est immanente à la lutte contre la surpopulation carcérale - soutenir, autrement dit, que les alternatives substituent les étrangers aux nationaux en prison, spécifiant ainsi les «synthèses de la vérité » qu'elle opère -, ce n'est pas soutenir que c'est ce que veulent les militants et les fonctionnaires qui combattent la surpopulation ou qui la gèrent. C'est repérer un des effets de la lutte, qui lui-même en produit d'autres ; un effet dont la cause la plus immédiate est matérielle, puisqu'il s'agit des conditions de détention.

318. Garland D., "Frameworks of Inquiry in the Sociology of Punishment”, art. cit., pp. 3-4. 319. Merton R. K., Éléments de théorie et de méthode sociologique, Paris, Plon, 1965, pp. 100-139. 
Certes, c'est aussi noter que la plupart des « segments discursifs 320 » supportant le "grand renfermement » des étrangers ne sont pas marqués au coin de la défense sociale, et prendre acte de ce que Foucault appelle la "polyvalence tactique des énoncés 321 » car, quelles qu'en soient les formes et quel que soit le front, territoire ou population, la lutte contre la surpopulation est le plus souvent motivée par des considérations humanistes ou gestionnaires, parfois mâtinées de considérations sur la crédibilité du système pénal et la satisfaction de citoyens positionnés comme un tribunal électoral. De même, c'est noter qu'en l'occurrence, les «vocabulaires à motivation humaniste » ou « à motivation gestionnaire » sont, en tant que "variable intervenante », aussi efficaces que les «vocabulaires à motivation punitive »; plus précisément, c'est observer l'efficacité de la synthèse que la lutte ainsi motivée opère. Efficacité en amont : prophétie autoréalisatrice, la «criminalité des immigrés » justifie aux yeux des policiers le ciblage des hommes jeunes dont l'apparence physique signale une probable extranéité. Efficacité en aval : les antécédents pénitentiaires condamnent le plus souvent soit à l'exercice irrégulier d'activités régulières, soit à l'exercice d'activités irrégulières. Foucault radicalise le théorème de Thomas 322 : définir les «synthèses de la vérité » comme « la constitution du nécessaire dans le domaine de l'expérience 323 ", c'est insister sur leur performativité et sur leurs performances, et voir qu'elles gouvernent notre appréhension des situations avant d'être réelles dans leurs conséquences. Montrer que les idées ont une existence matérielle et qu'avant de devenir des causes, ces synthèses sont des effets, c'est indiquer que ce sont les appareils, les rituels, les pratiques et les actes dans lesquels elles existent qu'il faut changer (il faut changer les dispositifs pour changer les mentalités).

Du reste, la conception foucaldienne de la pénalité - stratégique, mais non intentionnelle - vise à mettre en évidence des effets qui, pour n’avoir pas été voulus, n'en sont pas moins tragiquement réels et, sous certains rapports, tragiquement fonctionnels. Un exemple parmi d'autres : la traite des êtres humains ${ }^{324}$. Difficile, au vu du nom donné à l'infraction, de ne pas convenir de la nécessité et de la moralité de la répression. Pourtant, Carla Nagels et

\section{Idem.}

321. Cf. sur ce point Foucault M., La volonté de savoir. Histoire de la sexualité (1), Paris, Gallimard, 1976, pp. 132-133.

322. Le «théorème de Thomas ", formulé en 1928, veut que "si les hommes définissent des situations comme réelles, elles sont réelles dans leurs conséquences " ( if men define situations as real, they are real in their consequences », Thomas W. I., Thomas D. S., The Child in America: Behavior Problems and Programs, New York, Knopf, 1928, p. 572).

323. Foucault M., Introduction à l'Anthropologie, op. cit., p. 65.

324. L'article 433quinquies du Code pénal définit la traite comme fait de recruter, de transporter, de transférer, d'héberger, d'accueillir une personne, de prendre ou de transférer le contrôle exercé sur elle 1) à des fins d'exploitation de la prostitution ou d'autres formes d'exploitation sexuelle ; 2) à des fins d'exploitation de la mendicité ; 3) à des fins de travail ou de services, dans des conditions contraires à la dignité humaine ; 4) à des fins de prélèvement d'organes en violation de la loi du 13 juin 1986 [...], ou de matériel corporel humain en violation de la loi du 19 décembre 2008 [...] ; 5) ou afin de faire commettre par cette personne un crime ou un délit. 
Andrea Rea ont montré à partir d'une analyse de dossiers que « les situations de travail ressemblent bien souvent à la mise en place de mécanismes de solidarité informels ", visant "à pallier les insuffisances des mécanismes de solidarité formels $325 »$ : les infracteurs sont dans nombre de cas des parents ou des "pays » pratiquant comme leurs « victimes » une «économie de survie 326 » (la loi envisage d'ailleurs l'hypothèse du consentement des personnes à leur exploitation et précise qu'à l'exception de la prestation de services criminels ou délictuels, ce consentement est indifférent). La notion de traite recouvre des formes de travail qui sont, selon David Neilson et Thomas Stubbs, caractéristiques du prolétariat informel : du côté des infracteurs, micro-entrepreneurs employant de la main-d'œuvre sans la déclarer; du côté des "victimes ", travail non rémunéré effectué dans l'unité économique qu'est la famille, nucléaire ou élargie ; travail sous-rémunéré effectué comme employé non déclaré ; activités criminelles ou délictuelles mal rémunérées et pénalement risquées ${ }^{327}$. La notion d'êtres humains est restreinte à celle de ressortissant d'États tiers, dont la loi a institué la précarité ${ }^{328}$. Le risque pénal est inversement proportionnel au profit généré par l'infraction : les donneurs d'ordre dont les micro-entrepreneurs dépendent par le biais de sous-traitances en cascade sont protégés par l'absence de responsabilité solidaire, dont la fédération des entreprises de Belgique ne veut pas ${ }^{329}$; les infracteurs risquent la prison et, s'ils sont binationaux, la déchéance de la nationalité ; sauf à collaborer avec la justice, les victimes font le plus souvent l'objet de mesures d'éloignement ${ }^{330}$. L'opposition juridique passe entre les infracteurs et leurs victimes ; l'opposition stratégique répartit les protagonistes selon que, sur le marché configuré par la loi, le lot qui leur échoit consiste en profit ou en tragédie.

Parallèlement au processus de criminalisation de l'immigration non autorisée, une série de paniques morales 331 - une série de séries - a, en quelque trente ans, imposé à coups d'affaires hyper-médiatisées le thème du danger que «l'islam » constituerait pour l'Europe 332 et pour les sociétés occidentales.

325. Sur ce point, $c f$. Nagels C., Rea A., "De la criminalisation des travailleurs sans-papiers ", Champ pénal, vol. VII, 2010, $\$ 23$ (http://champpenal.revues.org/7865, consulté le 11 décembre 2013).

326. Neilson D., Stubbs T., "Relative surplus population and uneven deveopment in the neoliberal era. Theory and empirical application", art. cit., p. 442.

327. Idem.

328. Sur ce point, $c f$. Krzeslo E., «Le travail clandestin est un paravent », in Martiniello M., Rea A., Dassetto F. (eds.), Immigration et intégration en Belgique francophone, Louvain-laNeuve, Academia-Bruylant, pp. 253-268. Selon Carla Nagels et Andrea Rea, si «la première source de fraude sociale est le travail au noir des nationaux ayant un emploi déclaré », ce sont, au prétexte de lutter contre la traite, les secteurs où la probabilité d'occupation d'étrangers en séjour illégal est élevée que les services chargés de contrôler le respect des lois sociales ciblent en priorité (Nagels C., Rea A., art. cit., $\$ 38$ ).

329. Ibid., $\mathbb{} 35$.

330. Derrière la « victime », c'est l'informateur - le « collaborateur » - qui est visé ; pour l'intéresser, c'est l'« illégal » qui est interpellé : fructueuse, la collaboration est récompensée par un titre de séjour ; infructueuse ou refusée, elle vaudra à la victime d'être éloignée.

331. Sur la série d'épisodes comme type de panique morale, $c f$. Garland D., "On the concept of moral panic", Crime, Media, Culture, 4-1, 2008, p. 13. 
Affaires des manifestations contre le bombardement de Tripoli 333 et les guerres du Golfe en 1986, 1991 et 2003 ; affaires Rushdie, affaire Theo van Gogh et affaire des caricatures de Mahomet en 1989, 2004 et 2005 ; affaires du foulard en 1989, 1994, 2004, 2010 et 2013 ; attentats de Paris (1995), de New York (2001), de Londres (2004) et de Madrid (2005)... Chaque épisode est interprété en référence aux autres, en une « spirale de signification 334 »; tous sont censés manifester l'essence de « l'islam » et justifier la pratique du double standard dans l'évaluation des mesures nécessaires, dans une société démocratique, à la sécurité publique, à la protection de l'ordre public et à la protection des droits et libertés d'autrui 335 . Leur productivité est importante : recodage religieux des immigrés venus des derniers pays avec lesquels la Belgique a conclu des conventions bilatérales d'immigration et de leurs descendants ; pathologisation des musulmans; lois ou propositions de loi relatives à des délits « culturels 336 »; insertion dans le code pénal d'articles relatifs à des infractions et des groupements terroristes ${ }^{337}$, etc.

Il est établi qu'après une longue quête du « meilleur ennemi » entamée dès 1989338 , de puissants think tanks ont contribué à la construction du récit du choc des civilisations ${ }^{339}$; de puissants think tanks où le terrorisme est conçu, non pas comme un problème, mais comme la meilleure solution pour pro-

332. Tulkens F., "The European Convention on Human Rights and Church-State Relations: Pluralism vs. Plurailism", Cardozo Law Review, 30-6, 2009, p. 2587.

333. Bastenier A., Dassetto F., Elachy A., Media u Akbar. Confrontations autour d'une manifestation, Louvain-La-Neuve, Ciaco, 1987.

334. Hall S., Critcher C., Jefferson T., Clarke J., Robert B., Policing the Crisis, Londres, Macmillan, 1978, cité in Garland D., "On the concept of moral panic", art. cit., p. 13.

335. Meerschaut J., Gutwirth S., "Legal Pluralism and Islam in the Scales of the European Court of Human Rights: The Limits of Categorical Balancing”, in Brems E. (ed.), Conflicts between Fundamental Rights, Anvers, Intersentia, 2008, pp. 431-465 (http://works.bepress.com/cgi/viewcontent.cgi?article=1024\&context=serge_gutwirth, consulté le 1er janvier 2014).

336. Sur ce point, $c f$. Brion F., «User du genre pour faire la différence ? La doctrine des délits culturels et de la défense culturelle ", in Ringelheim J. (ed.), Le Droit et la diversité culturelle, Bruxelles, Bruylant, 2012, pp. 847-867.

337. Loi du 18 février 2013 modifiant le livre II, titre I ter du Code pénal, Moniteur belge, 4 mars 2013, p. 13233 ; loi du 19 décembre 2003 relative aux infractions terroristes, Moniteur belge, 29 décembre 2003, p. 61689. Sur l'histoire de l'incrimination du terrorisme en Belgique et de la décision-cadre du Conseil de l'Union européenne du 13 juin 2002 relative à la lutte contre le terrorisme, $c f$. Moucheron M., «Délit politique et terrorisme en Belgique : du noble au vil », Cultures E Conflits, $\mathrm{n}^{\circ}$ 61, 2006, pp. 77-100. L'auteur montre que, contrairement aux idées reçues, cette décision-cadre ne trouve pas son origine dans les attentats du 11 septembre 2001, ni même dans des attentats revendiqués par des groupes se réclamant de groupes musulmans recourant à la violence politique, mais dans le terrorisme nationaliste basque ; une proposition de décision-cadre était prête dès le 5 septembre 2001. Tout autant que l'histoire réelle, importe ici la distribution des souvenirs et des oublis qui construisent l'histoire qui se dit.

338. Huntington S. P., "La quête d'un ennemi ", Qui sommes-nous ? Identité nationale et choc des cultures, Paris, Odile Jacob, 2005, en particulier pp. 254-259. Selon l'auteur, le « fossé culturel entre l'islam, le christianisme et l'anglo-protestantisme renforce les qualifications de l'islam pour revêtir le titre d'ennemi » (p. 259).

339. Huntington S. P., "The Clash of Civilizations?", Foreign Affairs, 72-3, 1993, pp. 22-49 (http://www.polsci.wvu.edu/faculty/hauser/PS103/Readings/HuntingtonClashOf CivilizationsForAffSummer93.pdf). 
duire des effets de cohésion et d'identification dans des sociétés divisées par l'immigration ${ }^{340}$. Elite-engineered moral panic ? Les raisons de sa réception importent tout autant que les intérêts des élites théorisant l'incompatibilité de l'islam et de la démocratie. David Garland insiste, à raison, sur la dimension symptomatique des paniques morales et sur la nature projective de la construction des folk devils: le conflit qu'elles expriment de manière déplacée mettrait aux prises des groupes sociaux dont les relations évoluent, et serait lié à la compétition des statuts. Dans cette perspective, les paniques morales seraient un corrélat de l'intégration, mais auraient les mêmes fonctions que la criminalisation : la production d'un « effet de société » par la désignation d'un ennemi.

En 1978, Foucault disait lors d'une conférence que la signification donnée par l'École de Francfort à la devise de l'Aufklärung - « ose savoir » - avait été d'oser se demander s'il y a " quelque chose dans la rationalisation et peut-être dans la raison elle-même qui est responsable de l'excès de pouvoir ». Question d'une actualité brûlante, car « à force de nous chanter que notre organisation sociale ou économique manque de rationalité, nous nous sommes trouvés devant [...] trop ou pas assez de pouvoir »; et « à force de nous entendre chanter l'opposition entre les idéologies de la violence et la véritable théorie scientifique de la société, du prolétariat et de l'histoire, nous nous sommes retrouvés avec deux formes de pouvoir qui se ressemblaient comme deux frères : fascisme et stalinisme 341 ». Sept ans plus tôt, Mandel posait dans Der Spätkapitalismus que c'est la défaite du prolétariat européen par le fascisme et la Seconde Guerre mondiale qui, au sortir de la guerre, ont permis le retournement à la hausse de l'onde longue ${ }^{342}$; parallèlement à son travail théorique, l'économiste belge d'origine juive, ancien résistant, trois fois arrêté et deux fois évadé, s'attachait à la construction de la Quatrième internationale. Audelà de la lutte contre la surpopulation, le philosophe et l'économiste marxiste nous invitent à nous demander de quel prix - de quelles tragédies - nous acceptons que se paye le processus de développement du capitalisme ou le retournement à la hausse d'une de ses ondes longues 343 .

340. Huntington S. P., op. cit., p. 352. L'auteur compare les effets de cohésion et d'identification produits par quatre types de conflits, définis par le jeu de deux variables (gravité de la menace perçue, degré de mobilisation) dont les modalités sont définies de manière binaire (élevé/bas). Le terrorisme est la «meilleure solution » parce que la gravité de la menace perçue est élevée, contrairement au degré de mobilisation qu'elle implique.

341. Foucault M., "Qu'est-ce que la Critique ? [Critique et Aufklärung] », Bulletin de la société française de philosophie, 84-2, 1990, p. 44.

342. Mandel E., Der Spätkapitalismus. Versuch einer marxistischen Erklärung, Francfort, Suhrkamp, 1972 [1ère trad. française : Mandel E., Le Troisième Âge du Capitalisme, Paris, François Maspero, 1976].

343. Ce texte est une version légèrement modifiée d'un article initialement paru dans la Revue de droit pénal et de criminologie (Brion F., "Cellules avec vue sur la démocratie », Revue de droit pénal et de criminologie, septembre 2014, pp. 879-940). Sa reprise a été faite avec l'aimable autorisation de la revue. 